\title{
TRANSIENT MODELING AND SIMULATIONS WITH ANSYS FLOTRAN OF NATURAL GAS IN PIPELINES
}

Arthur Maclean ${ }^{1}$, Nana Asiedu $^{1 *}$, Emmanuel Bentum $^{2}$, Fabrice Abunde Neba ${ }^{3}$

${ }^{1}$ Department of Chemical Engineering, Kwame Nkrumah University of Science and Technology, Kumasi Ghana

${ }^{2}$ Department of Petroleum Engineering, Kwame Nkrumah University of Science and Technology, Kumasi Ghana

${ }^{3}$ Department of Civil and Environmental Engineering, Norwegian University of Science and Technology, Trondheim, Norway.

${ }^{*}$ Corresponding Author: nasiedusoe@yahoo.co.uk

\begin{abstract}
Transient analysis of gas flow in pipeline was studied. Finite Element Method based on ANSYS FLOTRAN was used to account for changes in pressure, temperature and flow rate. Compressibility factor function of temperature and pressure was considered. For nonisothermal transient results, the pressure and the flowrate gave wave propagation as a result of slow transients created by demand condition at the outlet end of custody transfer. Results obtained were in agreement with the demand restrictions at the outlet end of custody transfer indicating that the predictions are accurate and reliable. The results demonstrated that the Finite Element Method gave accurate prediction of pressure, temperature and flowrate in transient gas studies. For steady state non-isothermal model, results showed that the magnitude of the average pressure drop was higher when pressure was predicted with constant compressibility factor, but the same average pressure drop was reduced when the pressure was predicted with variable compressibility factor, z. Since compressibility factor is a function of temperature and pressure, the above findings signifies that in the case when gas temperature does not stabilize, the prediction of pressure with isothermal model and constant compressibility factor will lead to significant errors.
\end{abstract}

KEYWORDS: Transient models, Simulations, Natural Gas, Pipeline, Finite Element Method, Ansys Flotran 


\section{Introduction}

Modelling and simulation of gas flow in pipelines has been handled by many investigators. Some have analysed the gas flow as

Steady state isothermal

Steady state non-isothermal

Transient

In this work the gas flow in pipelines is analysed as transient non-isothermal

Analyzing the gas flow as transient means to predict the changes in the flow parameters with respect to time. It has several advantages:

* To satisfy contractual agreement between the operators

* Predict the flow scenario at the delivery point

- Assist to make pre-definition of turbo compressors that best fits a system

- Assist in performing failure analysis on the pipeline to foresee how the system would cope, define screening capacity and define much better maintenance procedure.

* The modeling of a physical gas transmission system leads to partial differential equations as will be seen latter in the mathematical development.

* In the subject of transient modeling and simulation of gas flow through pipelines, the problem has to do with seeking an efficient numerical scheme that enhances the solution of the partial differential equations obtained from the conservation of mass, conservation of momentum and conservation of energy in order to produce effective, reliable and accurate results [28].

* Runge-Kutta method, method of lines, finite difference and finite volume have all been used

* These methods have shown to produce adequate engineering results for the unsteady flow equation especially with the observation of pressure, temperature and flow rate oscillations

* It is not the objective of this study to apply the conventional route for the analysis of transient flow in pipe distributing systems but to apply Finite Element to simulate the same problem.

The main objectives of this study shall be:

* To model a non-isothermal pipeline thermal model that considers steady heat transfer and compressibility factor as a function of pressure and temperature.

* To treat the partial differential equations of gas flow model by finite element method and solve the problem numerically by means of the finite element software package Ansys Flotran.

* Relate the results to those of Osiadacz et al.[10] 


\section{Methodology of Study}

A two-data set on physical gas distribution system was used for the present study to analyze the transient behavior in the flow of the gas through the pipeline. One of the data set is the West Africa Gas Pipeline (WAGP) system. The WAGP system is a $570 \mathrm{Km}$ offshore single pipeline system from Nigeria to Ghana through Benin and Togo. The system operates with a diameter of $0.508 \mathrm{~m}$, fixed inlet pressure of $15.3 \mathrm{M} \mathrm{Pa}$ and an initial flow rate of $5.30 \mathrm{MMm}^{3} / \mathrm{D}$. The WAGP system parameters are provided in $\mathbf{S 1}$.

The second data is the test by Osiadacz et al [5] carried out to analyze isothermal and nonisothermal model on the pipeline hydraulics. These tests were carried out for gas transmission system described by Osiadacz [5] and Chaczykowski [12]. Calculations were done for the Yamal - Europe pipelines mainly for the $122 \mathrm{Km}$ pipe section between Kondratki and Wloclawek compressor stations on polish territory. This is a typical onshore gas transmission system with a maximum operating pressure of 8.4MPa. The distance between the compressor stations is $122 \mathrm{Km}$ and the pipe diameter is $1383.6 \mathrm{~mm}$. The average roughness of the pipe, $\varepsilon=0.03 \mathrm{~mm}$. The Osiadacz system parameters provided in $\mathbf{S 2}, \mathbf{S 3}$ and $\mathbf{S 4}$ Source: osiadacz system [5]

\section{Transient Gas Flow Model in Pipeline}

The basic equations governing the flow of natural gas in pipelines are the continuity equation, the momentum equation, the energy equation and the equation of state. In practice, the form of the mathematical model varies with assumptions made with regards to the condition of operation of the network.

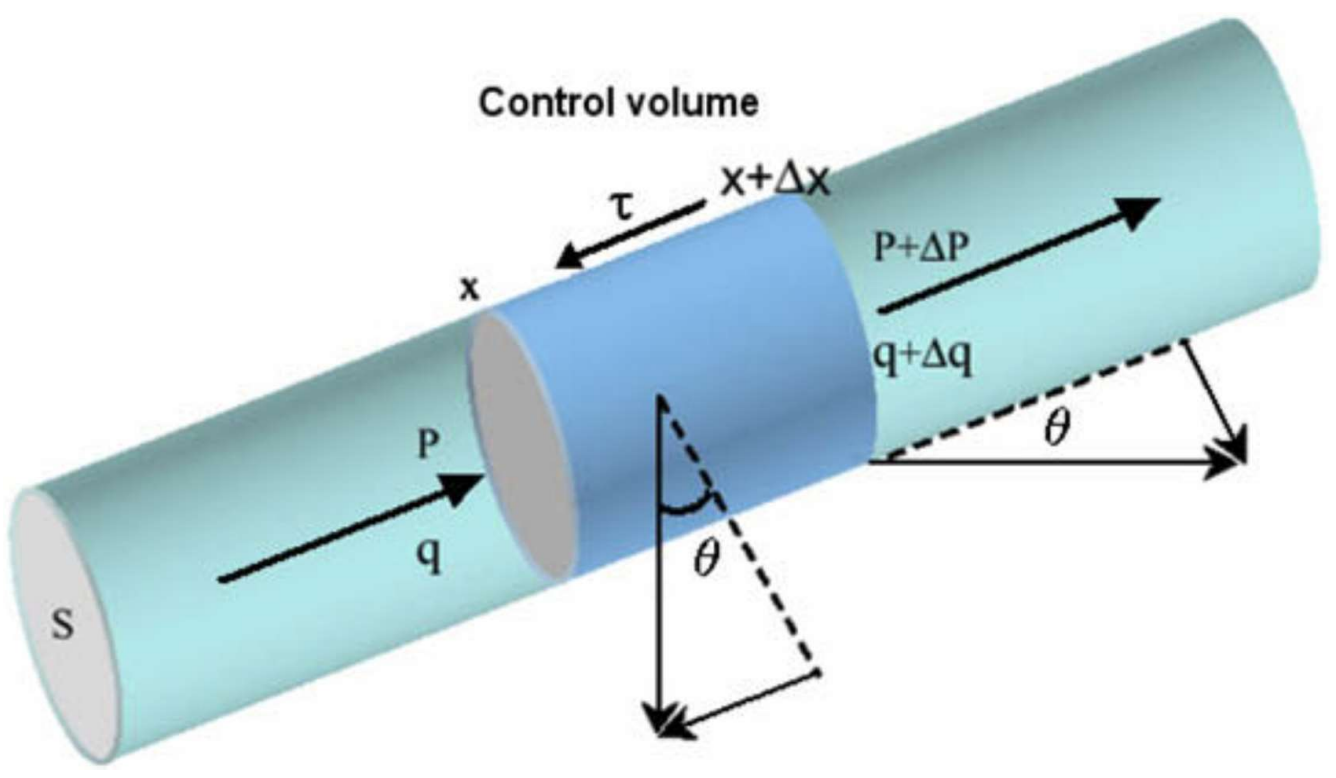

Figure1: Shows a gas flow through a control volume of a pipe.

In the diagram above, $\mathrm{P}=$ the pressure flowing into the control volume measured in Pascal, $\mathrm{q}=$ volumetric flowrate into the control volume measured in mmcd, $\mathrm{P}+\Delta \mathrm{P}=$ pressure flowing out of the control volume, $\tau=$ pipe wall stress, $\theta=$ angle of inclination of pipe, $\mathrm{dx}=$ length of control volume. 
From the consideration of mass, momentum and energy, modelling of gas flow lead to the following partial differential equations.

The Models

Transient non-isothermal flow of gas in a pipeline is described in this study by system of equations:

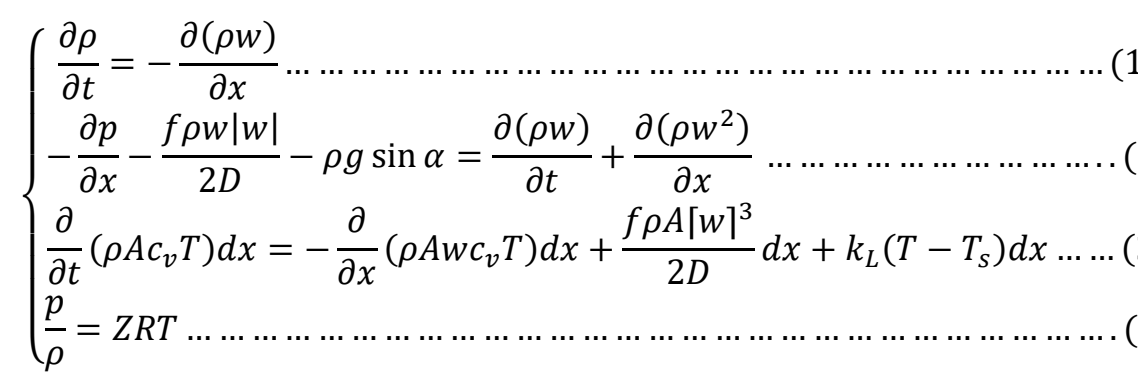

The developments underlying the above equation are provided on supplementary S5, S6,

\section{S7 and S8.}

\section{NUMERICAL SOLUTION OF TRANSIENT EQUATION BY FINITE ELEMENT METHOD}

\section{Type of PDE to be solve are:}

- Hyperbolic

- Non-linear

- Primary challenge is to create an equation that approximate the equation to be solved, but is numerically stable.

- The finite element (FE) method is a good choice for solving the PDE

- Several FE based compressible and incompressible fluid dynamics algorithms have been developed under the category of stabilized methods.

- One of such finite element method is the Characteristic Based Split (CBS) Scheme which is the method chosen for this study.

\section{Treatment of Model Equations in CBS Format}

The detailed CBS treatment is shown in S9.

The summary of CBS procedure used in this work is shown below.

- Convert the flow equations into conservative forms using set of codes

- Convert the conservative equations into non-dimensional forms

- Apply Characteristic-Galerkin method to the equations to stabilize the pressures and convection quantity in the equations

- Find an intermediate momentum in Split A

- Drop the pressure term and calculate the intermediate velocity

- Calculate the pressure and correct the intermediate velocity

- Calculate the temperature

- Apply spatial approximations and Standard Galerkin type FE to solve the equations

- Transform all equations into Matrix 
- Codes in Ansys Flotran were written to obtain flow prediction.

Transforming all the four equations into matrix we obtain:

$$
\begin{aligned}
& {\left[\begin{array}{ccc}
\left(C_{u}+\frac{K_{\tau T}}{\rho}-\Delta t K_{u}\right) & \left(G^{T}+\frac{\Delta t}{2} p\right) & 0 \\
G & \theta_{1} \Delta t\left(G M_{u}^{-1} G^{T}+\frac{\Delta t}{2} G M_{u}^{-1} p-H\right) & 0 \\
\frac{K_{\tau T}}{\rho} & \left(C_{p}-\Delta t K_{u p}\right) & \left(C_{T} \rho c_{v}+K_{T}-\Delta t K_{u T} \rho c_{v}\right)
\end{array}\right]\left\{\begin{array}{l}
\widetilde{U} \\
\tilde{P} \\
\widetilde{T}
\end{array}=\right.} \\
& \left\{\begin{array}{l}
f_{1} \\
f_{2} \\
f_{3}
\end{array}\right\}
\end{aligned}
$$

That is

- $[K]\{\tilde{a}\}=\{f\}$

Where

$$
\begin{aligned}
& f_{1}=-M_{u} \Delta t^{-1} \Delta \widetilde{U}+\left(f+\Delta t f_{s}\right)-G^{T} \theta_{2} \Delta \tilde{p} \\
& f_{2}=\left[M_{\rho}+\Delta t^{2} \theta_{1} \theta_{2} H\right] \Delta \rho \Delta t^{-1}-\theta_{1} \theta_{2} \Delta t G M_{u}^{-1} G^{T} \Delta \tilde{p}-\theta_{1} G \Delta \widetilde{U}+f_{\rho} \\
& f_{3}=-M_{E} \Delta E \Delta t^{-1}-f_{e}
\end{aligned}
$$

WAGP data and Osiadacz data on single pipeline was used for the simulation.

The choice of CBS Scheme is based on having a procedure for dealing with the pressure instability in the compressible flow problem. Other advantages include:

Having ability to reduce oscillations in convection dominated flow problems

Ability to paralyze codes and its small memory requirement during program implementation.

\section{Applications: Solution Implementation}

The construction of solution to engineering problems using finite element analysis (FEA) requires either the development of a computer program based on FEA formulation or the use of a commercially available-general purpose FEA program. In this work, a computational fluid dynamics (CFD) model based on a commercial code ANSYS FLOTRAN was used for the numerical simulation of the steady and transient flow of gas through pipeline.

An ANSYS Parametric Design Language (APDL) code was written to establish the numerical simulation generating a two-dimensional mesh of 1500 nodes. The ANSYS Parametric Design language conducts the simulation by using the generated nodes and elements to generate solution to the gas flow problem. The pressure, velocity and the temperature are solved iteratively to convergence. The ANSYS Parametric Design Language code can be referred in the appendix.

During FLOTRAN solution process, ANSYS obtained an approximate solution to the momentum equation and used them as forcing functions to solve the pressure equation based on the conservation of mass. The resulting pressures were then used to update the velocities so that the velocity field conserves mass. To solve the energy equation, ANSYS FLOTRAN solved for the temperature equation and used it to update the temperature dependent properties. As FLOTRAN simulation proceeds, ANSYS calculated convergence monitors for each degree of freedom for every global iteration. Convergence monitors were computed for velocity (VX, VY), pressure (PRES) and temperature (TEMP). 
Convergence monitors are a normalized measure of the solutions rate of change from iteration to iteration. It represents the sum of changes of the variable calculated from the results between the $\mathrm{k}^{\text {th }}$ iteration and the previous $(\mathrm{k}-1)^{\text {th }}$ iteration divided by the sum of the current values. The problem statement and data that were used in the ANSYS simulation are given herein below.

\section{Application of Model Solutions : Transient Conditions}

The example considered is an onshore single horizontal pipe of $122 \mathrm{Km}, 1.3836 \mathrm{~m}$ diameter with an initial pressure of $8.4 \mathrm{MPa}$ and inlet temperature of $315.65 \mathrm{~K}$. The system has a variable flow demand at the outlet end given by a function $\mathrm{f}(\mathrm{t})$. Details of the system are shown in Table 1.3 as follows: 
Parameter

Flow under standard conditions

Length of Pipeline

Cross sectional area of Pipeline

Average Pipe roughness, $\varepsilon$

Diameter of Pipeline

Density of Gas at normal conditions

Density of soil

Thermal conductivity of soil, $\lambda$

Specific heat at constant pressure, $\mathrm{Cp}$

Specific heat at constant volume, $\mathrm{Cv}$

Thermal conductivity, $\lambda$

Heat transfer coefficient, kL

Initial Temperature of Gas

Initial Pressure

Gas dynamic viscosity, $\mu$

Gas Constant, R
Value

$2019950 \mathrm{~m} 3 / \mathrm{h}$

$122 \mathrm{Km}$

$1.5035 \mathrm{~m} 2$

$0.03 \mathrm{~mm}$

$1.3836 \mathrm{~m}$

$0.7156 \mathrm{Kg} / \mathrm{m} 3$

$1640 \mathrm{Kg} / \mathrm{m} 3$

$1.0 \mathrm{~W} / \mathrm{m} \mathrm{K}$

$2278 \mathrm{~J} / \mathrm{Kg} \mathrm{K}$

$1759 \mathrm{~J} / \mathrm{Kg} \mathrm{K}$

$0.034 \mathrm{~W} / \mathrm{m} \mathrm{K}$

$25 \mathrm{~W} /(\mathrm{mK})$

$315.65 \mathrm{~K}$

$8.4 \mathrm{MPa}$

$1.35 \mu \mathrm{PaS} / 0.0135 \mathrm{cp}$

$8314 \mathrm{~J} /(\mathrm{Kmol} \mathrm{K})$

Source: Osiadacz, 2001

$$
\left.\begin{array}{c}
P(0, t)=8.4 M P a \\
Q(L, t)=f(t) \\
T(0, t)=315.65
\end{array}\right\} \text { Boundary condition }
$$

Where the function $f(t)$ is periodic in nature. The outlet boundary function was converted into flow per second.

\section{Application of Model Solutions: West African Gas Pipeline Project}

The example considered is an offshore single horizontal pipe of $570 \mathrm{Km}, 0.508 \mathrm{~m}$ diameter with an initial pressure and flow rate of $15.3 \mathrm{M} \mathrm{Pa}$ and 5.30 MMCM/D respectively. The system has a variable flow demand at the outlet given by a function fig 3.3. Details of the system are given Table 1as follows: 


\begin{tabular}{ll} 
Parameter & Value \\
Optimum flow rate & $13.10 \mathrm{MMcm} / \mathrm{d}$ \\
Distance of Pipeline & $570 \mathrm{~km}$ \\
Onshore Diameter of Pipeline & $508 \mathrm{~mm}$ \\
Pipe roughness & $0.015 \mathrm{~mm}$ \\
Cross sectional area & $0.202 \mathrm{~m} 2$ \\
Density of gas & $0.7841 \mathrm{Kg} / \mathrm{m} 3$ \\
Temperature of gas & $288.15 \mathrm{~K}$ \\
\hline Initial Flowrate, Q(0,t) & $5.3 \mathrm{MMcm} / \mathrm{d}$ \\
\hline Initial Pressure, P(0,t) & $15.3 \mathrm{MPa}$ \\
\hline Gas Viscosity & $0.105 \mathrm{e}-04 \mathrm{Pas}$ \\
\hline Gas molecular weight & $18.58 \mathrm{Kg} / \mathrm{Kmol}$ \\
\hline Gas constant & $447.63 \mathrm{~J} /(\mathrm{Kmol} \mathrm{K})$ \\
\hline Heat capacity at constant pressure, Cp & $2278 \mathrm{~J} /(\mathrm{Kg} \mathrm{K})$ \\
\hline Heat capacity at constant volume, $\mathrm{Cv}$ & $1759 \mathrm{~J} /(\mathrm{Kg} \mathrm{K})$ \\
\hline Heating value & $39.31 \mathrm{MJ} / \mathrm{m} 3$ \\
\hline Wobbe index & $1,347.48 \mathrm{MJ} / \mathrm{m} 3$ \\
\hline
\end{tabular}

Source: www.wagpco.com/

The ANSYS Parametric Design Language code base on FORTRAN was written for the transient simulation.

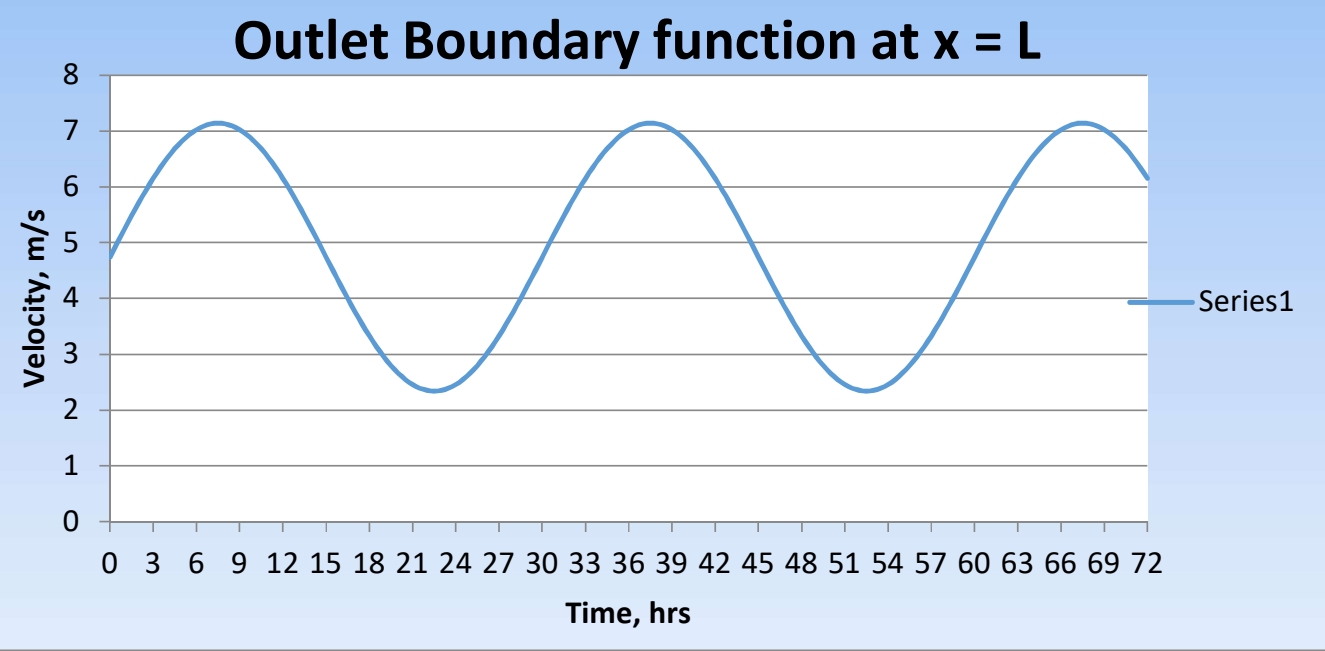

Fig 1: Boundary condition function at $x=L$ for Osiadacz data 


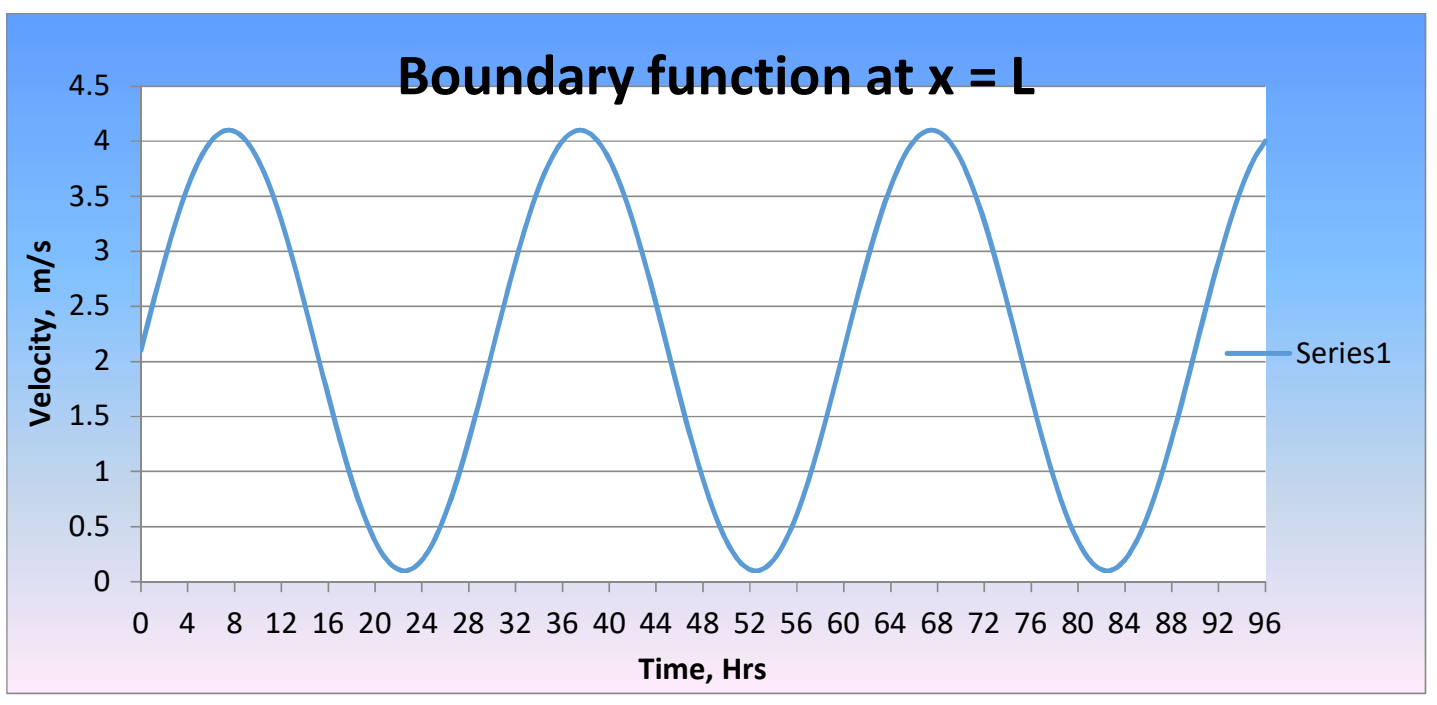

Fig. 2: Boundary condition function at $x=L$ for WAGP 


\section{Results and Discussion}

Numerical simulation was carried out using ANSYS FLOTRAN for the values of the system given in Table 1.1 and 1.3. A function $\mathrm{V}(\mathrm{L}, \mathrm{t})=\mathrm{f}(\mathrm{t})$ was imposed at the outlet boundary and $\mathrm{V}(\mathrm{L}, \mathrm{t})$ shown in fig 3.2 is defined by $f(t)=4.74+2.4 \sin \left(\frac{2 \pi t}{30}\right)$. The same problem was simulated by Osiadacz [5] except that the outlet boundary function $\mathrm{f}(\mathrm{t})$ was changed in the present work. ANSYS FLOTRAN gave erroneous results for table functions such as the outlet boundary function used by Osiadacz [5] therefore a function $f(t)$ that works well with FLOTRAN was used. For the West Africa Gas Pipeline system, an outlet boundary function $\mathrm{f}(\mathrm{t})=2.1+2 \sin \left(\frac{2 \pi t}{30}\right)$ was used to satisfy the system's operating restriction of $4.5 \mathrm{~m} / \mathrm{s}$ optimum velocity (fig 3.3). With regards to the boundary conditions of the problem, the inlet gas pressure, inlet temperature, inlet flow rate (converted to velocity) and density was kept fixed by reason of uniform flow whiles the flow rate at the outlet was varied with a 72-hour cycle to reflect the changes in consumer demand within three days (fig 3.2). In the simulation, density and viscosity were varied.

The numerical simulation was performed with a 2-D axisymmetric mesh made up of 1500 nodes and 1616 elements with a FLOTRAN fluid element, fluid-141. Four different transient simulations were performed for system details outlined in Table 1.The first case (case 1) was the simulation with an initial gas temperature of $315.65 \mathrm{~K}$, the second (case 2) was the simulation with an inlet gas temperature of $303.15 \mathrm{~K}$, the third (case 3 ) was the one with an initial gas temperature of $285.15 \mathrm{~K}$ and the final case (case 4) was the simulation of the West African Gas Pipeline system with an initial temperature of $303.15 \mathrm{~K}$. The results of the simulations are presented in fig 3 to fig 4.59 . Figures $4.1-4.8$ show the contour plot and profile of the gas pressure along the pipe length.

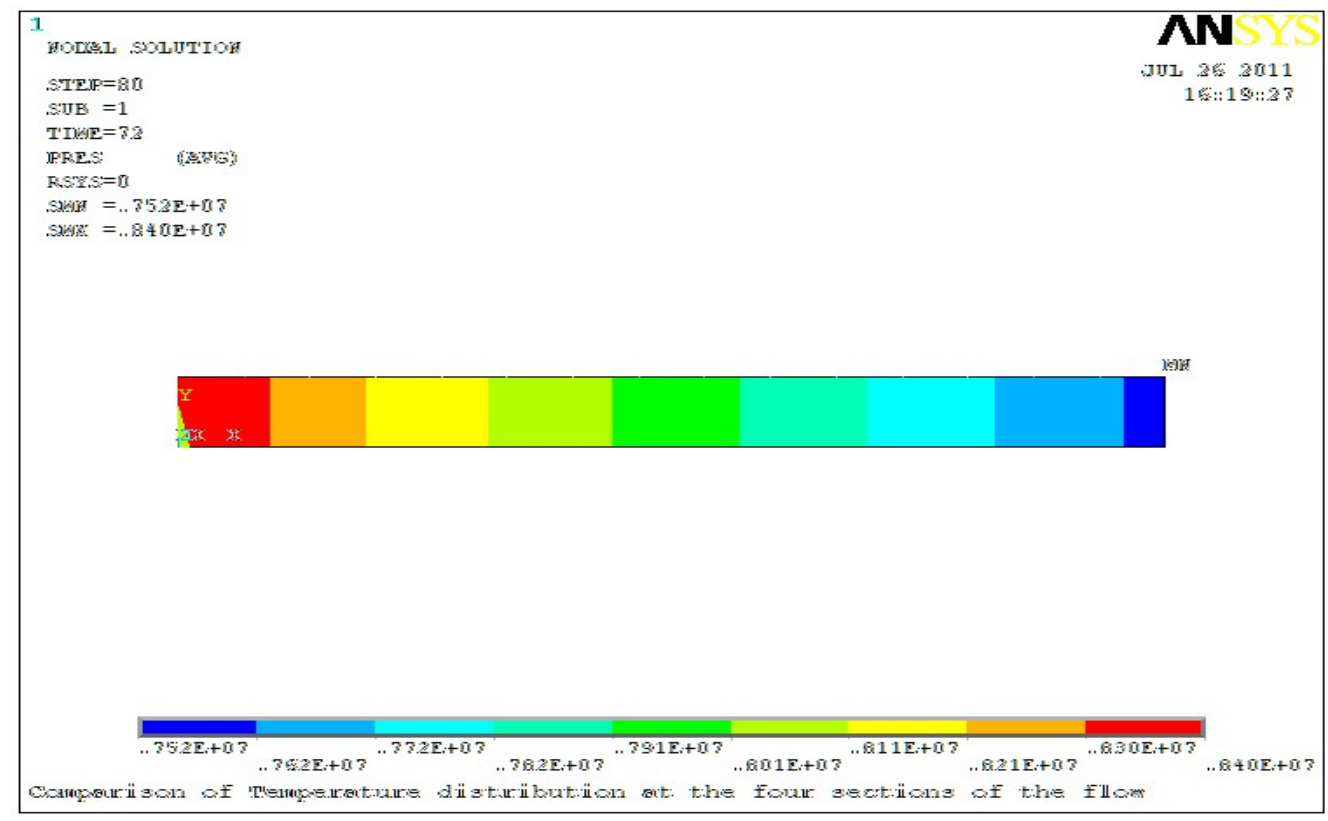

Fig. 3: Contour Plot of gas pressure at time, $t=72 \mathrm{hrs}(\mathrm{T} 0=315.65 \mathrm{~K})$ 


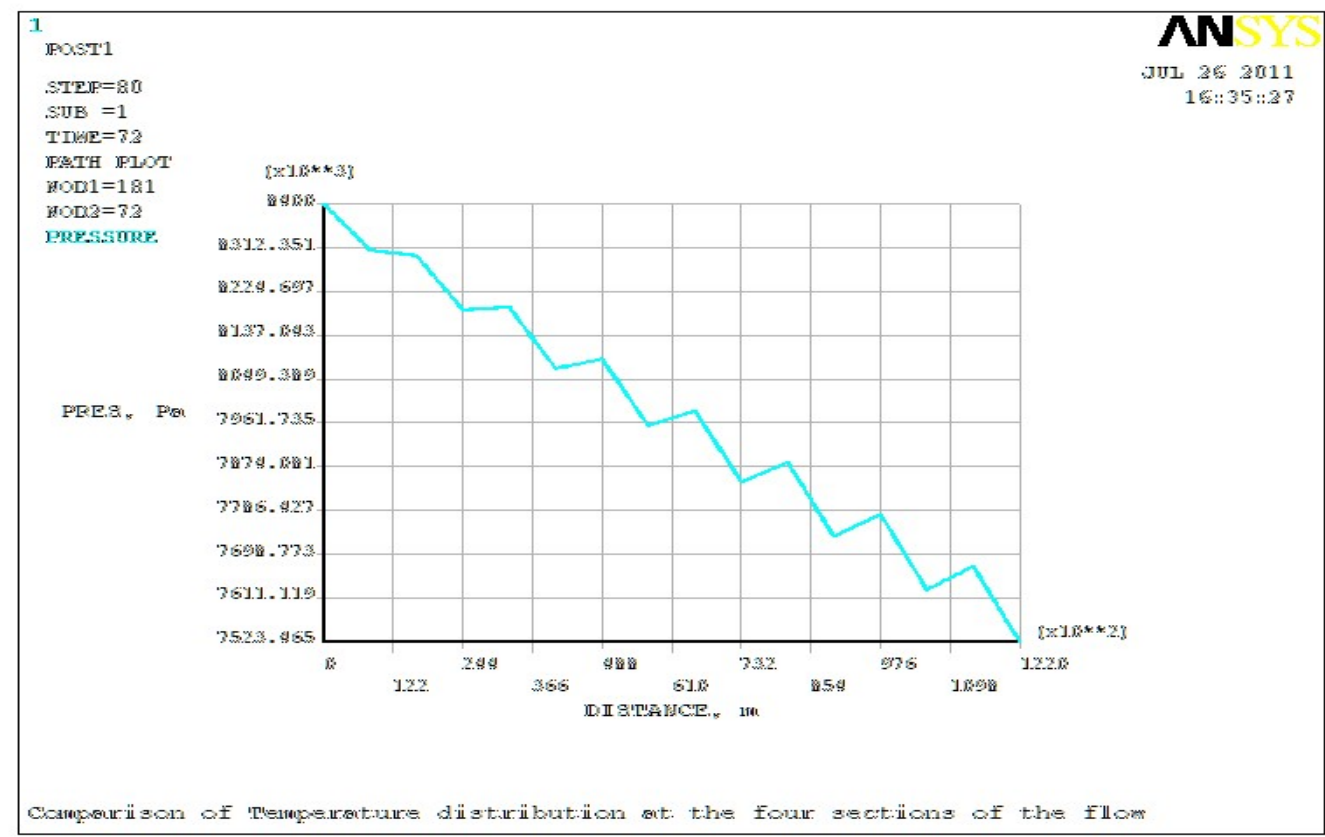

Fig 4: Pressure versus pipeline distance at time, $t=72 \mathrm{hrs}(\mathrm{T0}=\mathbf{3 1 5 . 6 5 K})$

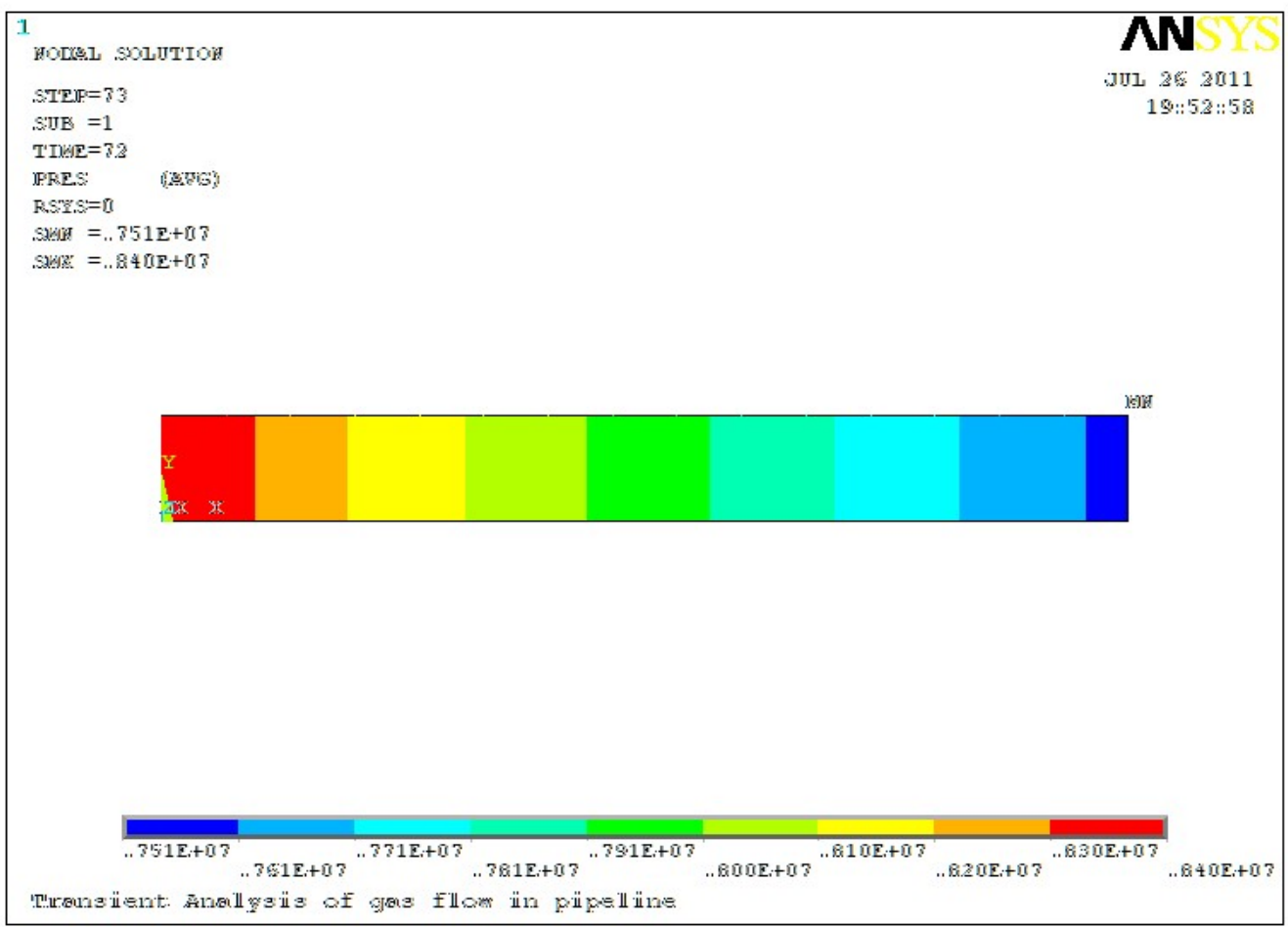

Fig 5: Contour plot of gas pressure at time $t=72 \mathrm{hrs}(\mathrm{T} 0=303.15 \mathrm{~K})$ 


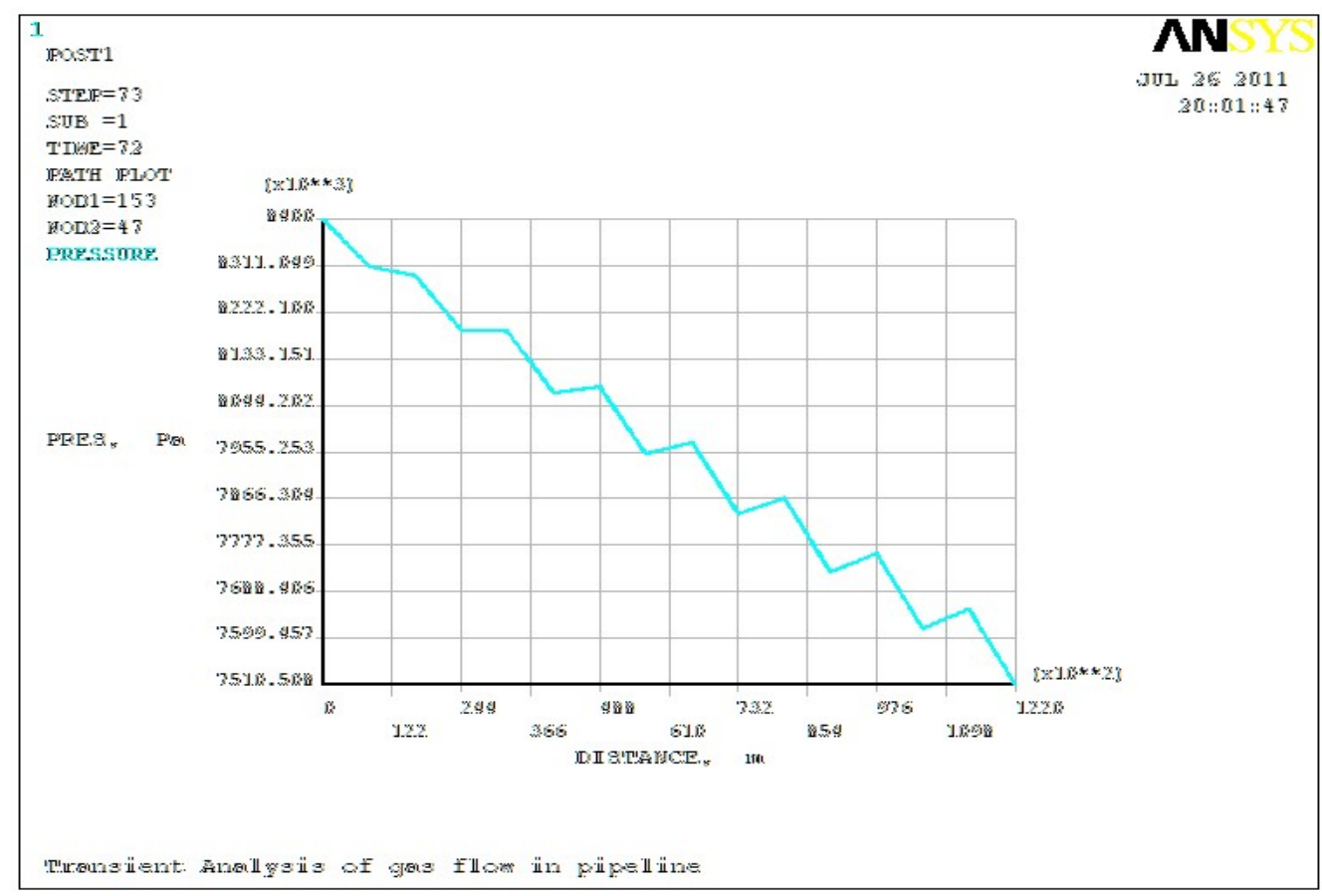

Fig : Pressure versus pipeline distance at time, $t=72 \mathrm{hrs}(\mathrm{T0}=303.15 \mathrm{~K})$

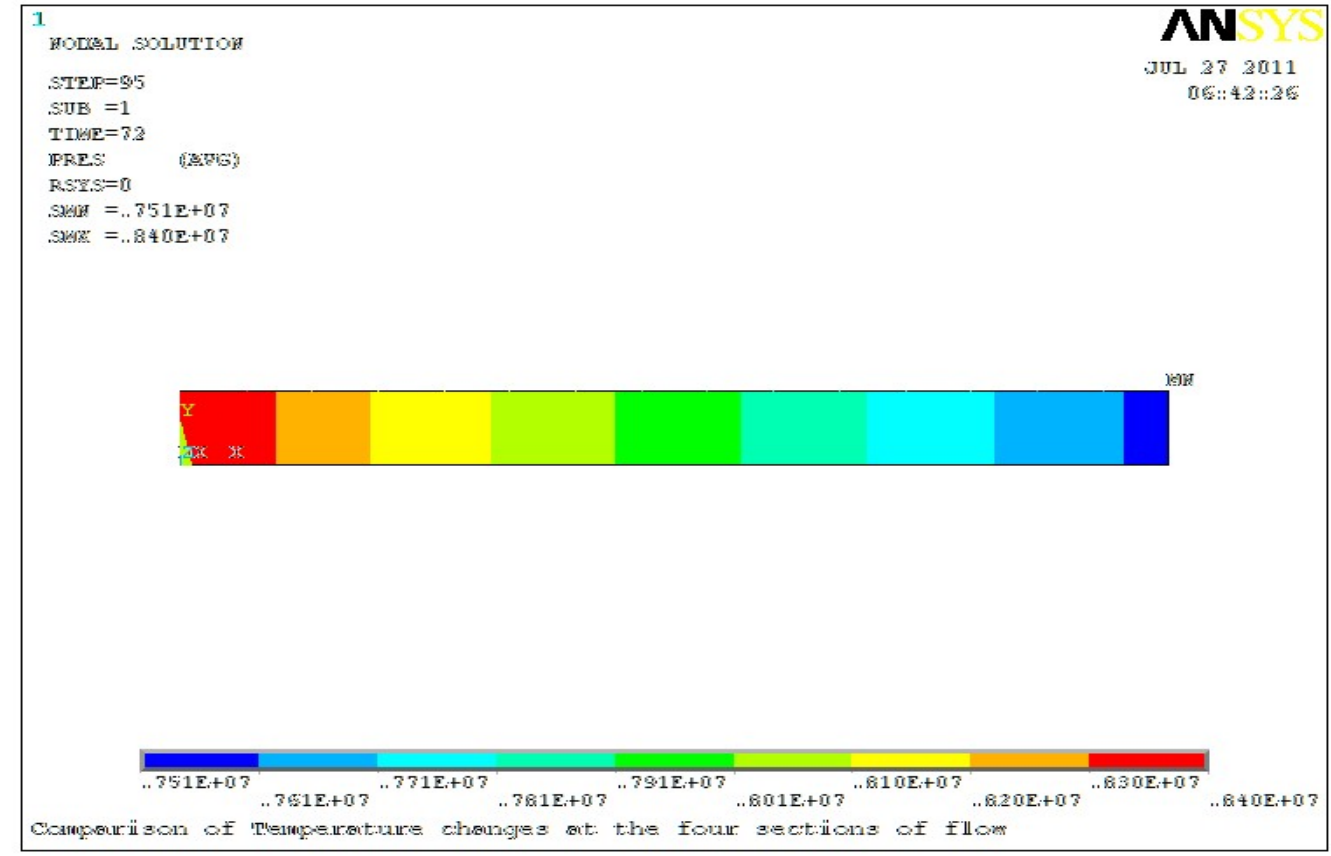

Fig 7: Contour plot of gas pressure at time, $t=72 \mathrm{hrs}(\mathrm{T0}=285.15 \mathrm{~K})$ 


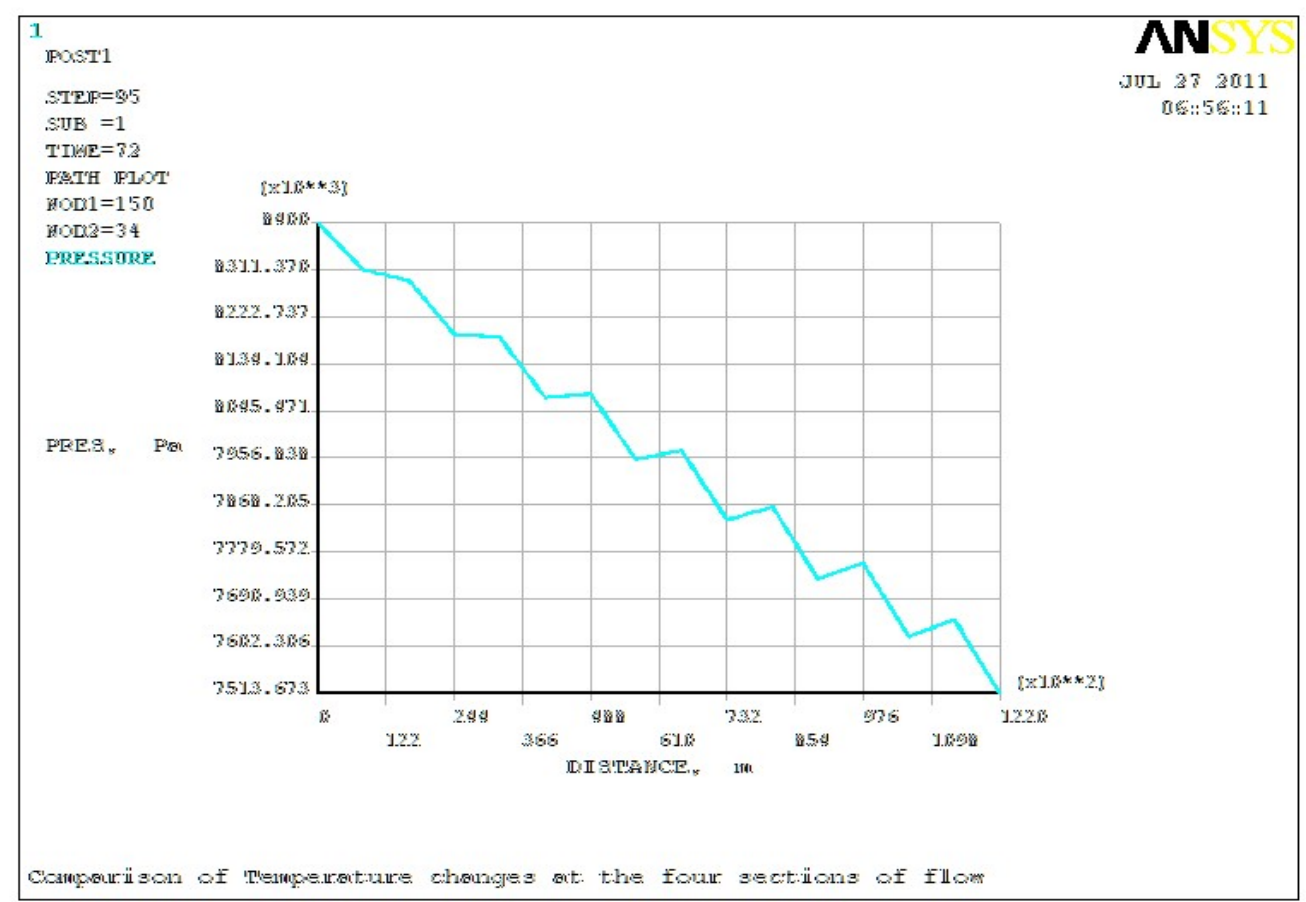

Fig 8: Pressure versus pipeline distance at time, $t=72 \mathrm{hrs}(\mathrm{T0}=285.15 \mathrm{~K})$

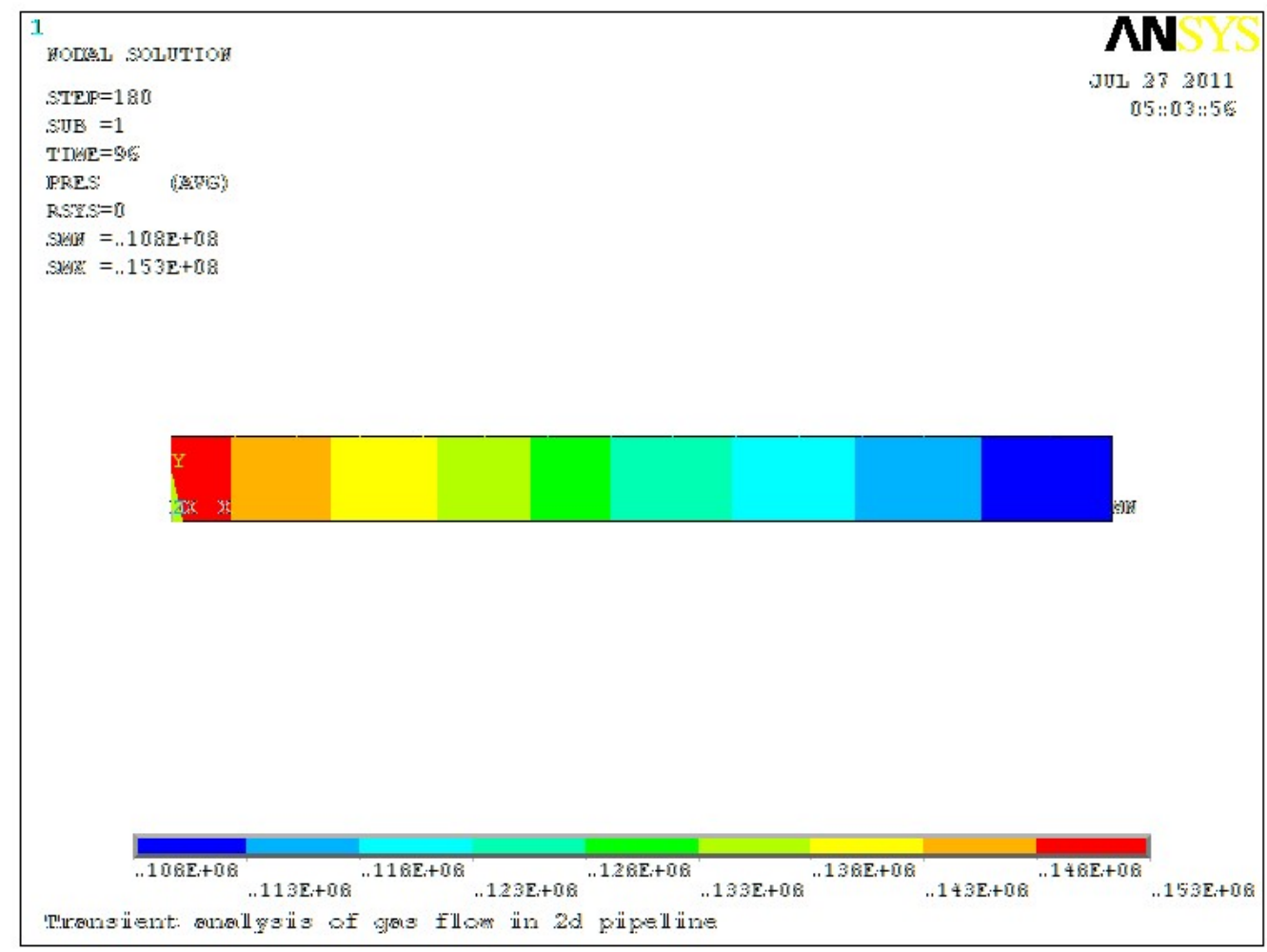

Fig 9: Contour plot of gas pressure at time $\mathrm{t}=96 \mathrm{hrs}$ for WAGP 


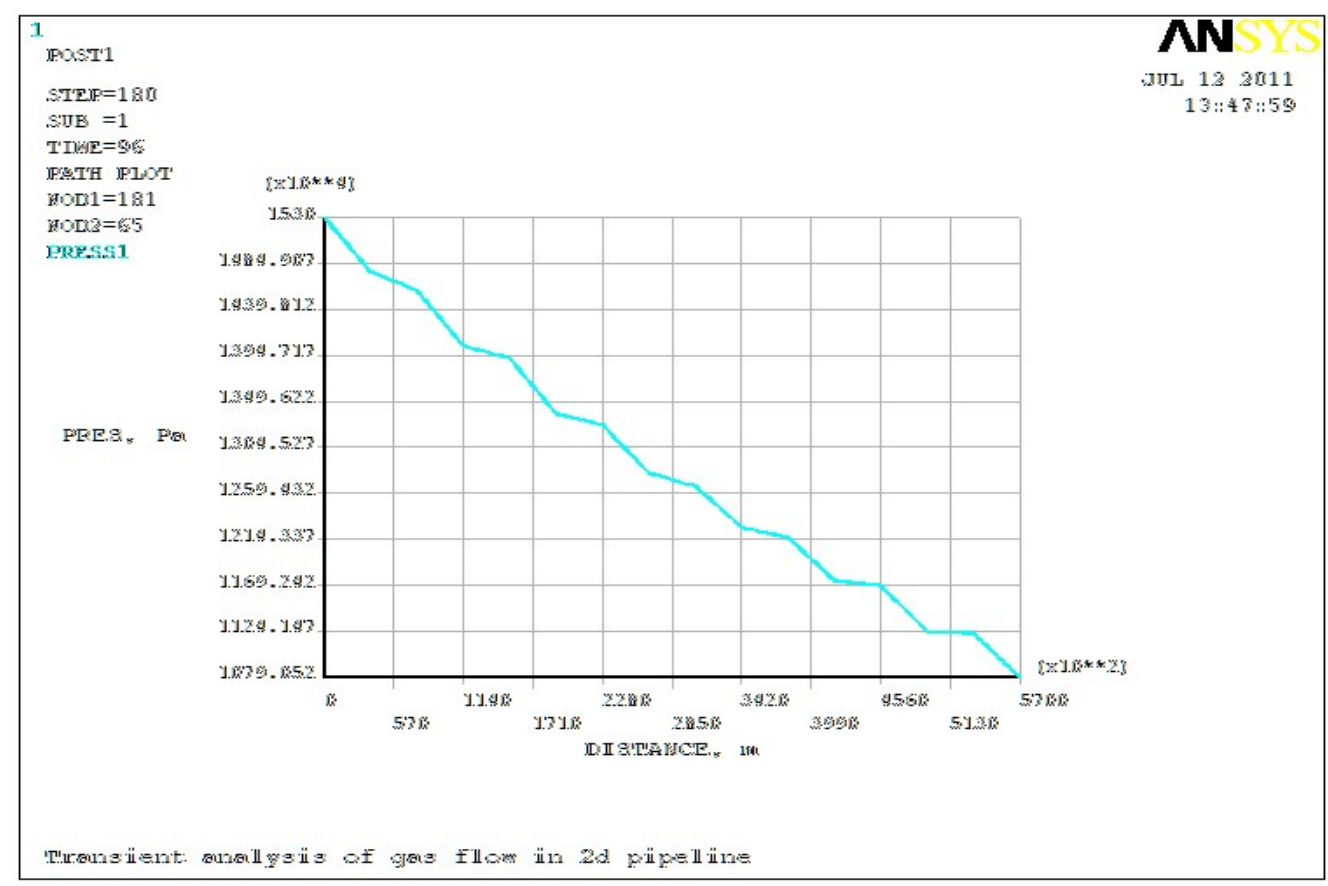

Fig 10 : Pressure versus pipeline length at time $\mathrm{t}=96 \mathrm{hrs}$ for WAGP

It is observed in fig $4.1-4.8$ that the pressure decreased with increased pipe length along the profile from the upstream to downstream. The contour behaviors demonstrate steady state pressure results at time, $\mathrm{t}=72 \mathrm{hrs}$. Several steady state results at different times could be obtained and compared. The profile trend is consistent with literature and the result of Osiadacz [5, op. cit.]. In all profiles, pressure decreased monotonically from inlet to outlet of pipe due to pressure drop in the flow direction.

Temperature contours and profiles (fig $4.12-4.20$ ) along the pipeline from the inlet to the outlet are depicted. Those of temperature contour plots are illustrated in fig. 4.13, 4.15, 4.17 and 4.19. From the graph and contour plots, it is seen that the temperature records a sharp decrease in value from the initial $315.65 \mathrm{~K}$ to about $291 \mathrm{~K}$ for case $1 \mathrm{in}$ fig. 4.13 at a distance of about $10 \mathrm{~km}$. From there it becomes stable and constant between the distance of about $11 \mathrm{~km}$ to $100 \mathrm{~km}$. Between 100 $\mathrm{km}$ and $122 \mathrm{~km}$ there is a discontinuity in the trend. The observed discontinuity may be explained by two phenomena: Joule Thompson effect and heat transfer between the gas and the surroundings. By Joule Thompson effect, the temperature predictions of all simulations gradually drop below the ambient temperature when the heat transfer coefficient is kept constant [22]. The heat transfer coefficient in this simulation was isotropic and constant. Temperature profile along the pipeline should therefore approach the ambient temperature asymptotically or decrease below the ambient temperature as observed in fig. 4.14, 4.16, 4.18 and 4.20. However, when the size of the mesh is increased it is believed that the predictions would be more accurate than previous. In a long pipeline flow simulation the temperature would eventually stabilize and assume an asymptotic behavior close with the ambient or ground temperature. It is anticipated that when the pipeline length is extended the temperature would again stabilize and assume an asymptotic behavior. Nevertheless, the temperature prediction in gas flow in pipelines cannot always stabilize [59]. In comparing the numerical results to the analytical steady state results (fig $4.60-4.65$ ), it is found that the numerical results agree with the analytical results. 


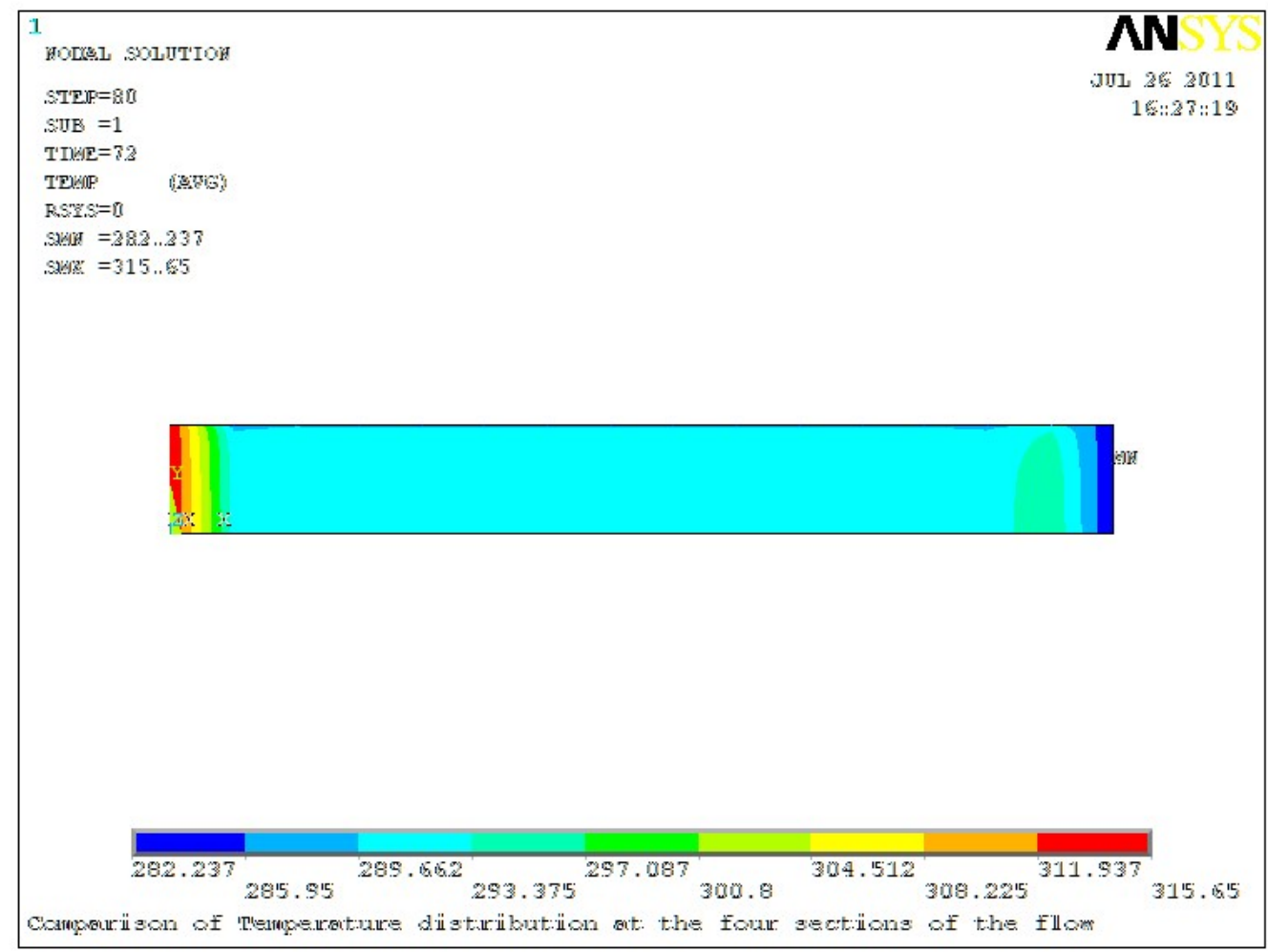

Fig 11: Contour Plot of gas temperature at time, $t=72$ hrs $(\mathrm{T} 0=315.65 \mathrm{~K})$

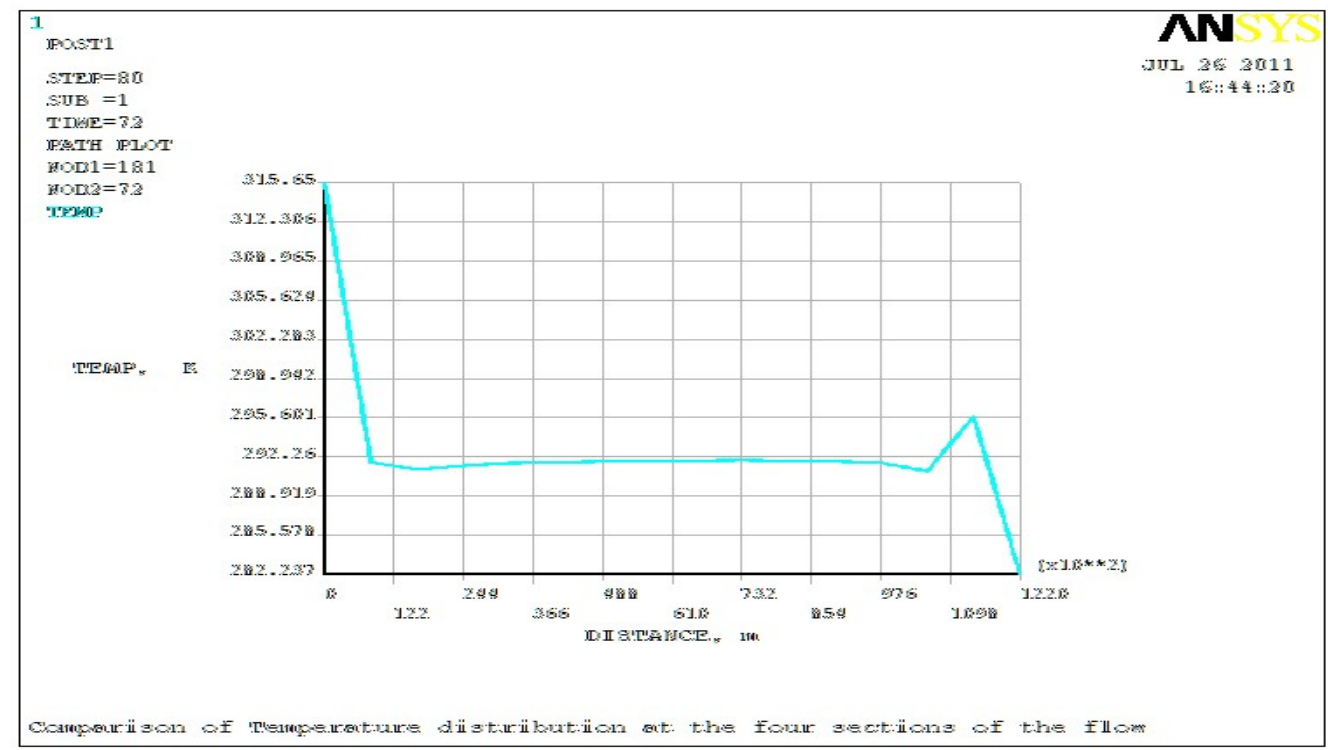

Fig 12: Temperature versus pipeline length at time, $t=72 \mathrm{hrs}(\mathrm{T} 0=315.65 \mathrm{~K})$ 


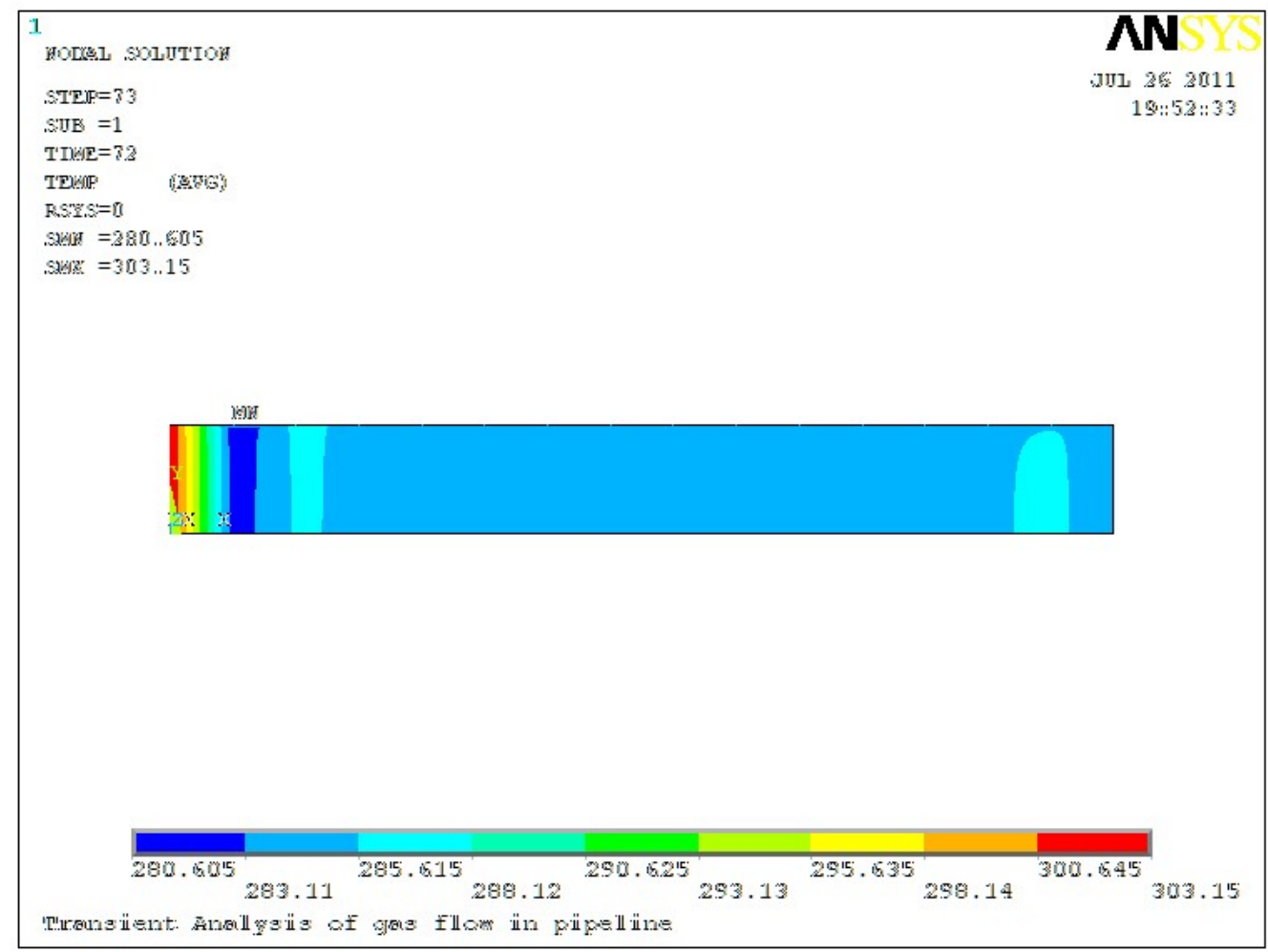

Fig 13: Contour plot of gas temperature at time $t=72 \mathrm{hrs}(\mathrm{T0}=303.15 \mathrm{~K})$

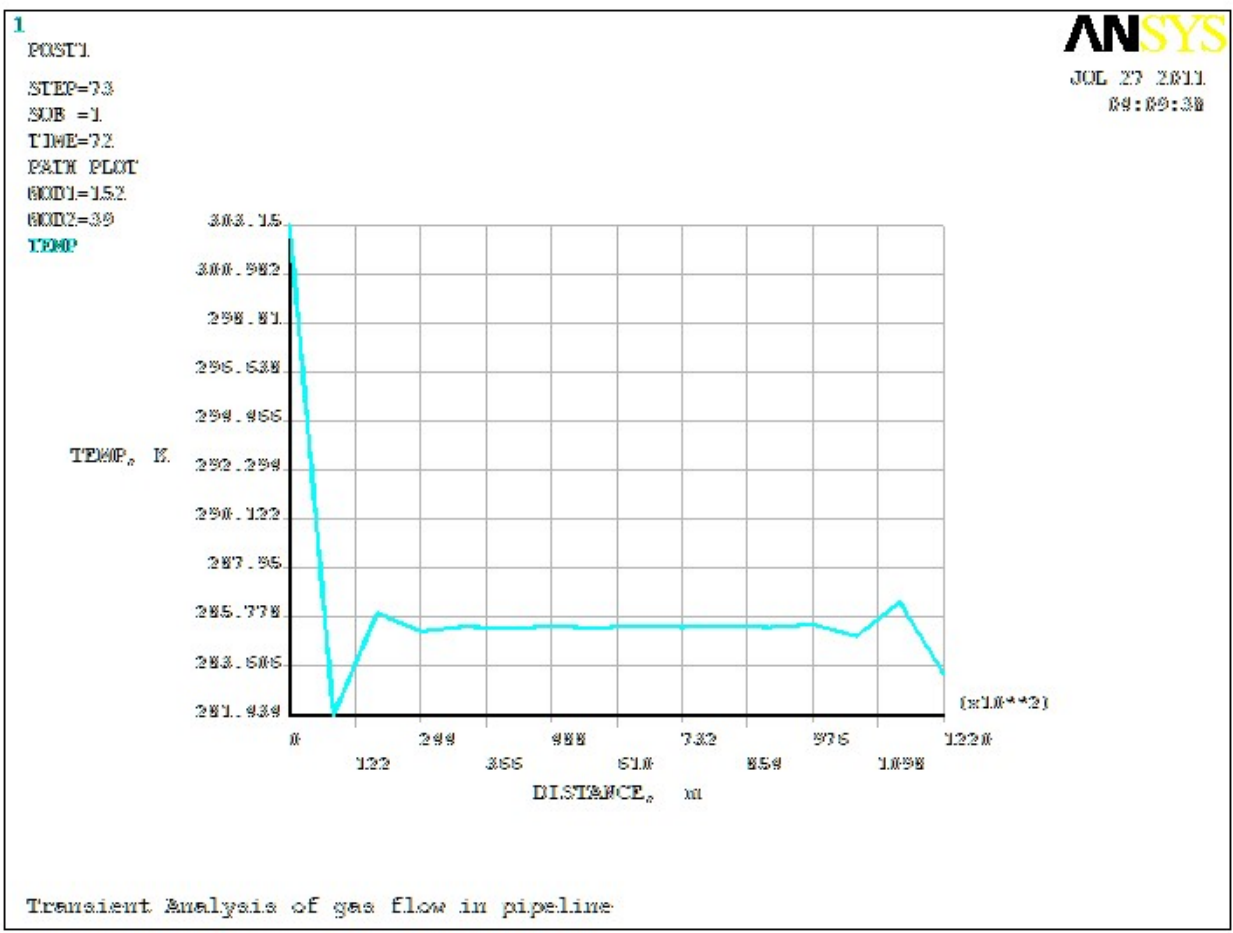

Fig 14: Temperature versus pipeline length at time, $t=72 \mathrm{hrs}(\mathrm{T0}=303.15 \mathrm{~K})$ 


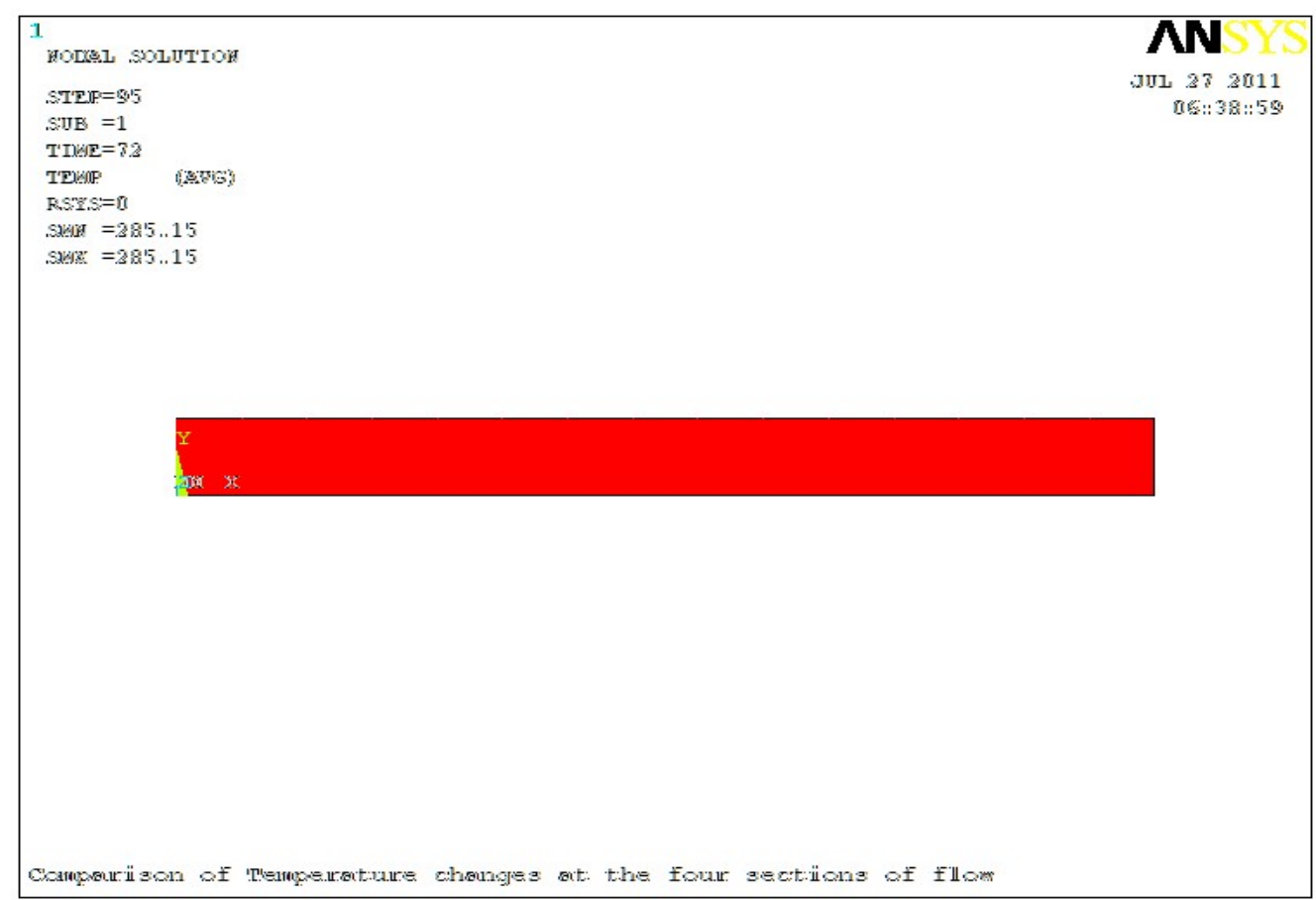

Fig 15: Contour plot of gas temperature at time, $t=72 \mathrm{hrs}(\mathrm{TO}=\mathbf{2 8 5 . 1 5 K})$

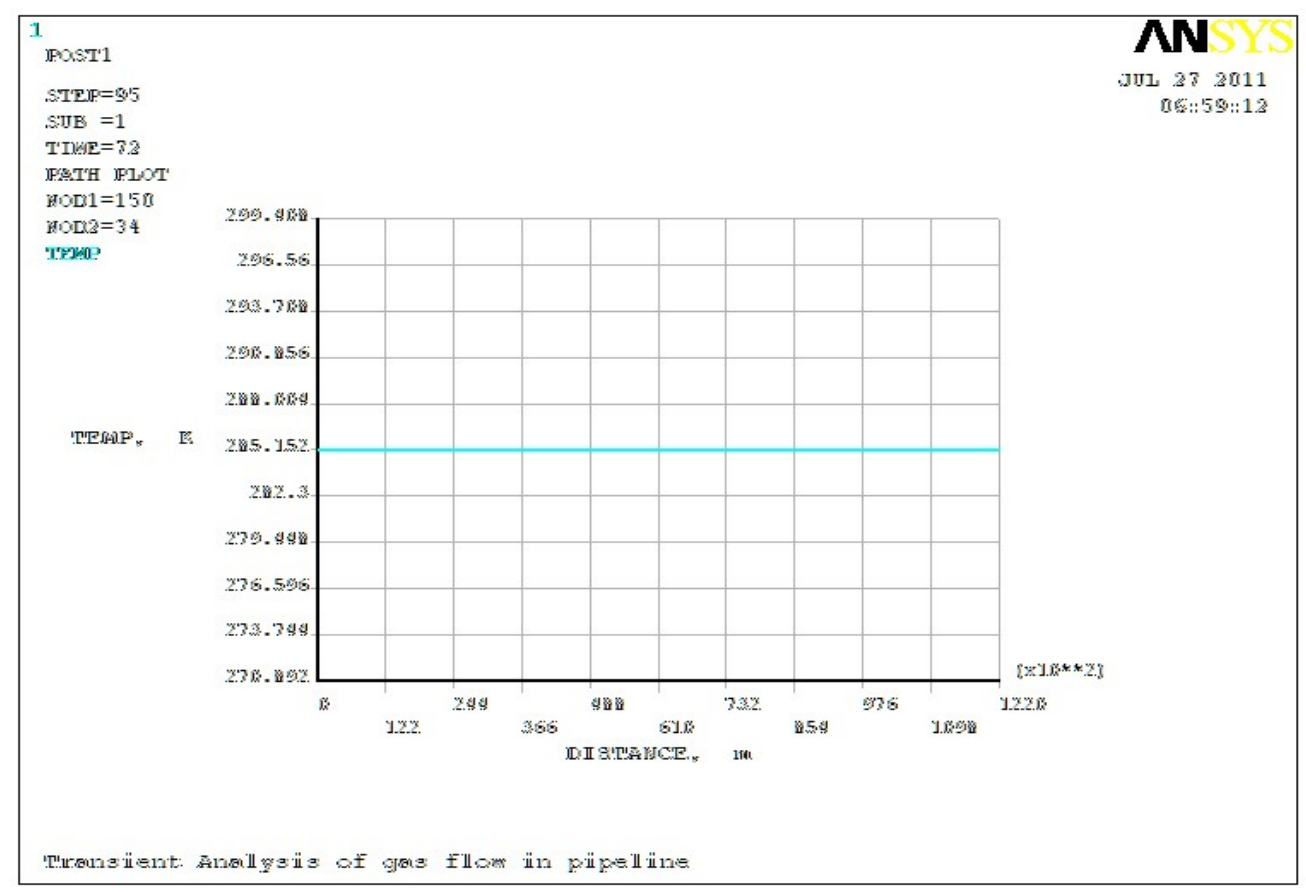

Fig 16: Temperature versus pipeline length at time, $t=72 \mathrm{hrs}(\mathrm{T0}=\mathbf{2 8 5 . 1 5} \mathrm{K})$ 


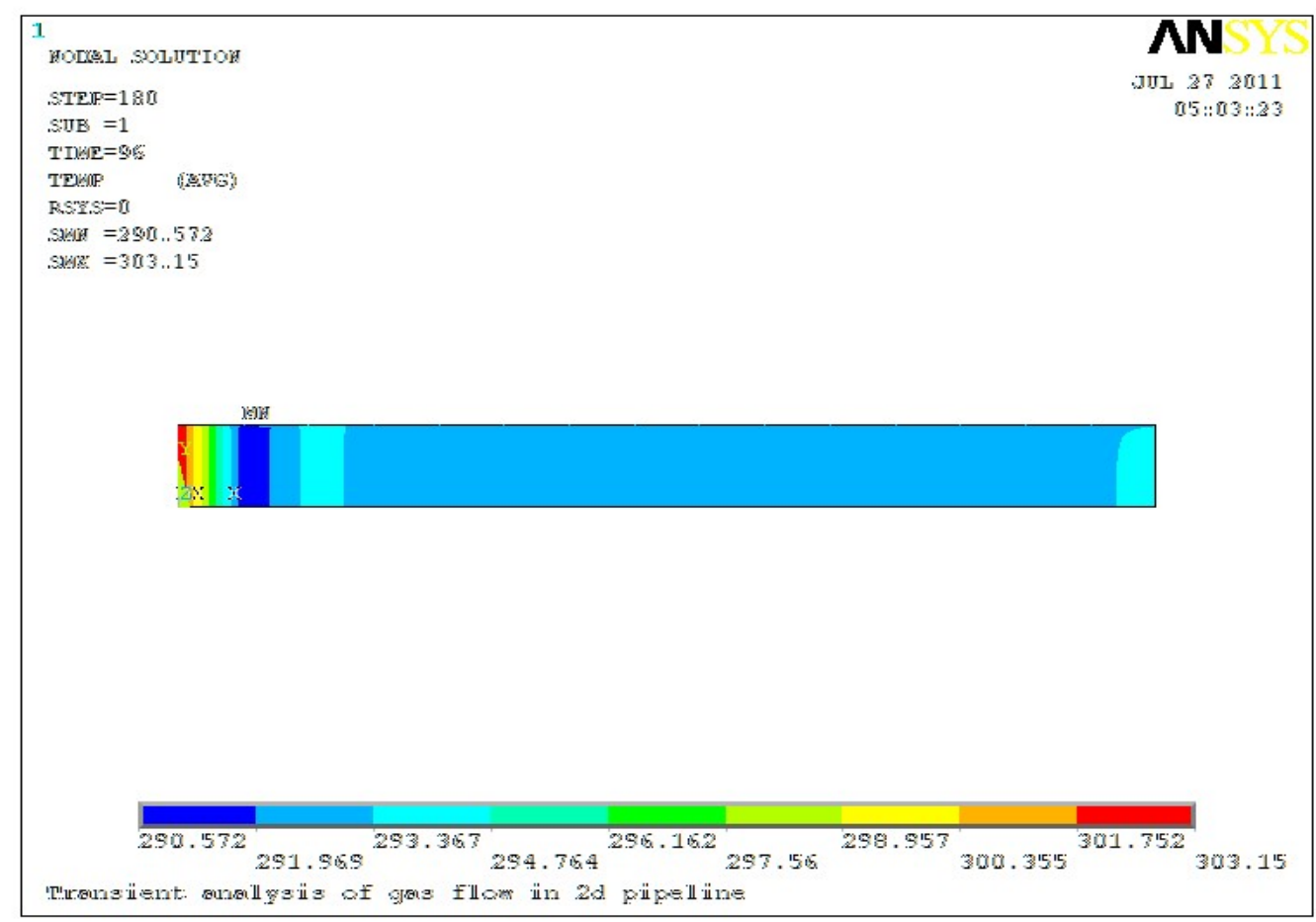

Fig 17: Contour plot of gas temperature at time $t=96 \mathrm{hrs}$ for WAGP

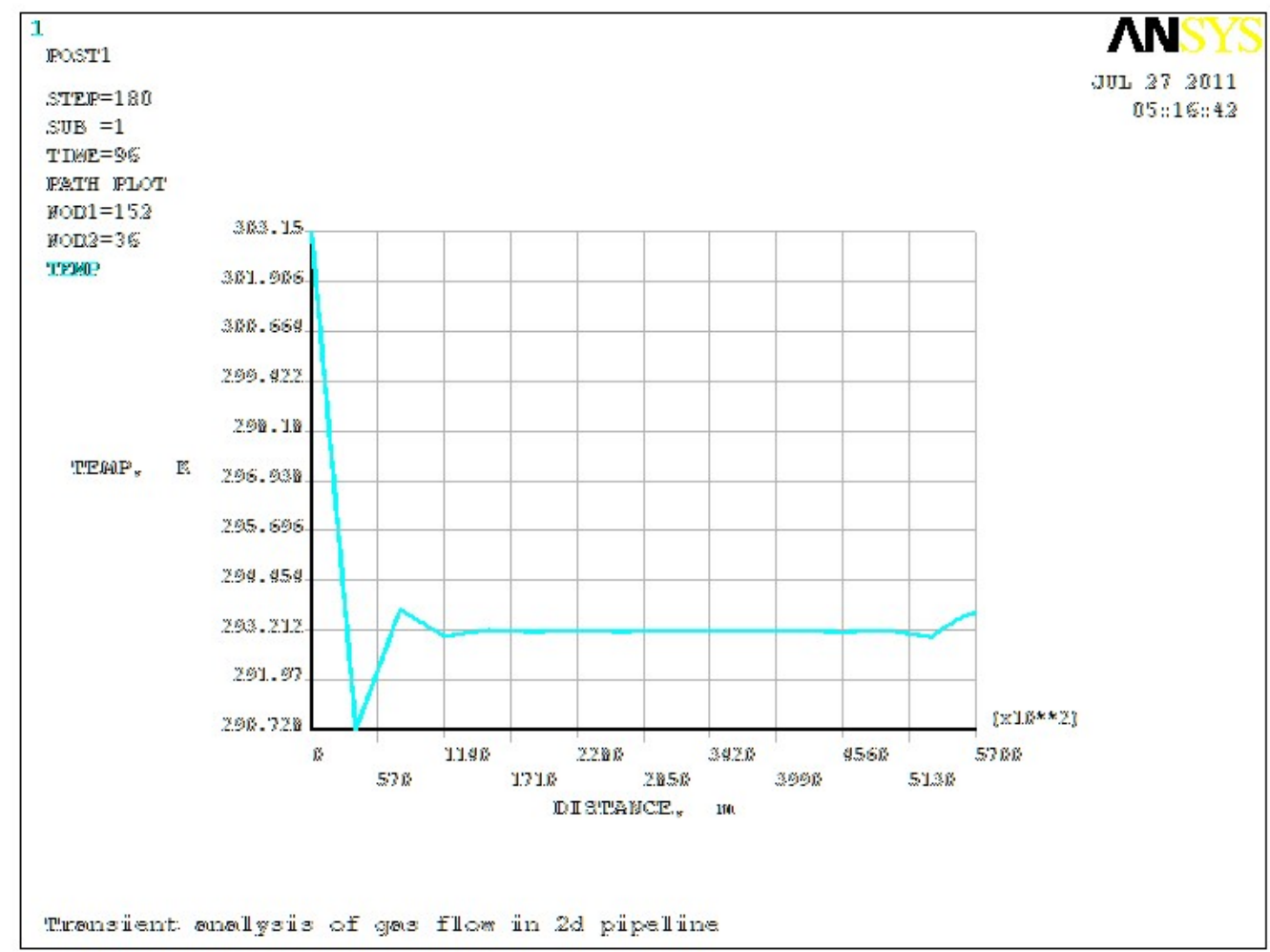

Fig 18: Temperature versus pipeline length at time $t=96 \mathrm{hrs}$ for WAGP 
In all these behavior of the temperature and pressure, the velocity contours and profiles from inlet to outlet as shown in fig $4.25-4.32$ are not constant but varying according to the varying flow conditions at the outlet.

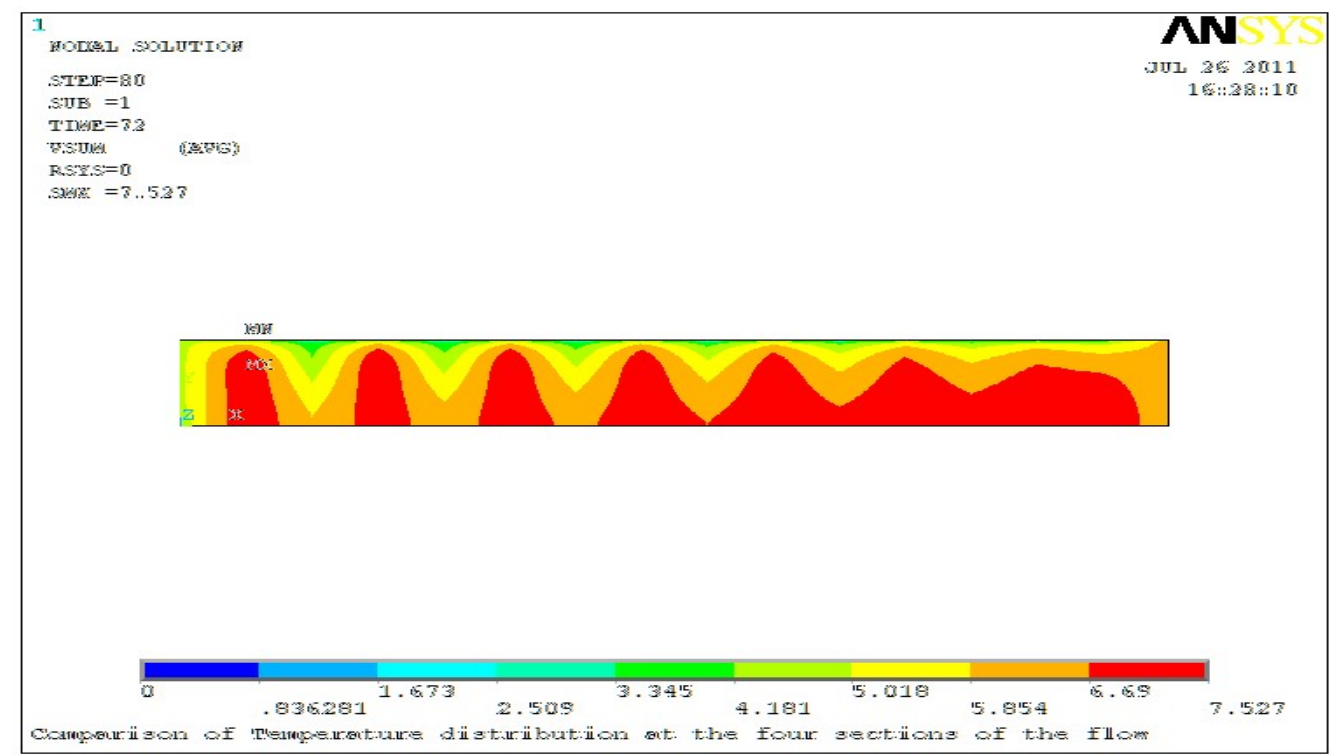

Fig 19: Contour plot of gas velocity at time, $t=72 \mathrm{hrs}(\mathrm{T} 0=315.65 \mathrm{~K})$

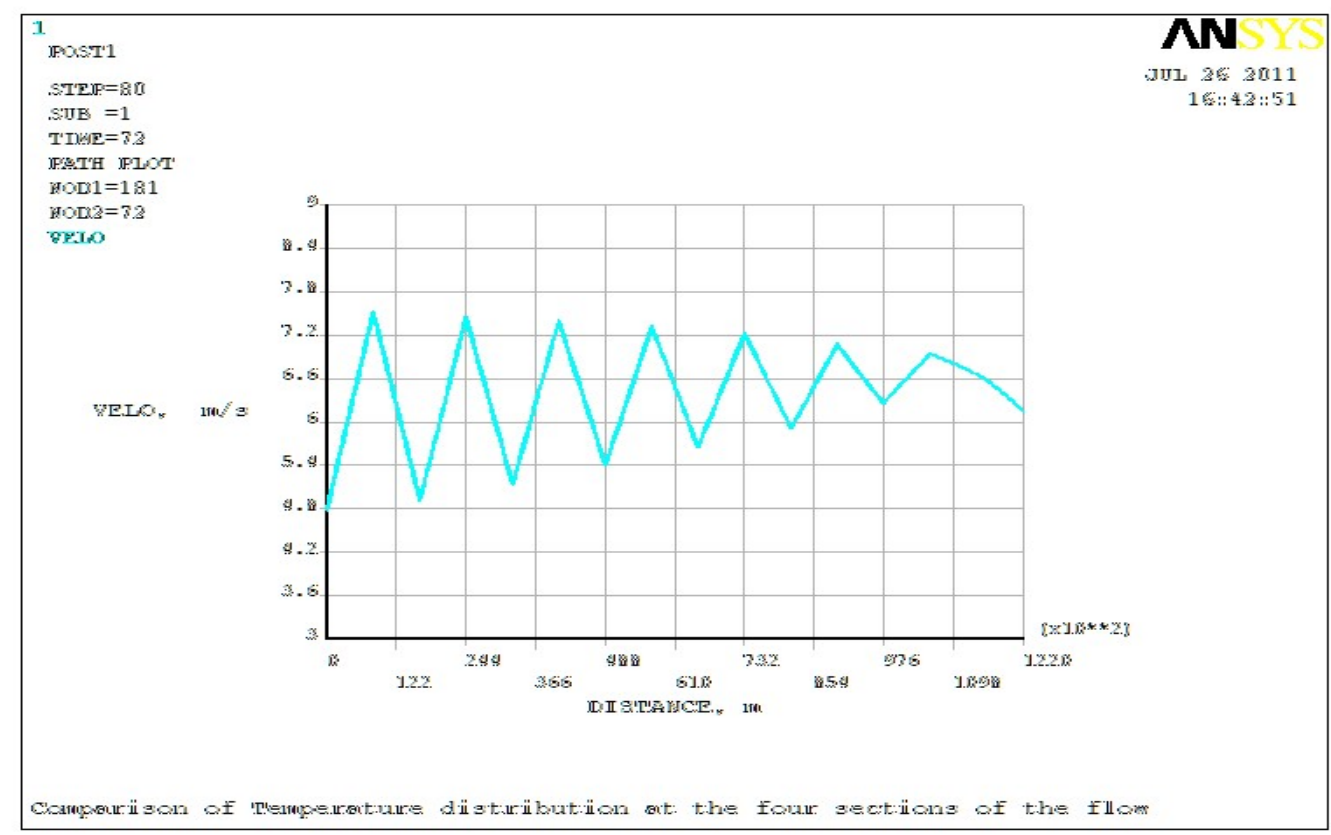

Fig 20: Velocity versus pipeline length at time, $t=72 \mathrm{hrs}(\mathrm{T} 0=315.65 \mathrm{~K})$ 


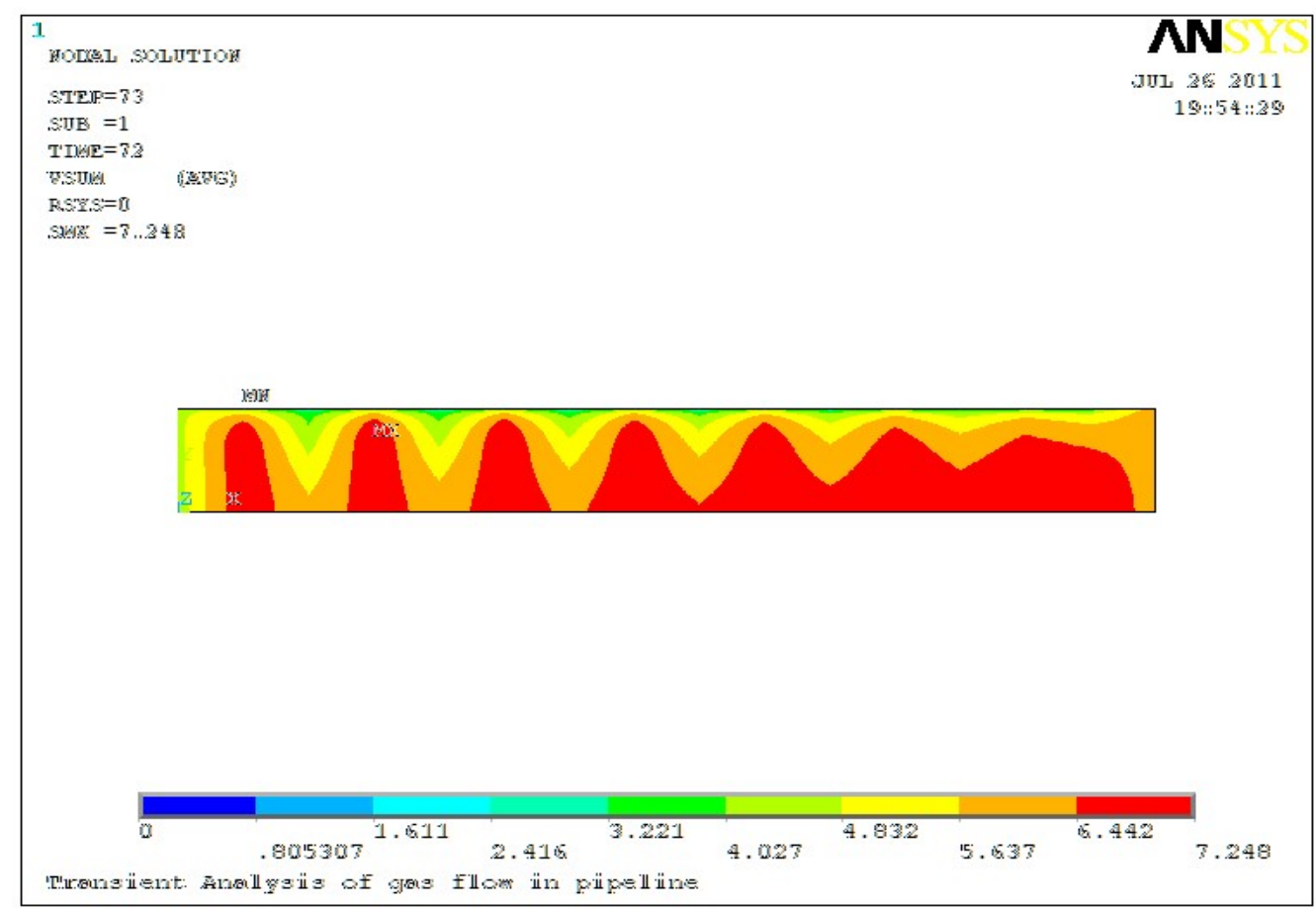

Fig 21: Contour plot of gas velocity at time $\mathrm{t}=72 \mathrm{hrs} \mathrm{T0}=303.15 \mathrm{~K}$

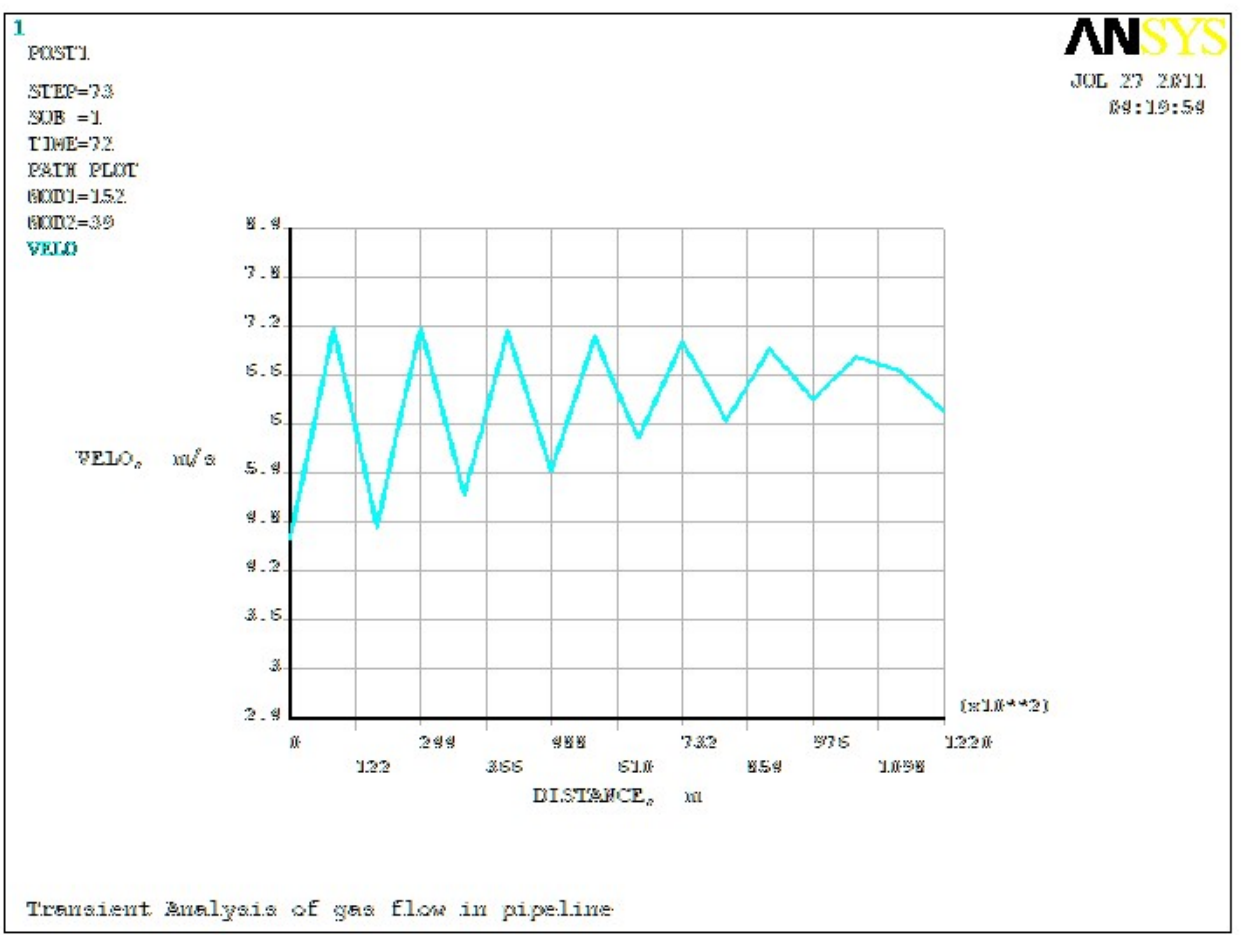

Fig 22: Velocity versus pipeline length at time, $t=72 \mathrm{hrs}(\mathrm{T0}=303.15 \mathrm{~K})$ 


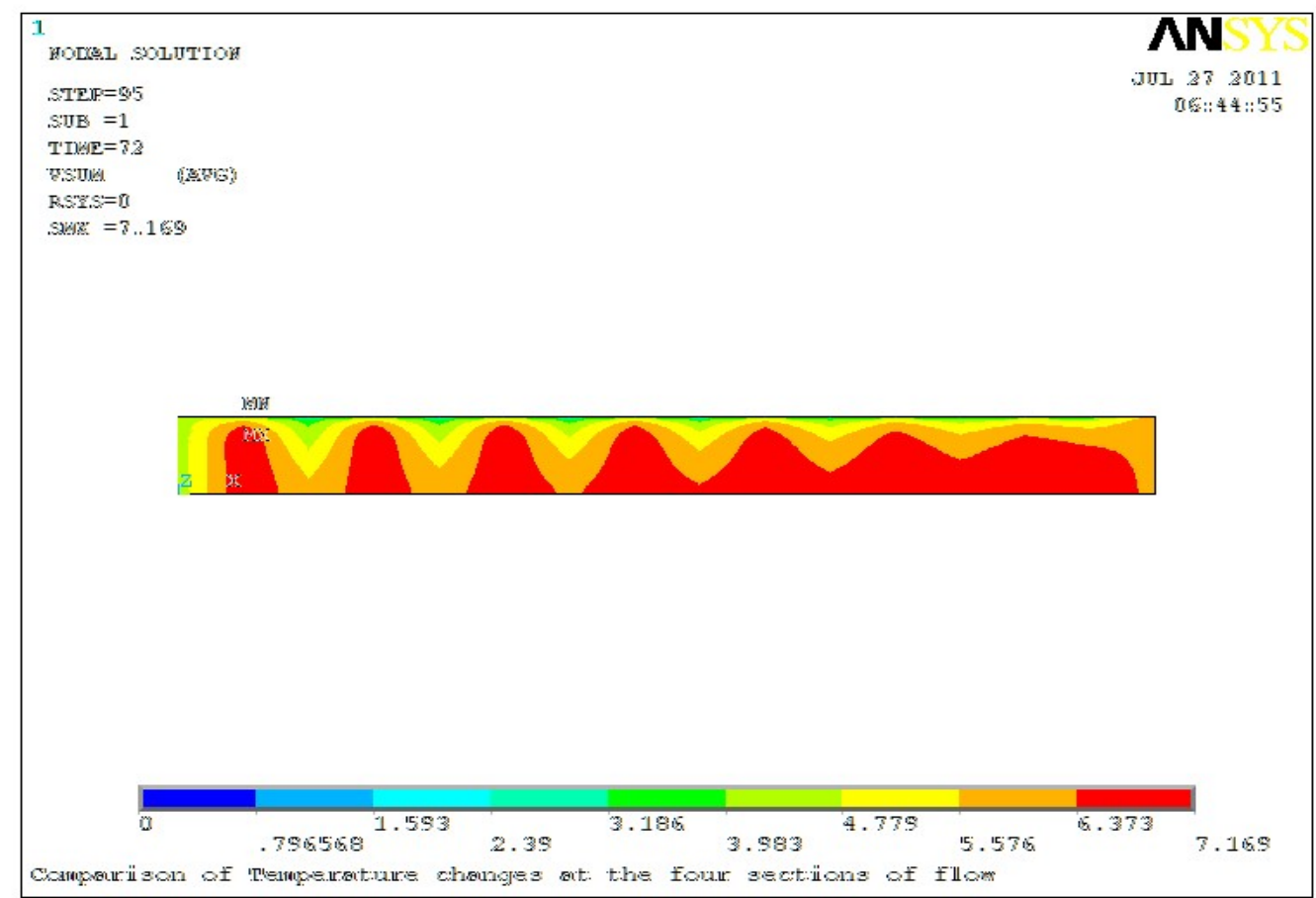

Fig 23: Contour plot of gas velocity at time, $t=72 \mathrm{hrs}(\mathrm{T} 0=285.15 \mathrm{~K})$

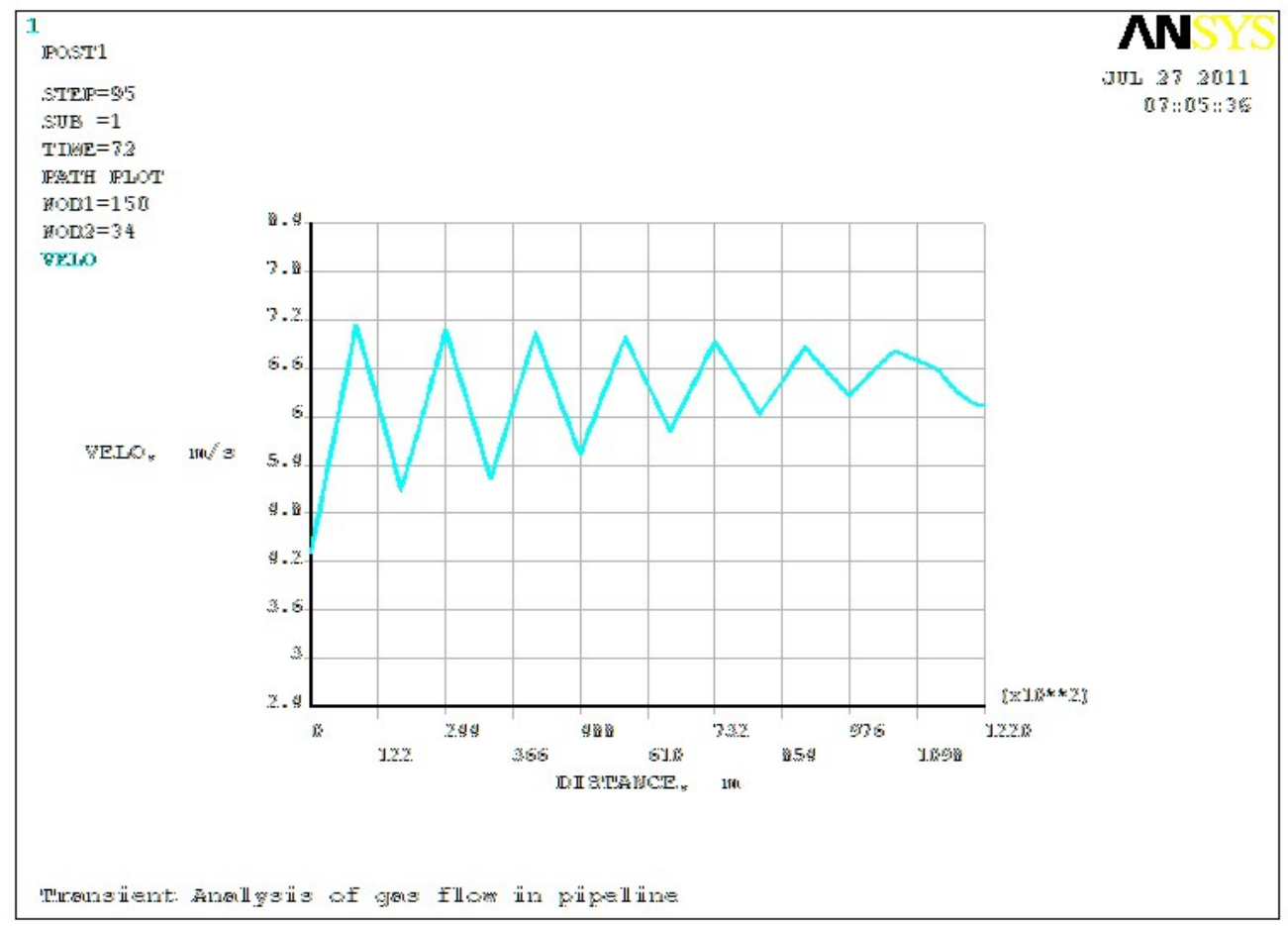

Fig 24: Velocity versus pipeline length at time, $t=72 \mathrm{hrs}(\mathrm{T0}=\mathbf{2 8 5 . 1 5} \mathrm{K})$ 


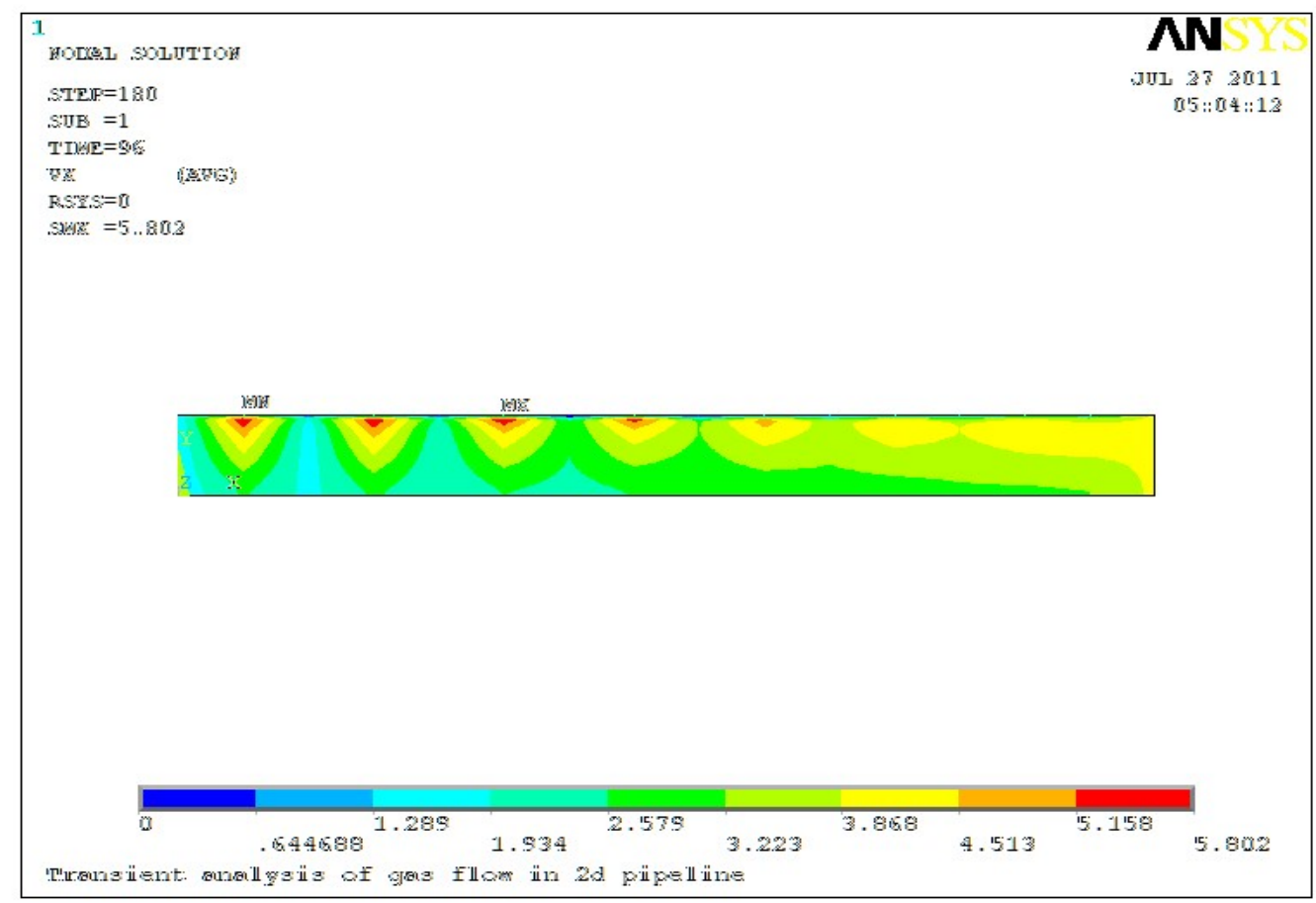

Fig 25: Contour plot of gas velocity at time $t=96 \mathrm{hrs}$ for WAGP

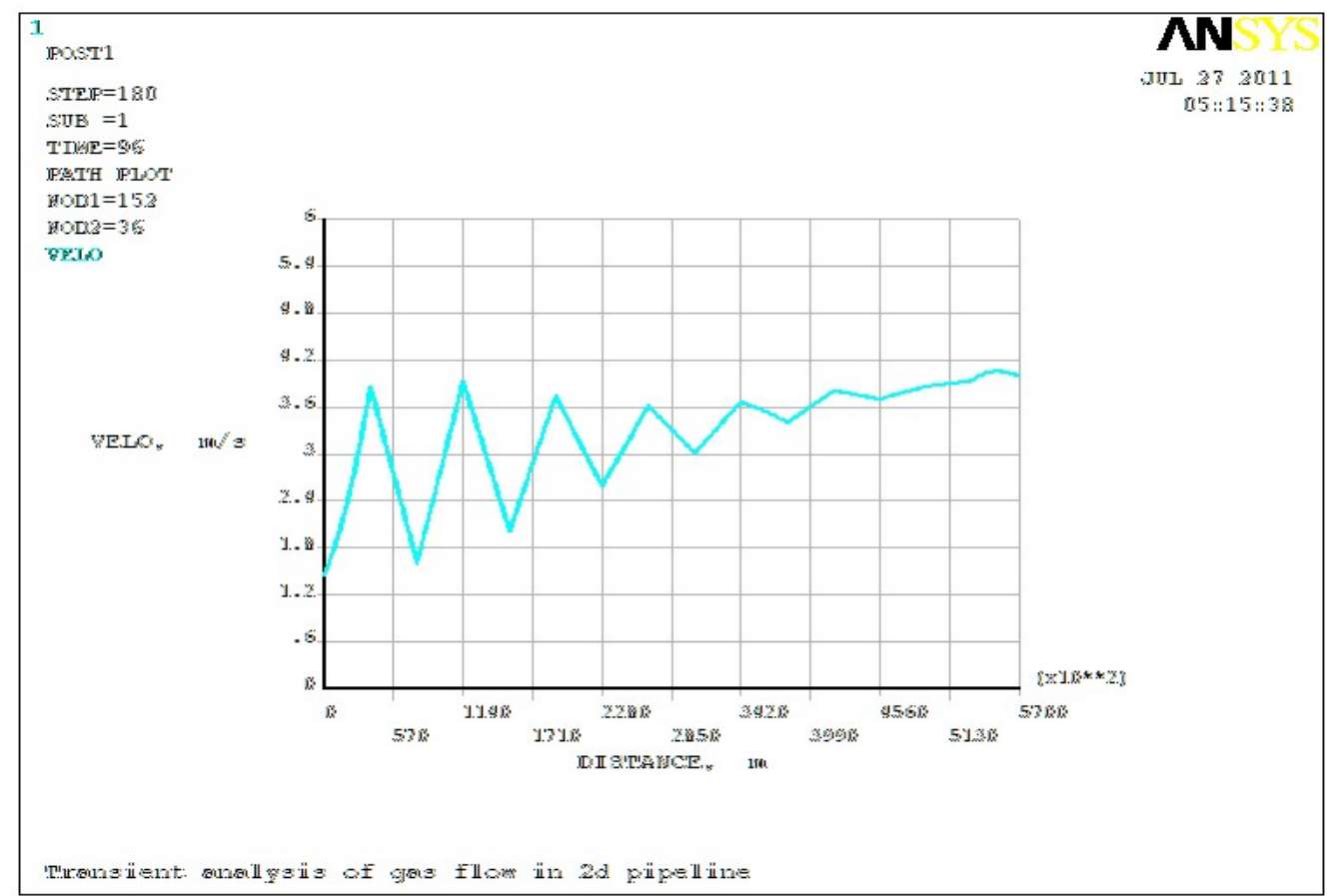

Fig 26: Velocity versus pipeline length at time $t=96 \mathrm{hrs}$ for WAGP

In the case of the transient results, all the transient pressures at $\mathrm{x}=\mathrm{L}$ from case 1 to case 4 showed that outlet pressure profiles increased with decreased velocity profiles and vice versa (fig 4.33 4.40). The initial oscillations in outlet pressures are expected because the flow model is non-linear and initially turbulent with average Reynolds number of over 350000 . Secondly, in the initial stages the system has not yet attained the actual value of the flow demand imposed at the outlet. Therefore, 
for about $15 \mathrm{hrs}$ as can be observed in fig $4.33-4.40$, the system was adjusting to the flow. After about $15 \mathrm{hrs}$ that the system attained stability, pressure responded appropriately to the demand flow at the outlet. The transient pressure results are consistent with the results in literature $[5,6,9,13]$. The results with time indicated that the pressures responded appropriately to velocity flow behavior.

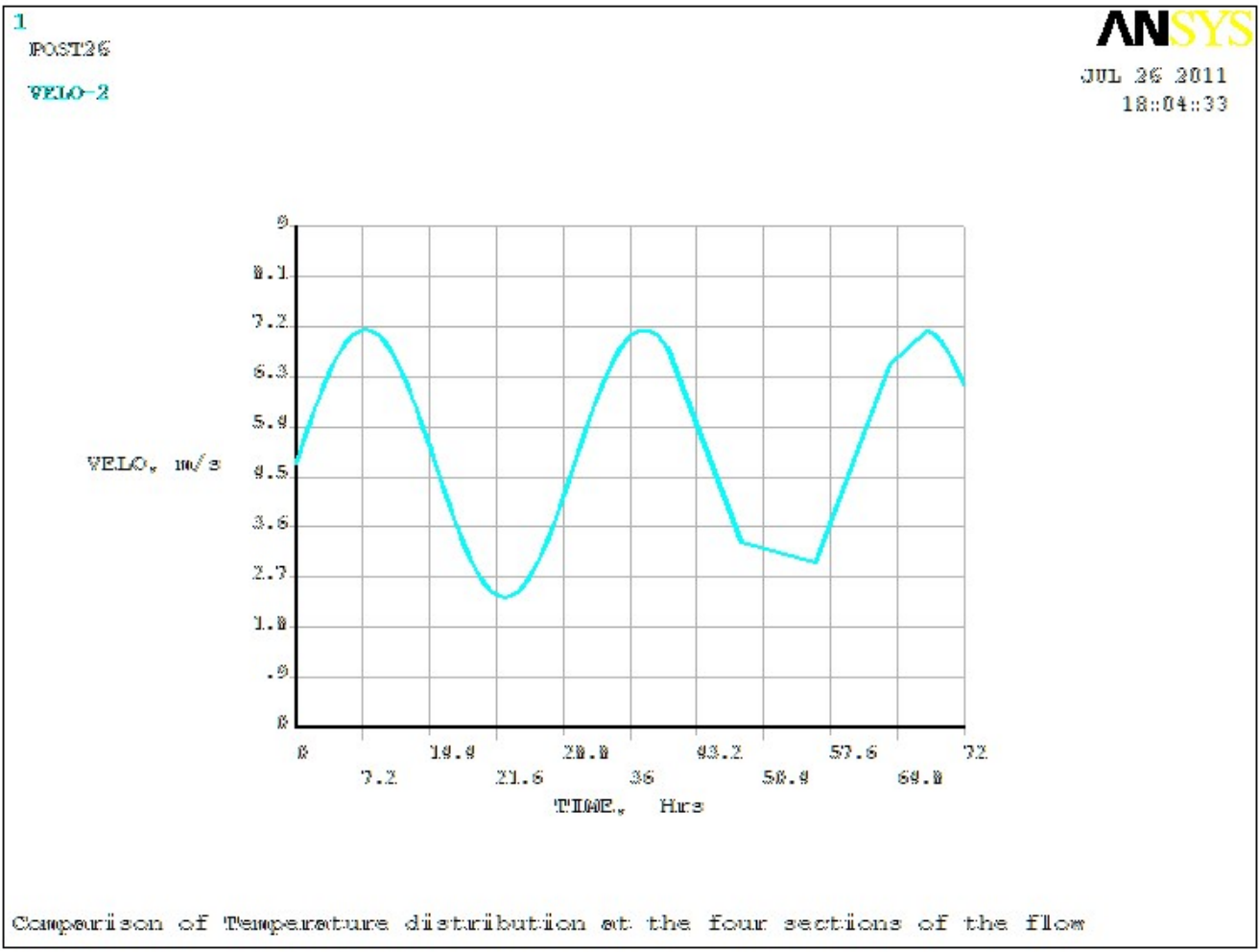

Fig 27: Velocity changes at $x=L$ depicting the function $f(t)(T 0=315.65 K)$

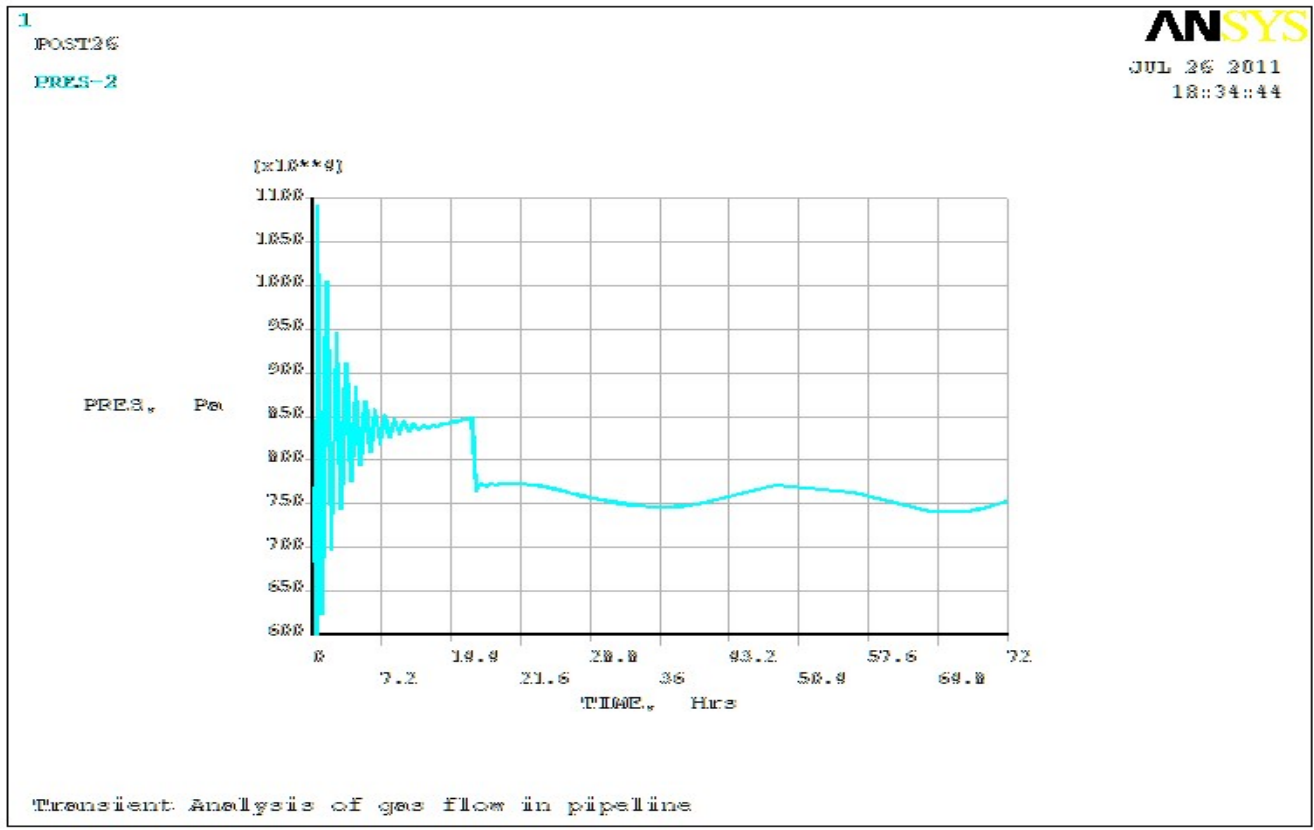

Fig 28: Pressure changes at $x=L(T 0=315.65 K)$ 


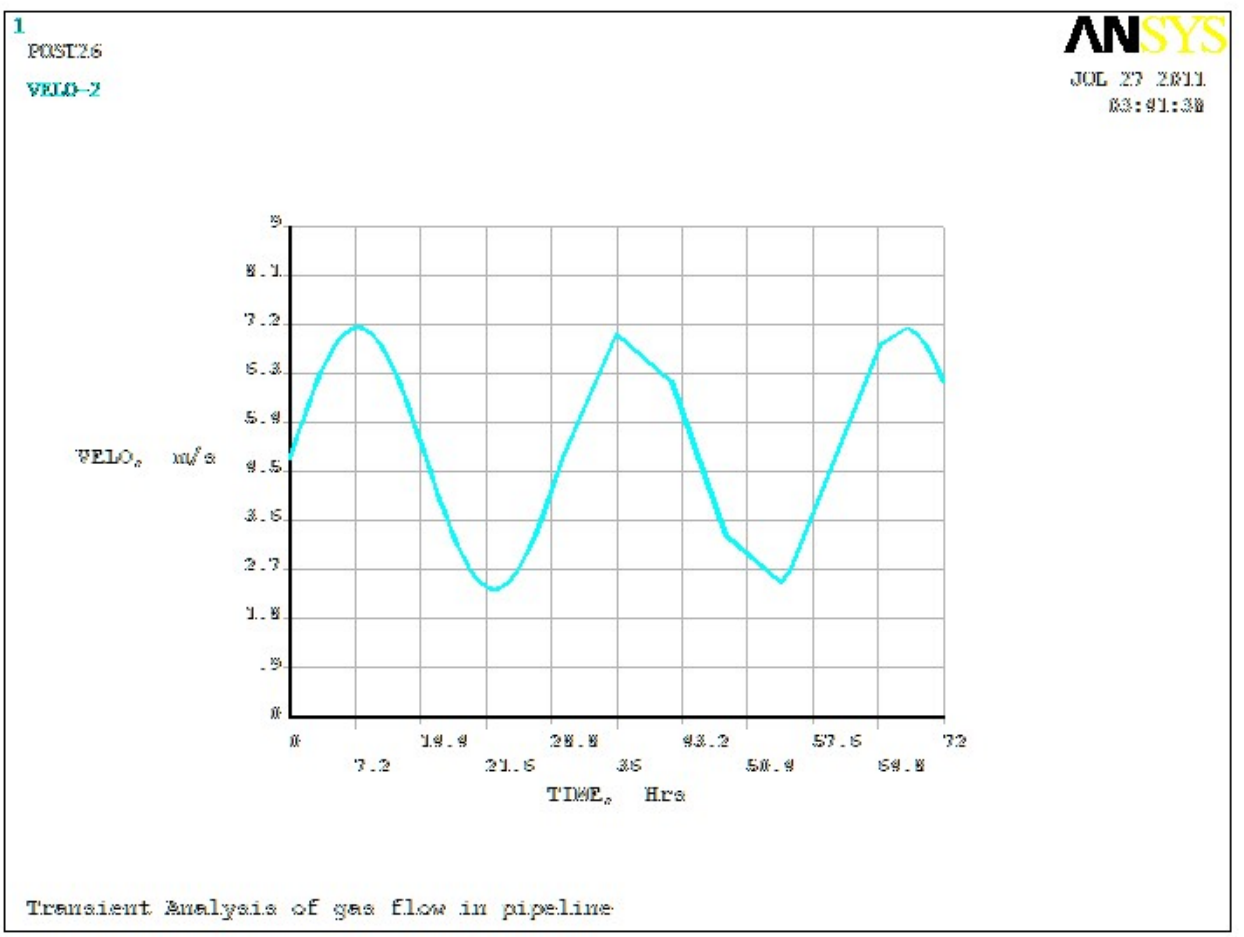

Fig 29: Velocity changes at $x=L(T 0=303.15 ~ K)$

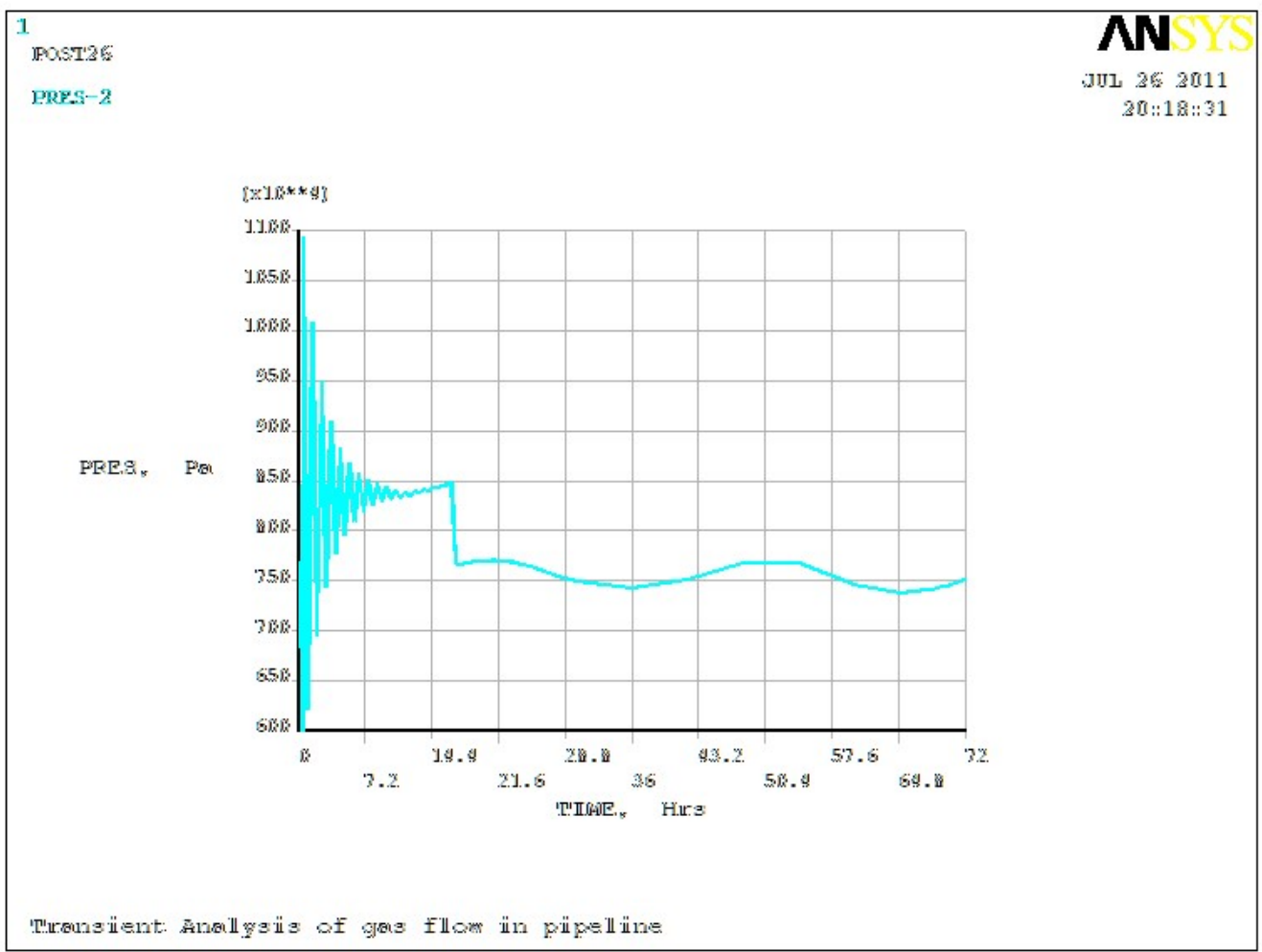

Fig 30: Pressure changes at $x=L(T 0=303.15 ~ K)$ 


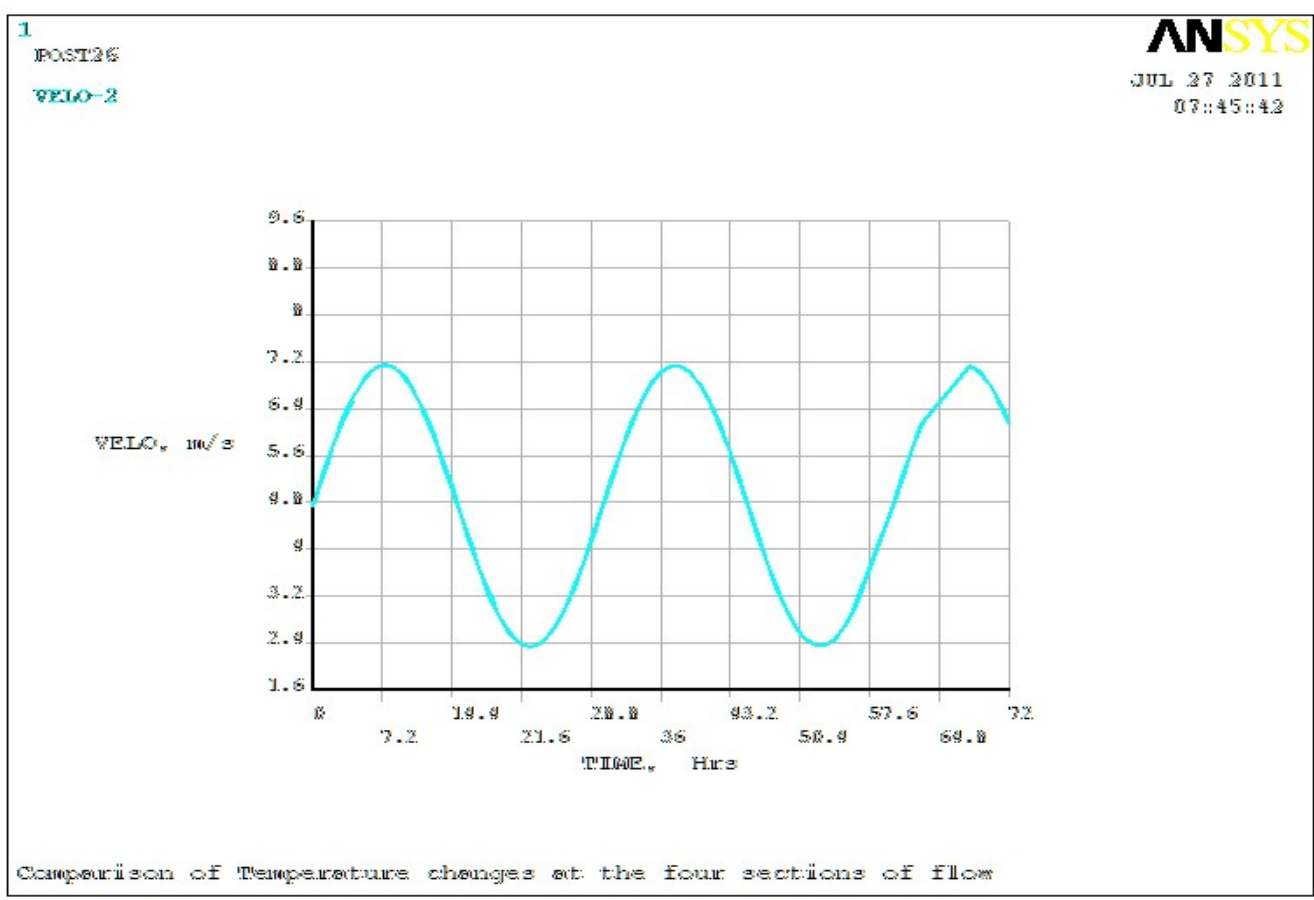

Fig 31: Velocity changes at $x=L(T 0=285.15 K)$

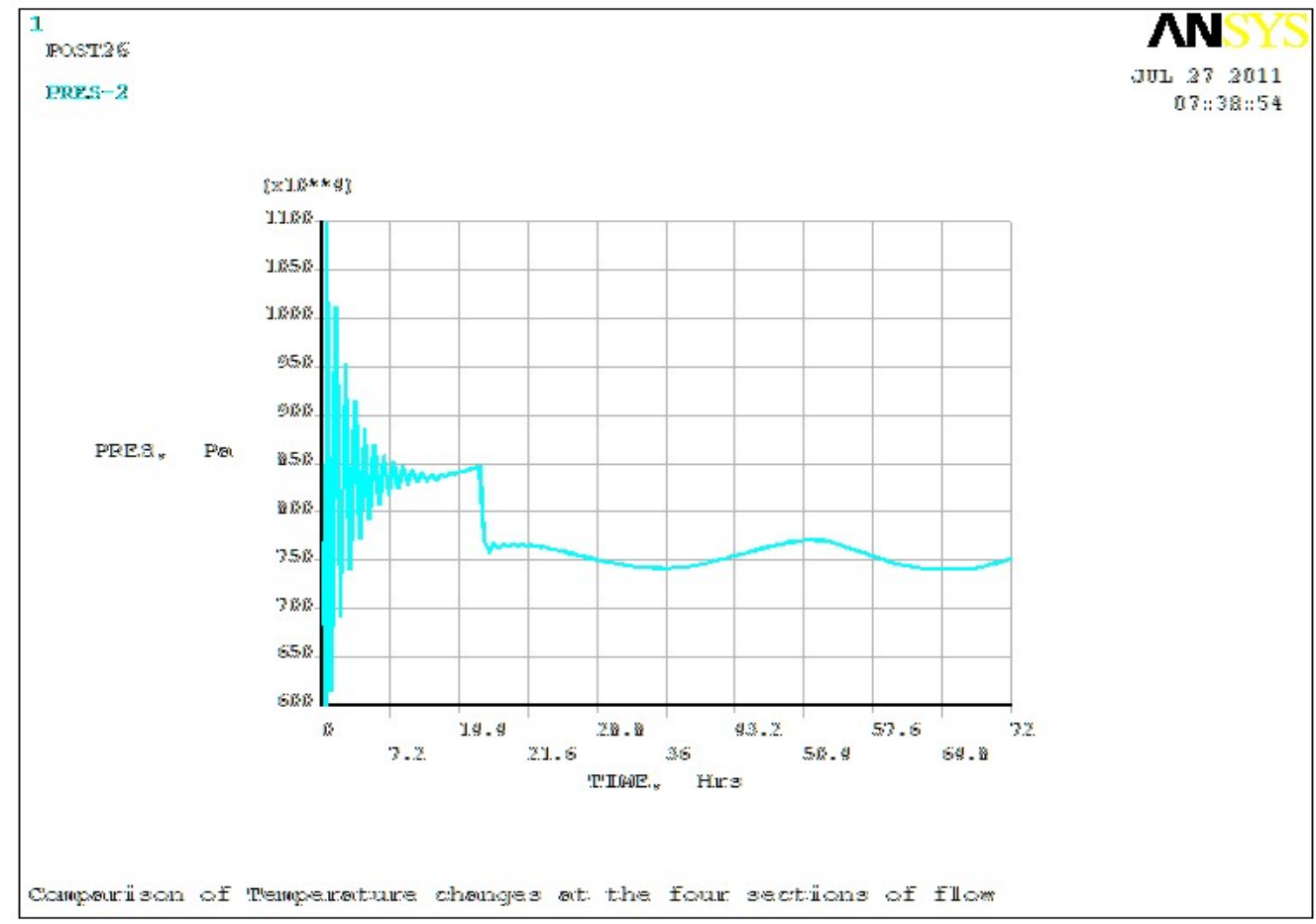

Fig 32: Pressure changes at $x=L(T 0=285.15 ~ K)$ 


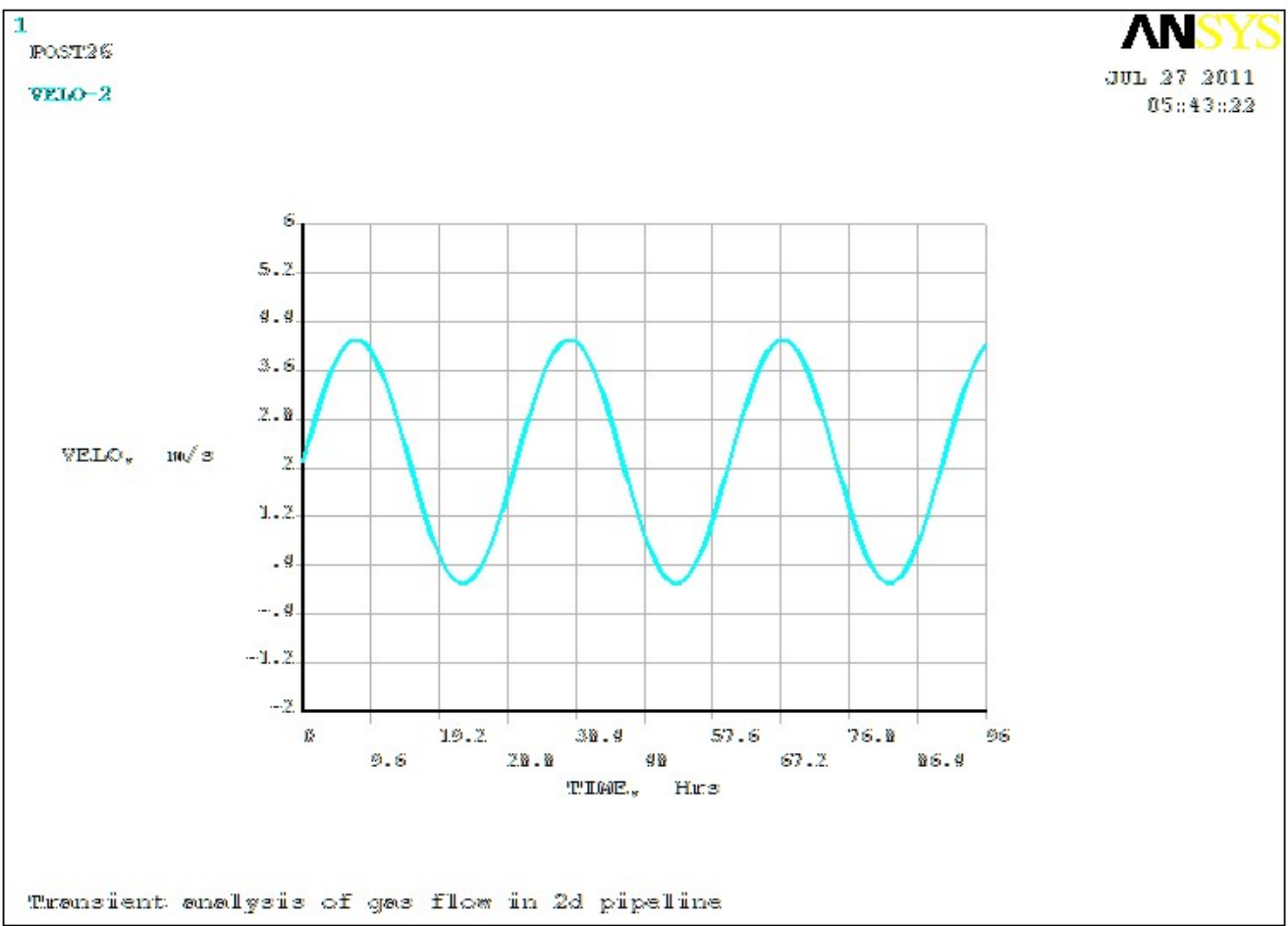

Fig 33: Velocity changes at $x=L$ (WAGP)

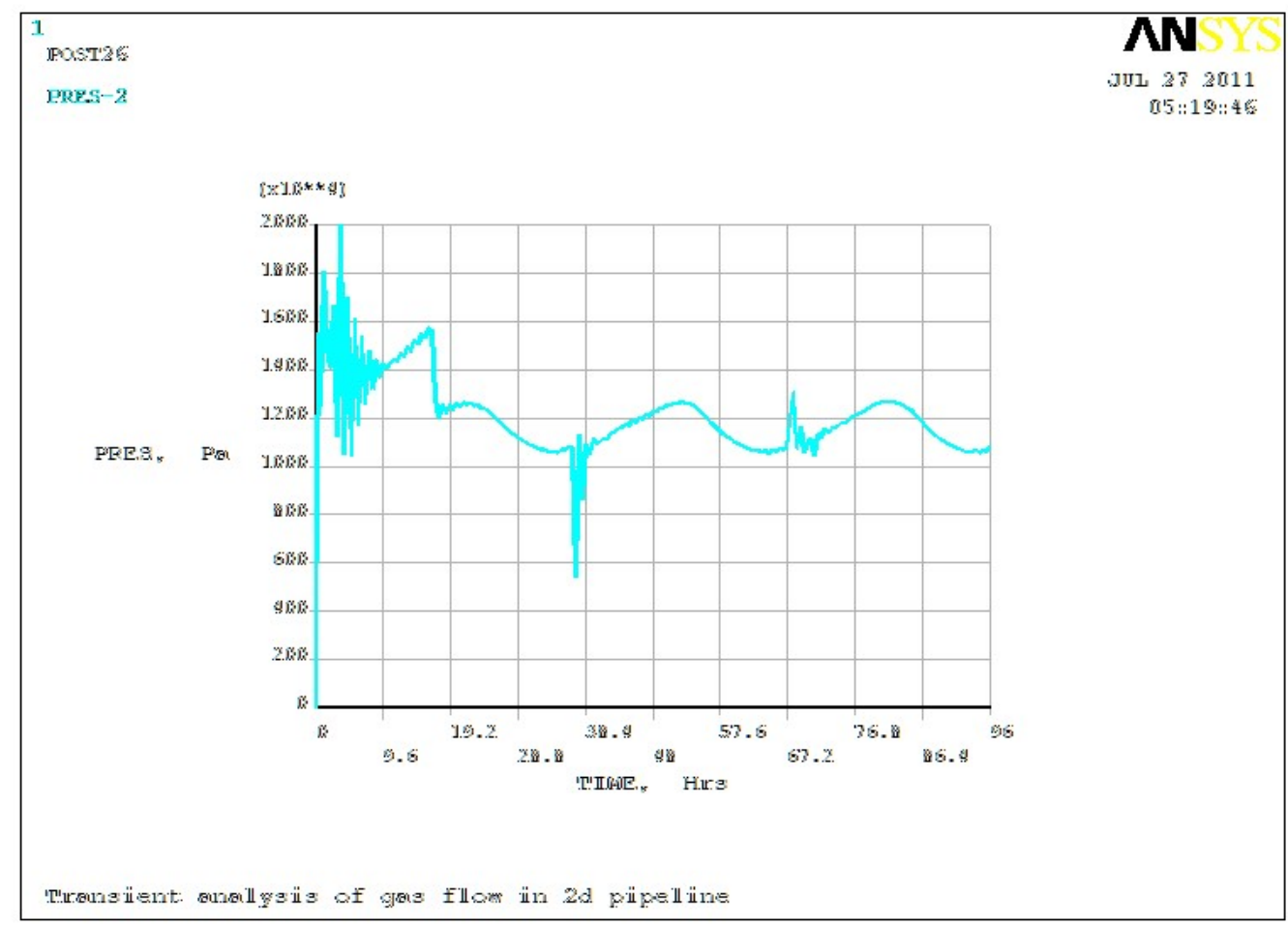

Fig 34: Pressure changes at $x=L$ (WAGP)

For transient temperature results at $\mathrm{x}=\mathrm{L}$, both case 1 , case 2 and case 4 showed a curve with the same trend except case 3 that showed constant straight line at $\mathrm{T}=285.15 \mathrm{~K}$. This behavior for case 
3 is explained by the fact that temperature conditions at the inlet and ground are the same (fig. 4.43) compared to the fig $4.41-4.42$ and 4.44 which is gradually changing. The transient temperature profiles (fig $4.41-4.42$ and 4.44) approaches the ground temperature gradually with time but still subject to small changes in value. The plots show that longer time would results in more temperature losses to the ground by reason of heat transfer and Joule Thompson cooling and the end result would be that the temperatures would fall below the ground or ambient temperature with time as seen in fig 4.41 or be asymptotic with the ground temperature with time as pictured in fig 4.44. This result establishes that transient gas flow temperatures are a function of both time and distance.

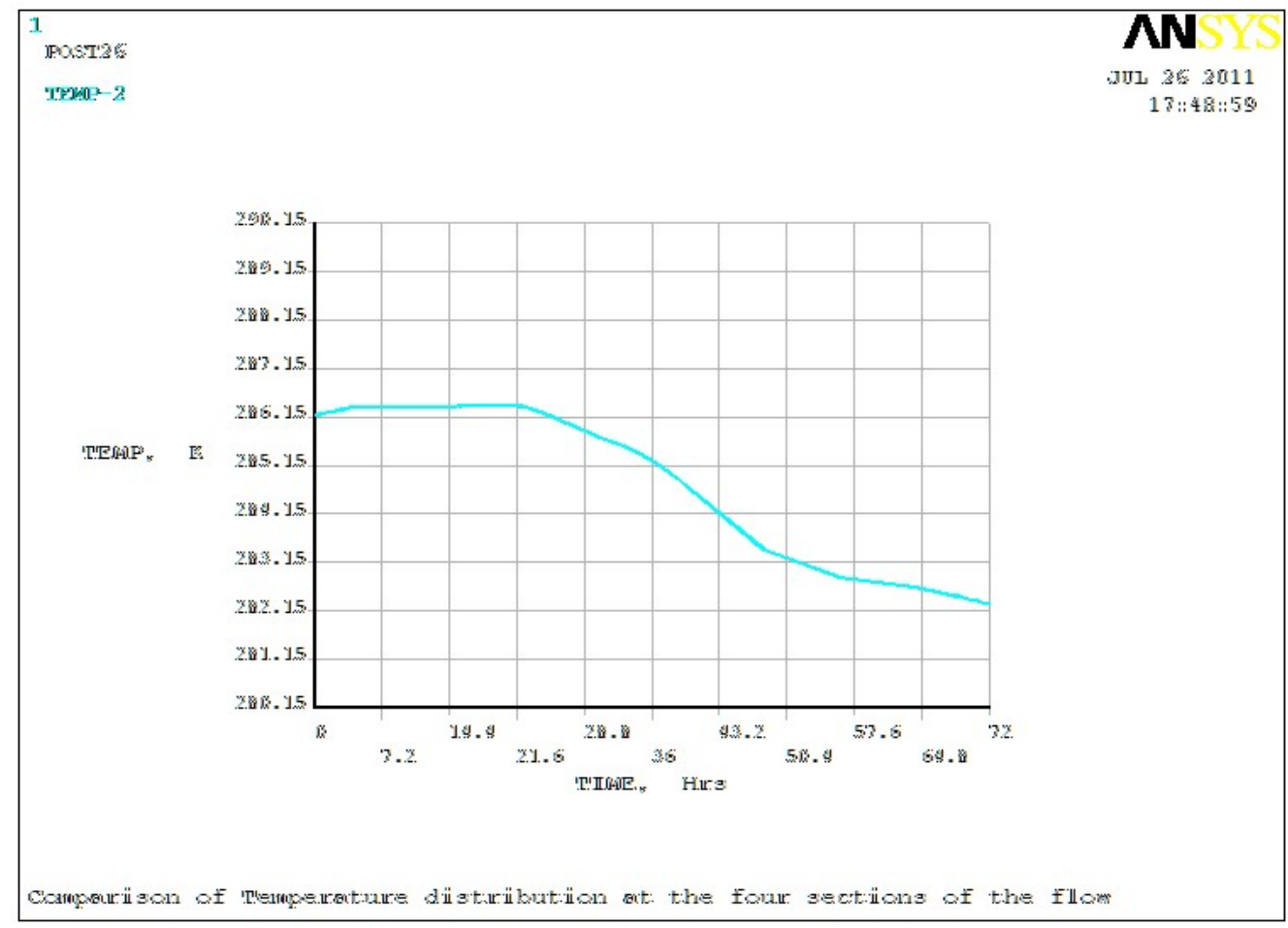

Fig 35: Temperature changes at $x=L(T 0=315.65 K)$ 


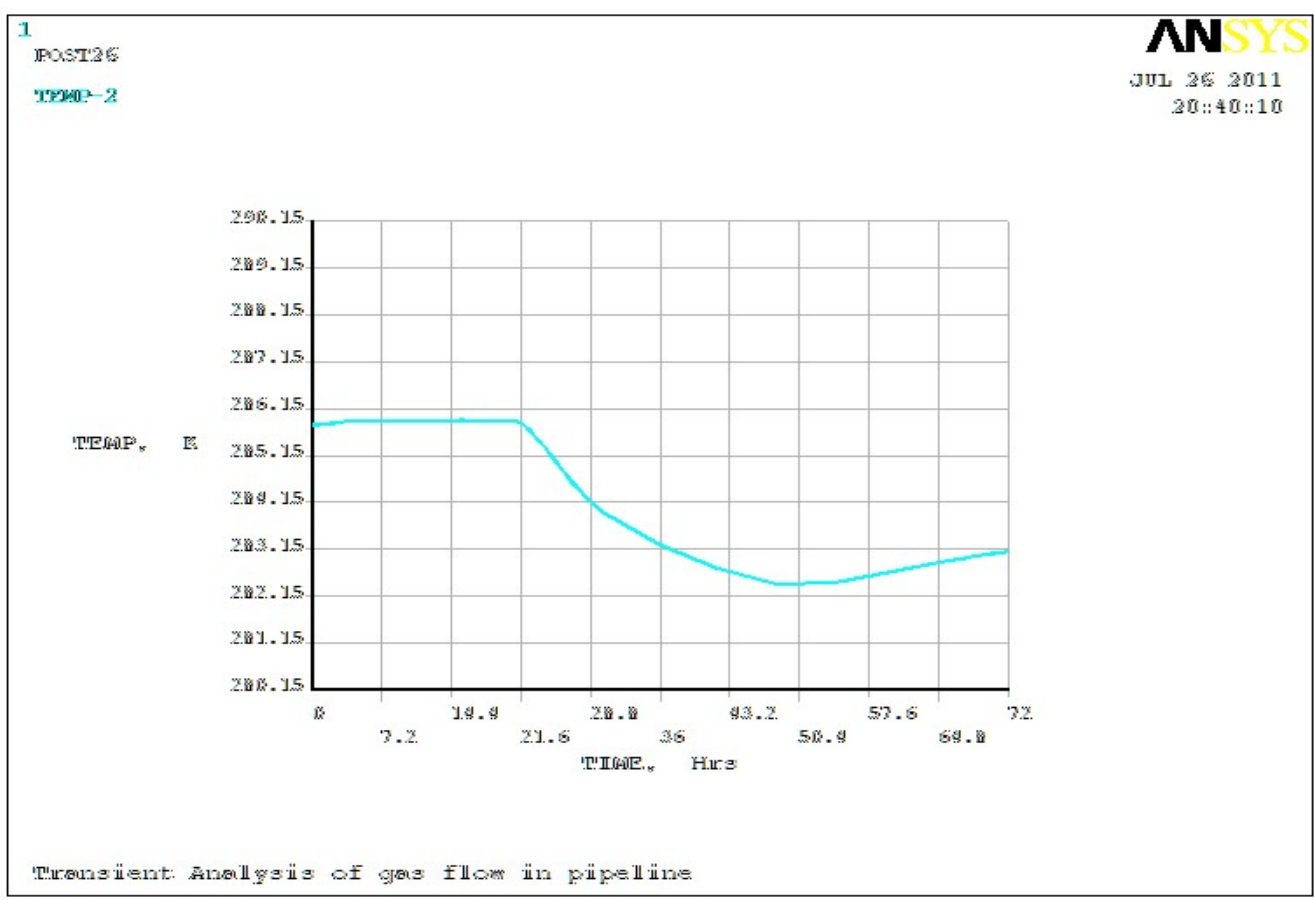

Fig. 36: Temperature changes at $x=L(T 0=303.15 \mathrm{~K})$

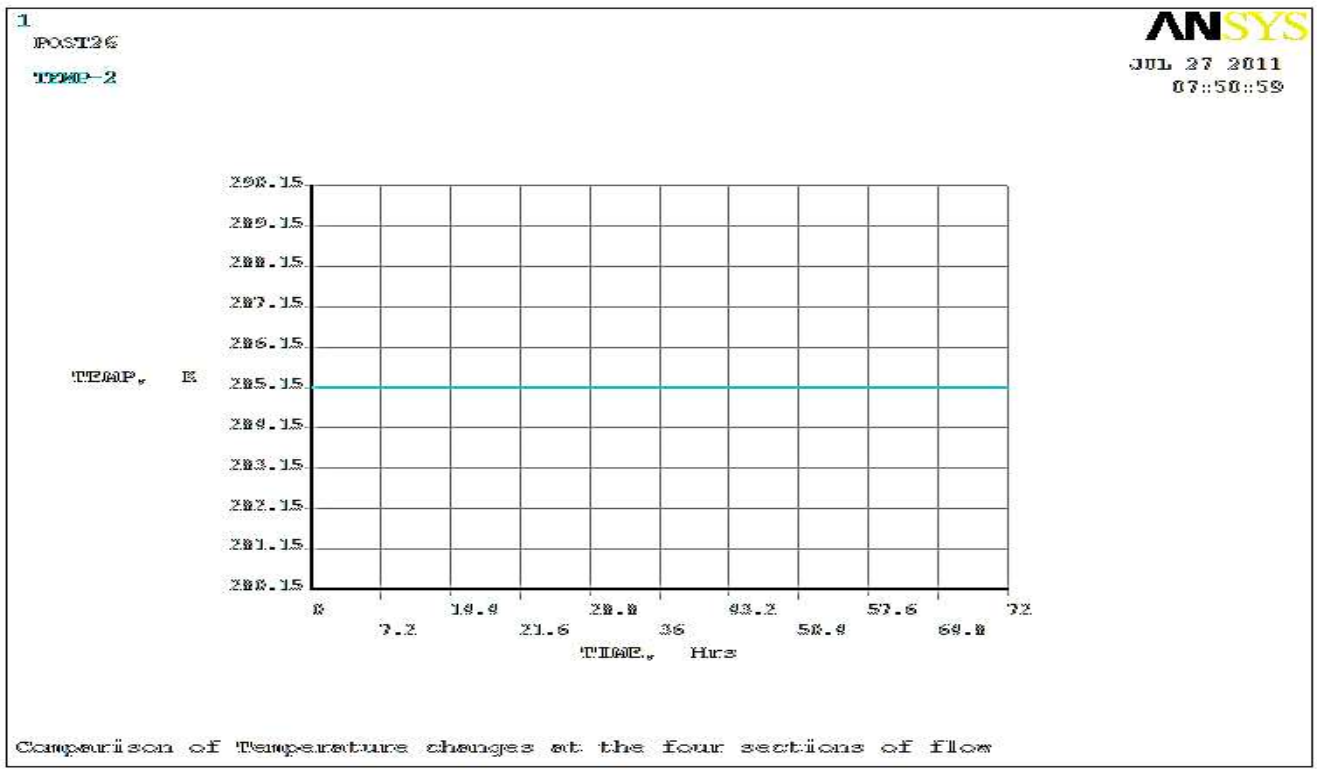

Fig 37: Temperature changes at $x=L(T 0=285.15 K)$ 


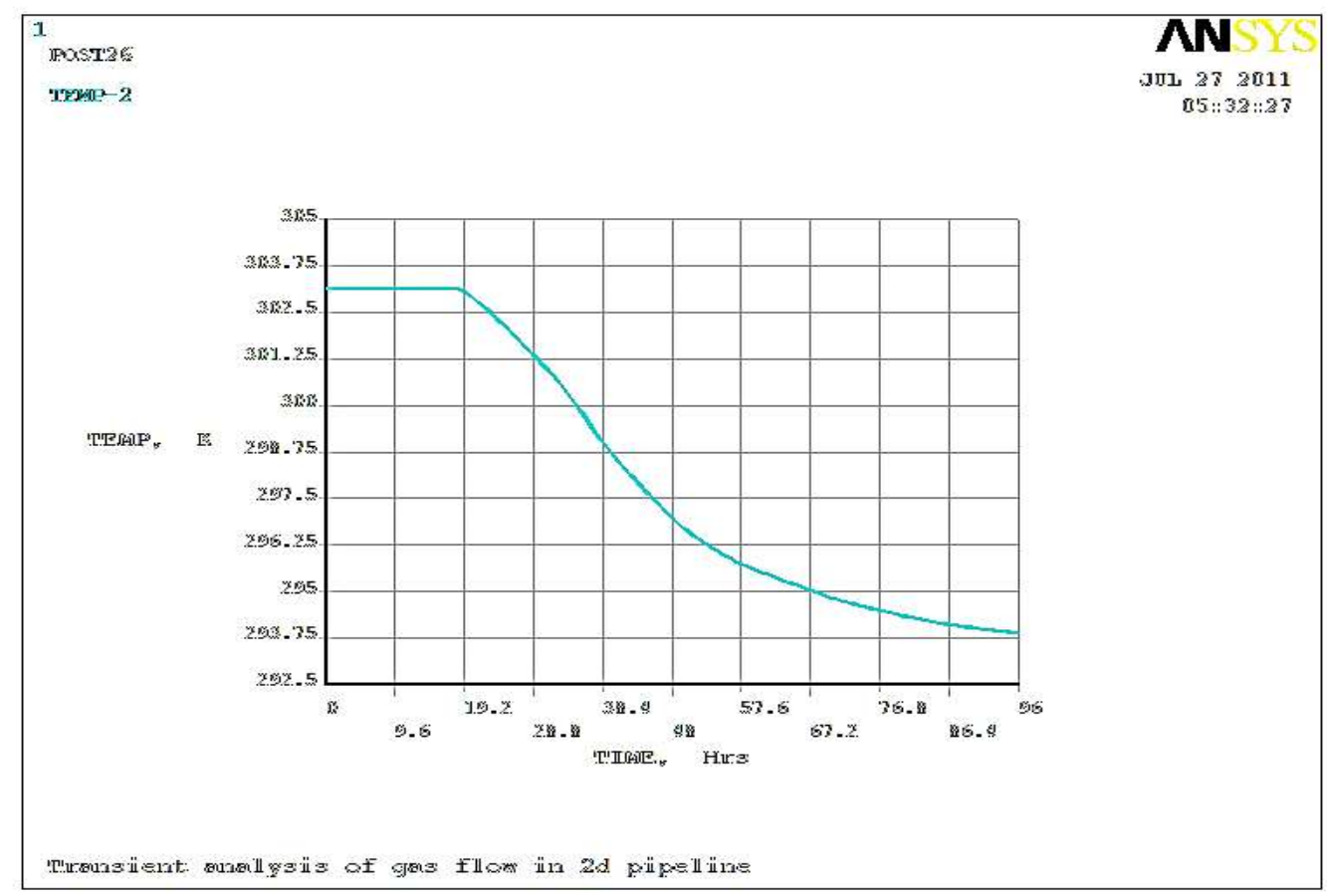

Fig 38: Temperature changes at $x=L$ for WAGP

So far, it is pressure, temperature and velocity results at the pipeline outlet that has been discussed. It is expedient at this point to examine the flow behavior at the other point of the flow. In order to appreciate the flow behavior at various point of the flow, a comparative analysis of the flow behavior was done at the inlet, outlet, symmetry and the surface boundary. Fig $4.45-4.56$ showcase the comparative results at various point of the pipeline. However, to be able to understand the graphs, the following keys are necessary:

1 - Inlet

2 - Outlet

3 - Symmetry (region where $\mathrm{v}_{\mathrm{y}}=0$ )

4 - Surface condition (region of no-slip condition) 


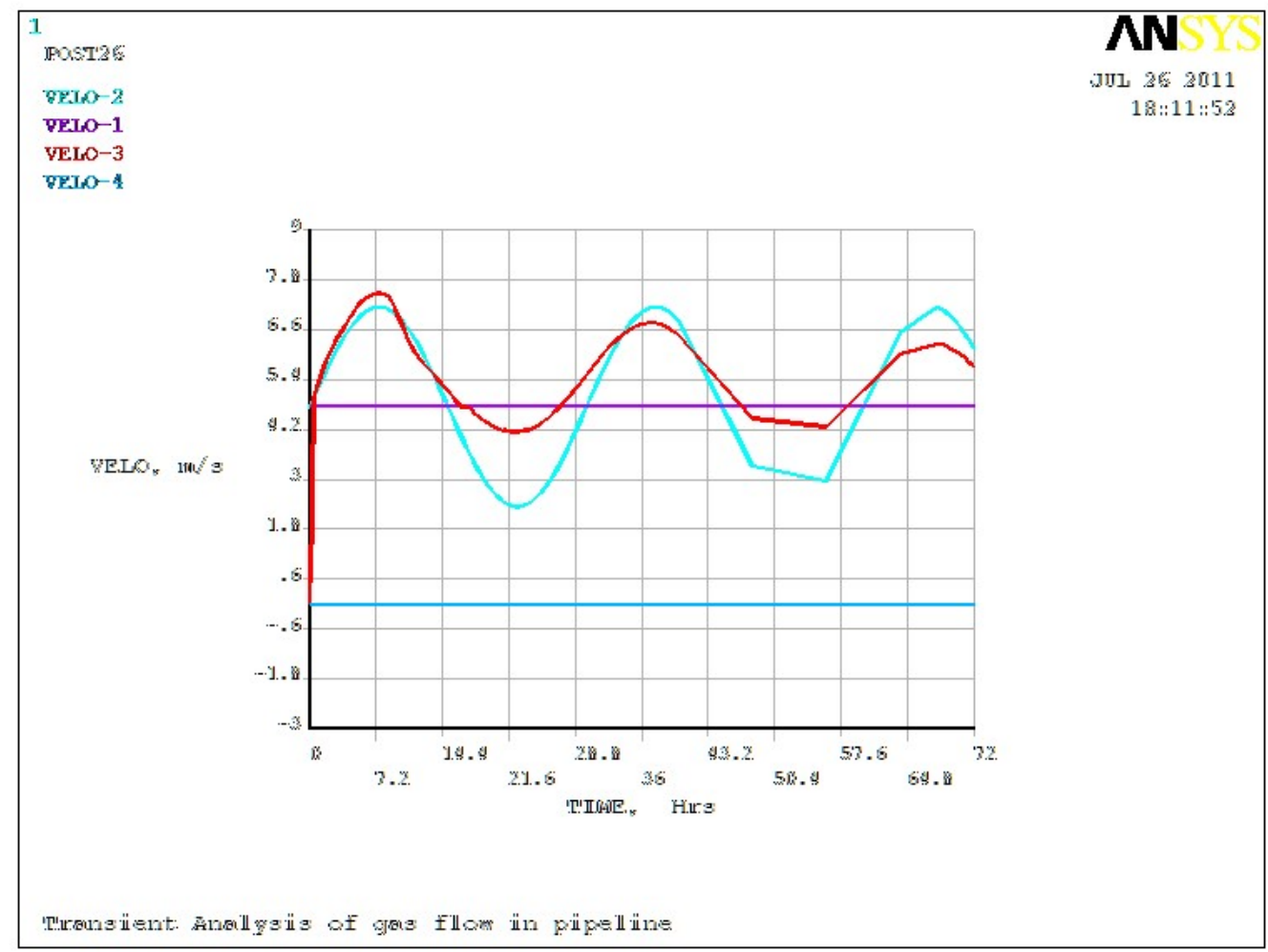

Fig 39: Comparison of velocity at the four sections of the flow $(\mathrm{T} 0=315.65 \mathrm{~K})$

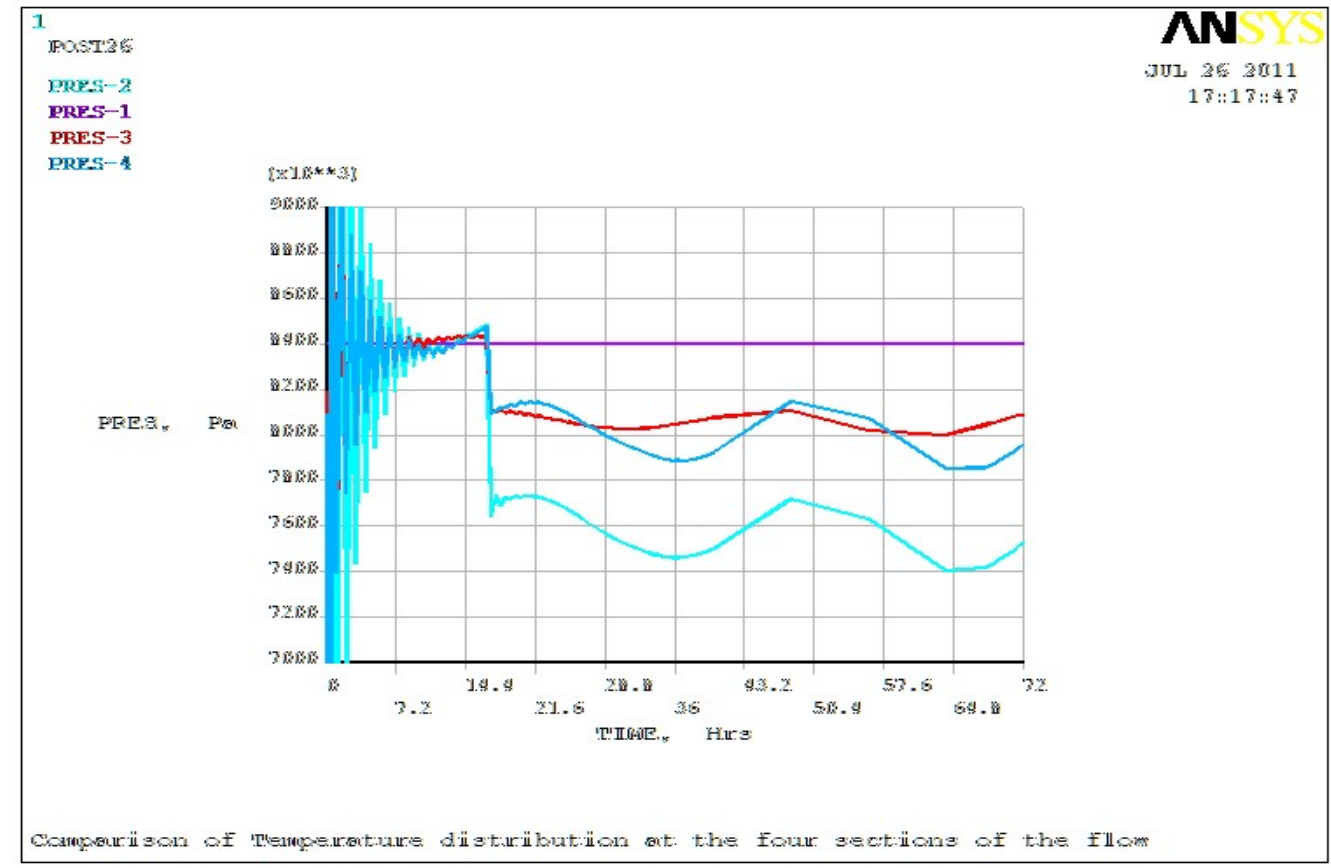

Fig 40: Comparison of pressure at the four sections of the flow $(\mathrm{T} 0=315.65 \mathrm{~K})$ 


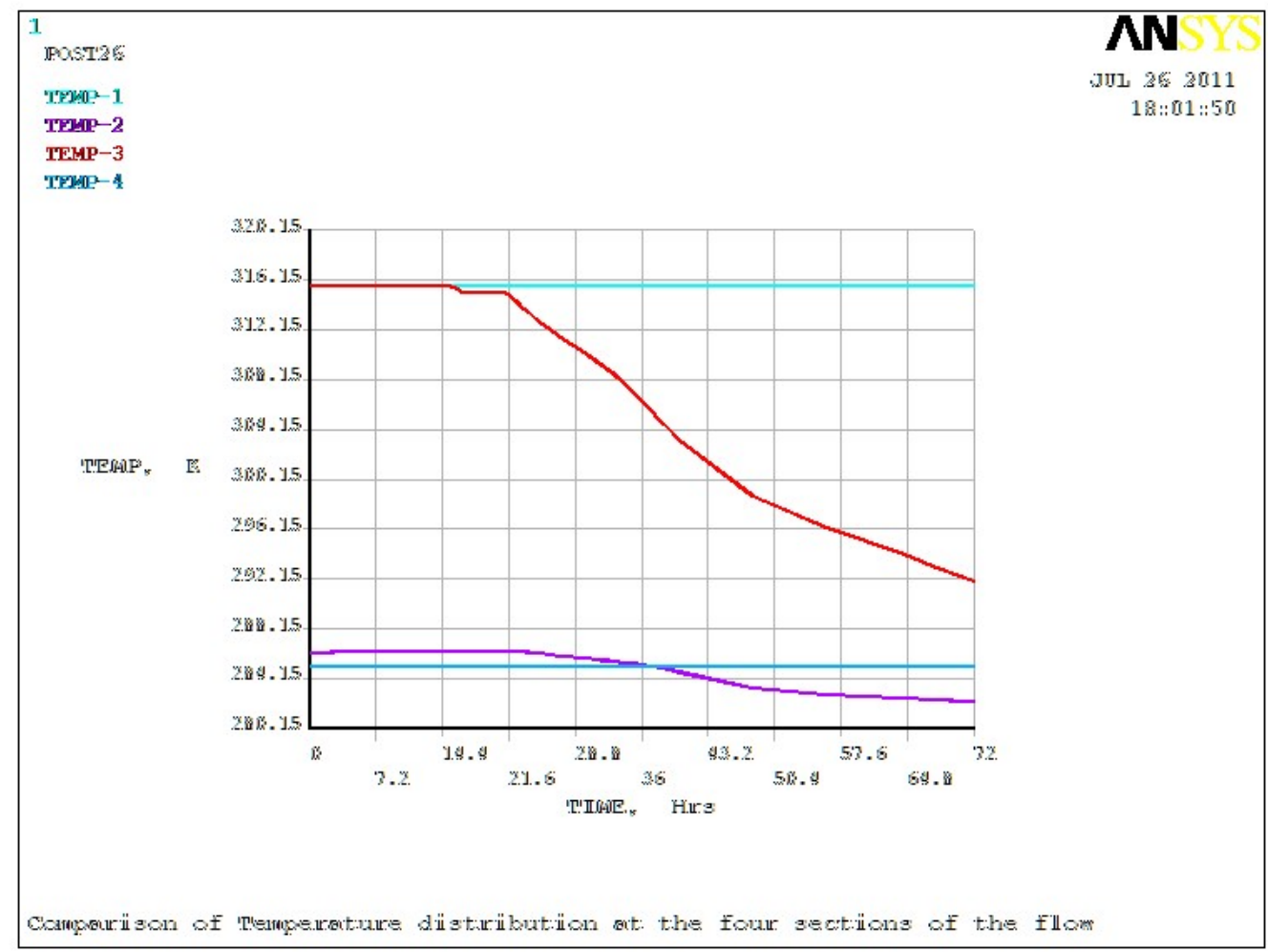

Fig 41: Comparison of Temperature changes at the four sections $(\mathrm{T} 0=315.65 \mathrm{~K})$

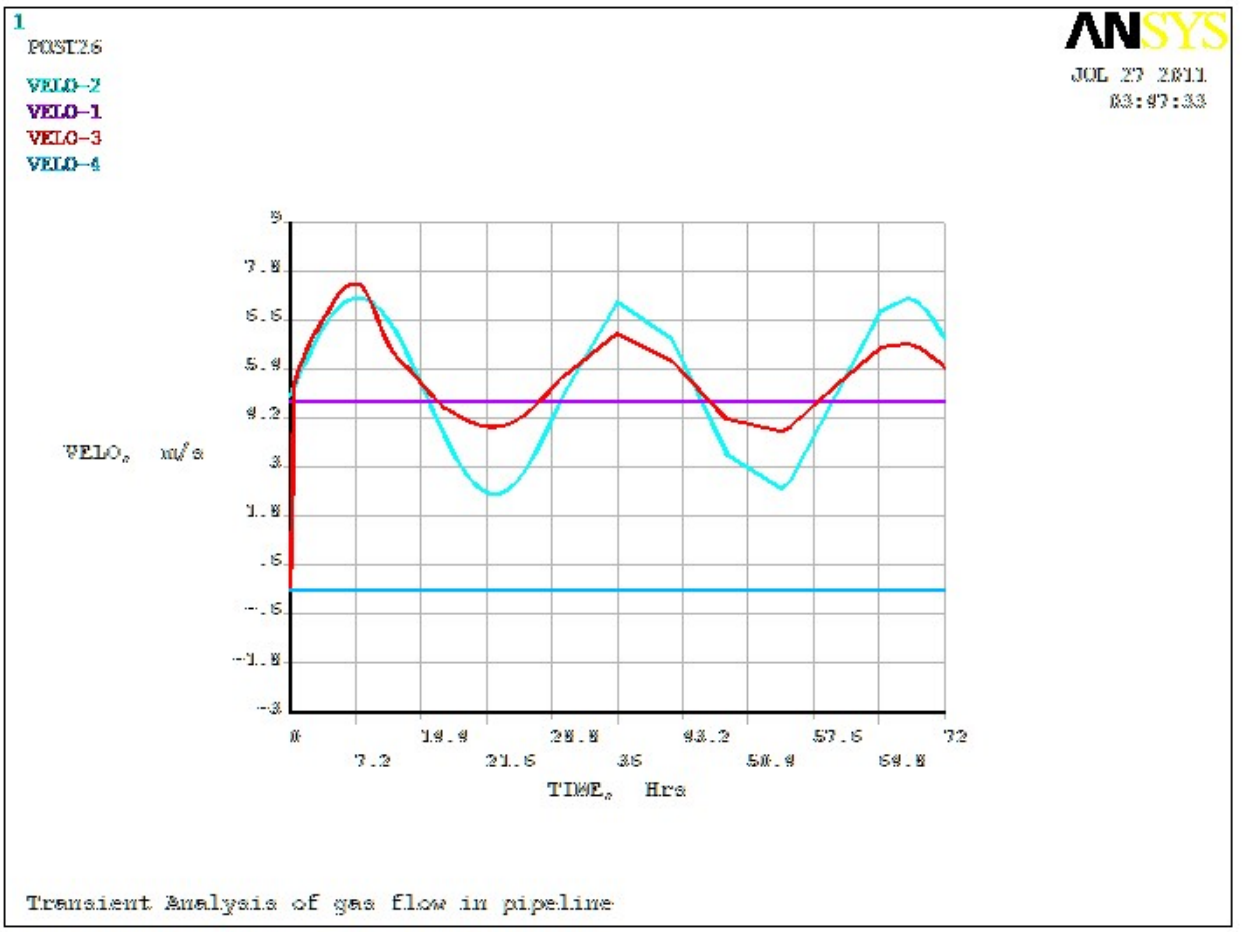

Fig. 42: Comparison of Temperature changes at the four sections $(\mathrm{T} 0=303.15 \mathrm{~K})$ 


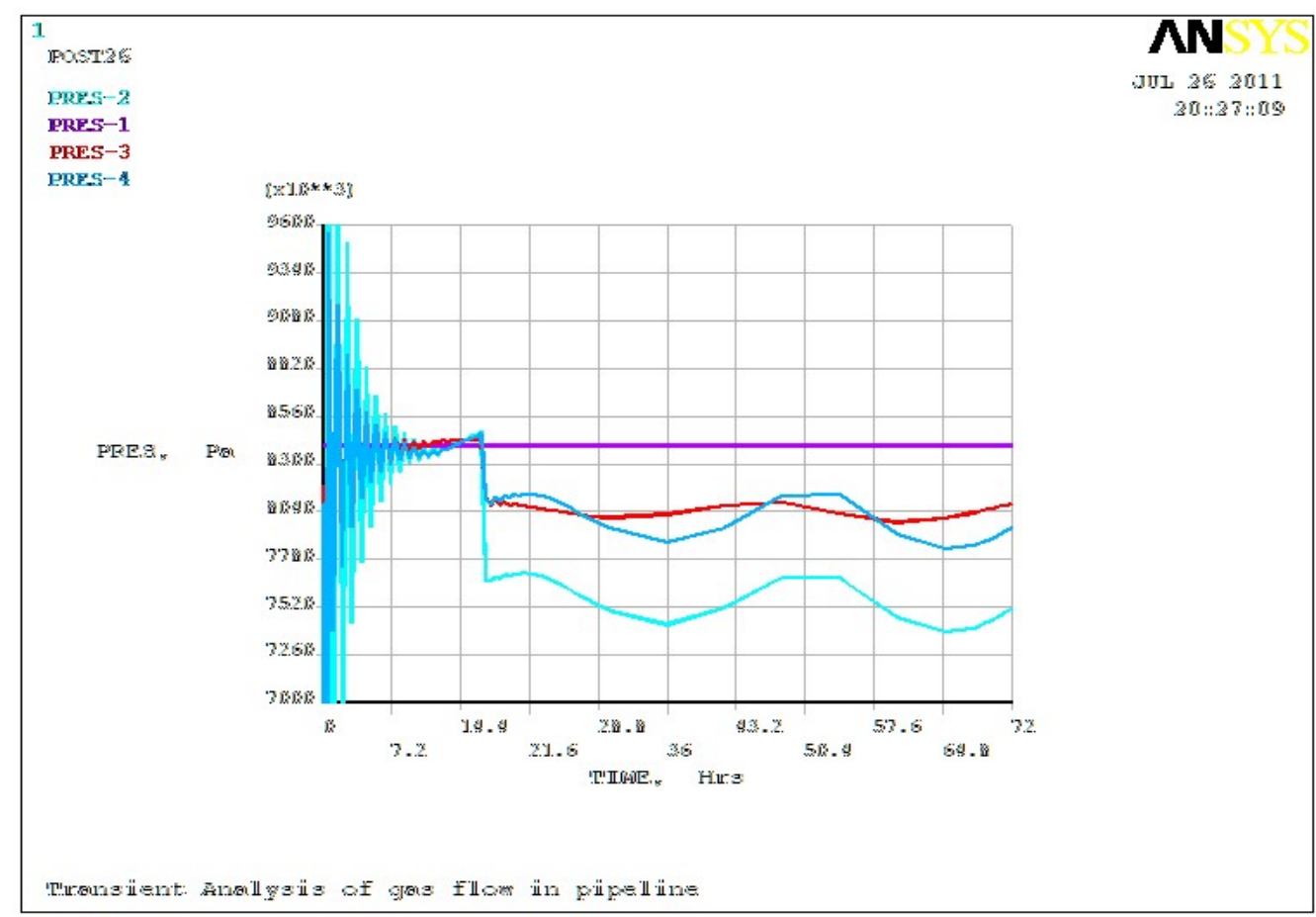

Fig 43: Comparison of pressure changes at the four sections $(\mathrm{T} 0=303.15 \mathrm{~K})$

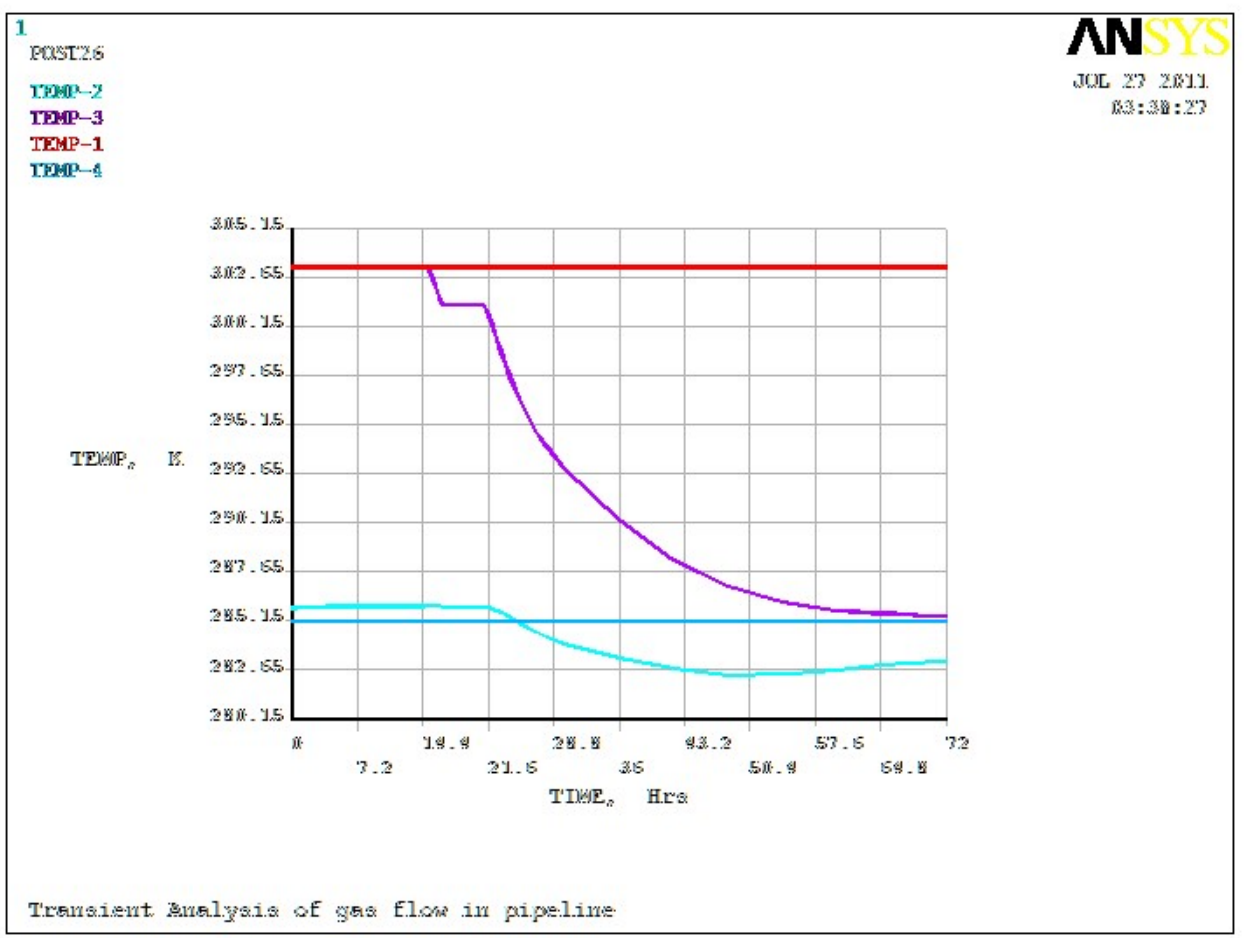

Fig 44: Comparison of temperature changes at the four sections $(\mathrm{T} 0=303.15 \mathrm{~K})$ 


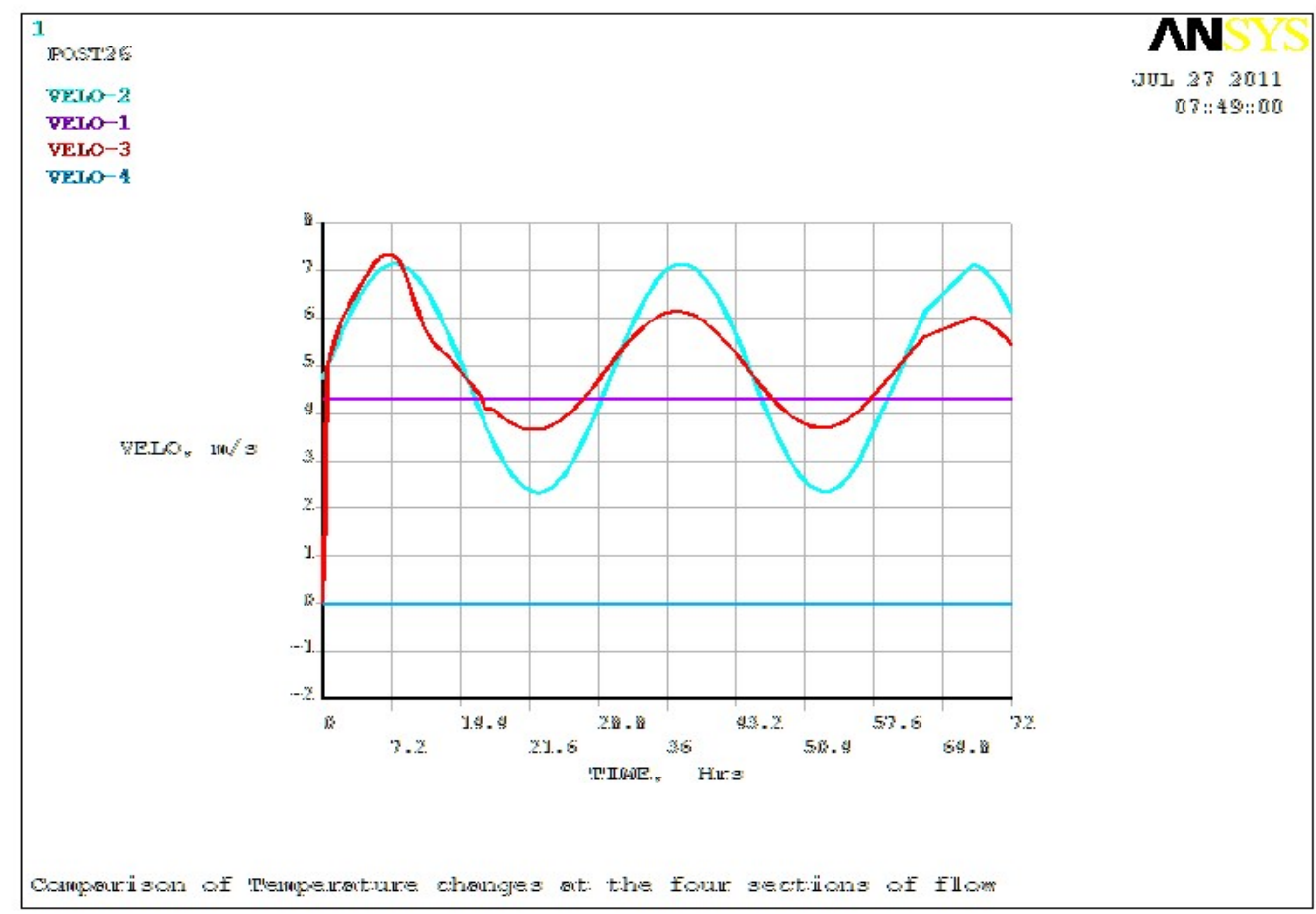

Fig 45: Comparison of velocity changes at the four sections $(\mathrm{T} 0=285.15 \mathrm{~K})$

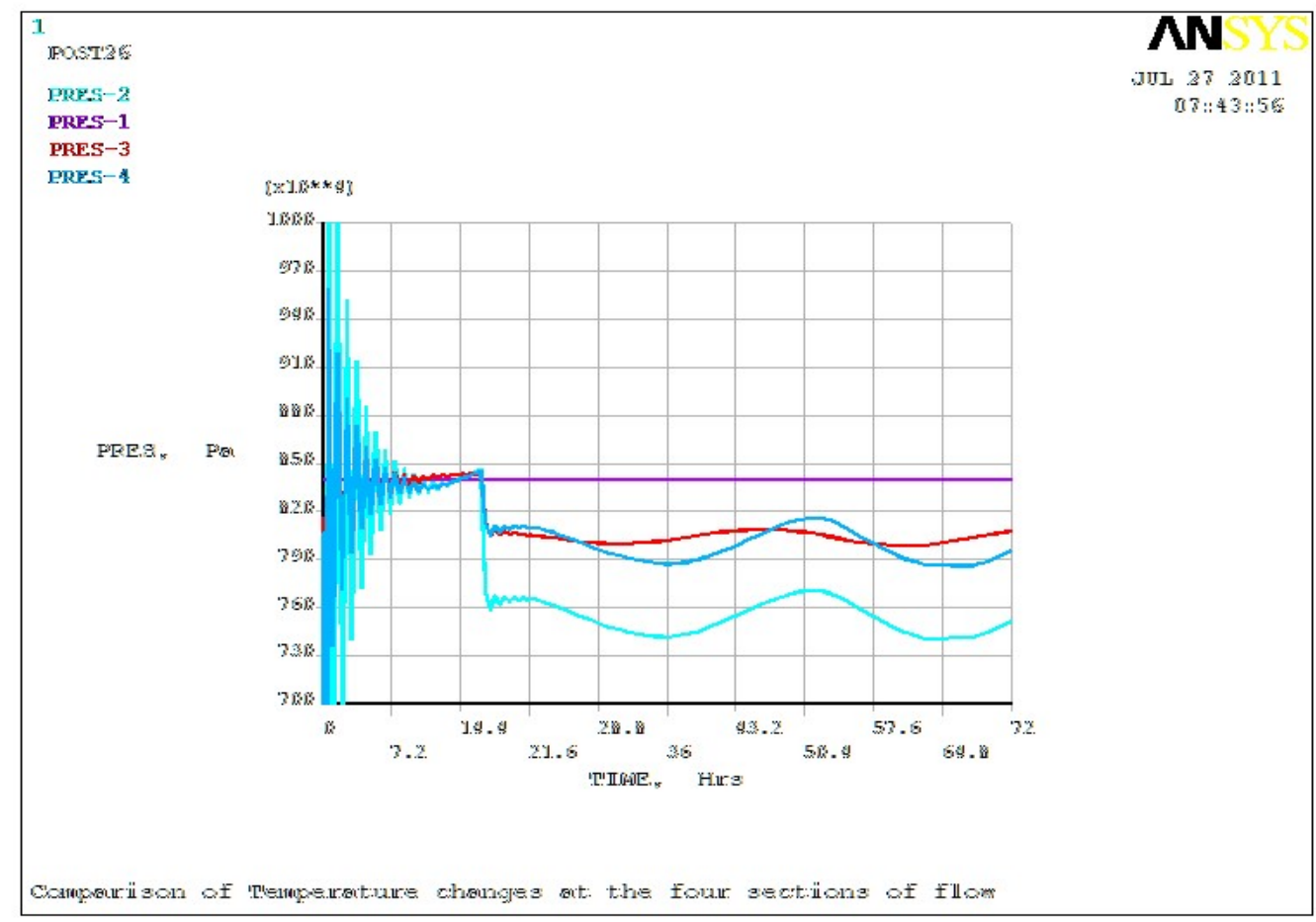

Fig 46: Comparison of pressure changes at the four sections $(\mathrm{T} 0=\mathbf{2 8 5 . 1 5} \mathrm{K})$ 


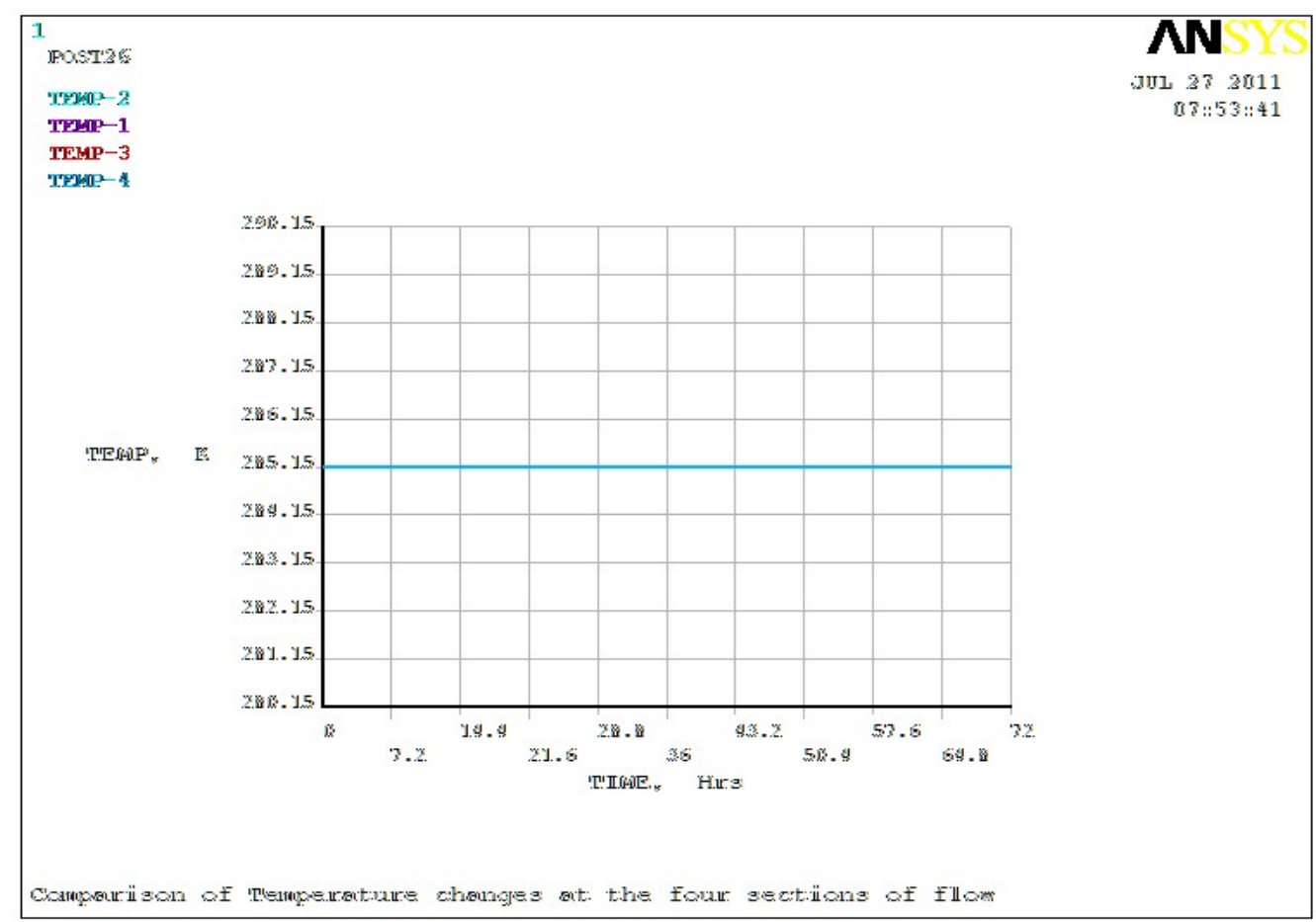

Fig 47: Comparison of temperature changes at the four section $(\mathrm{T} 0=\mathbf{2 8 5 . 1 5} \mathrm{K})$

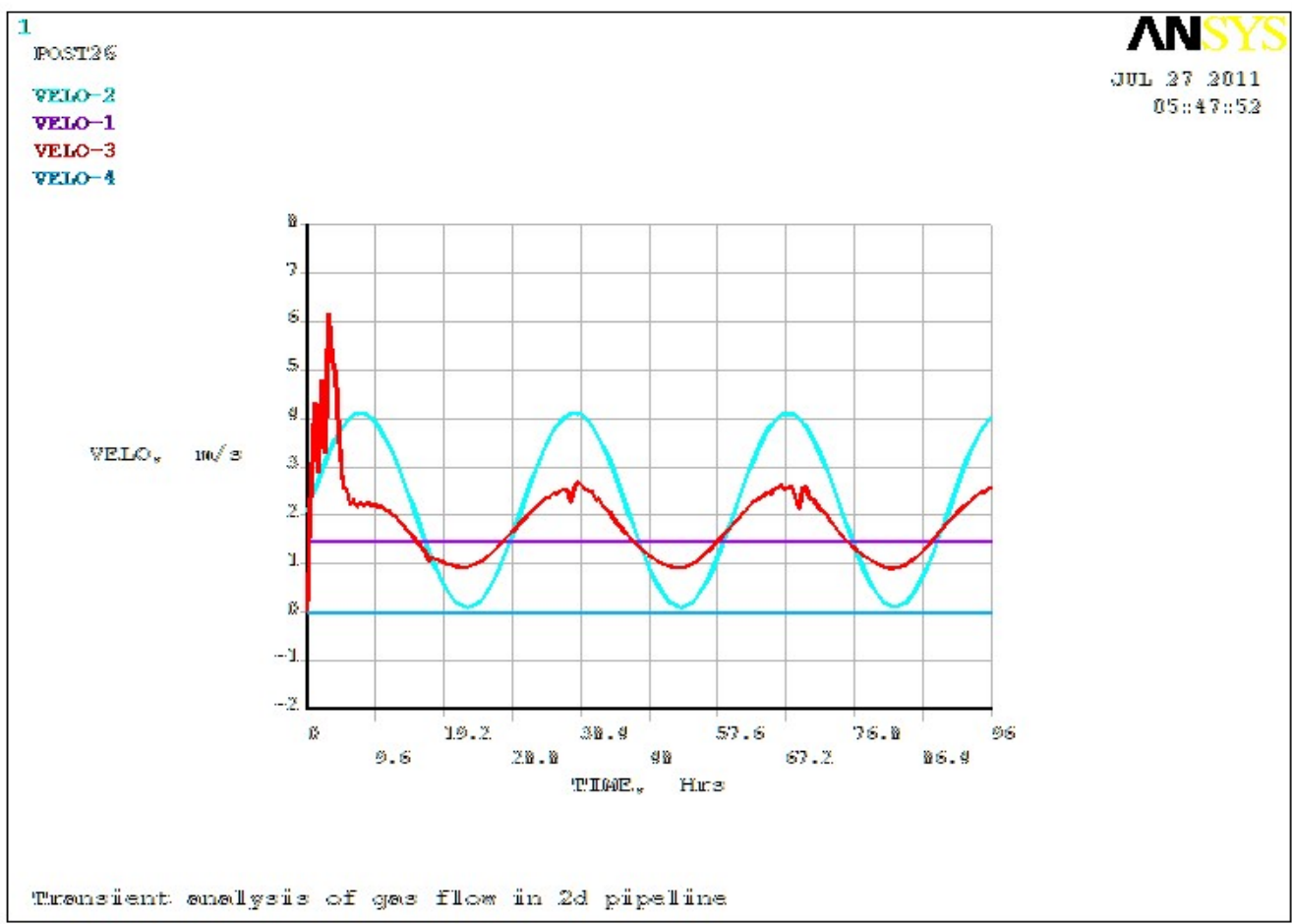

Fig 48: Comparison of Velocity changes at the four sections of flow (WAGP) 


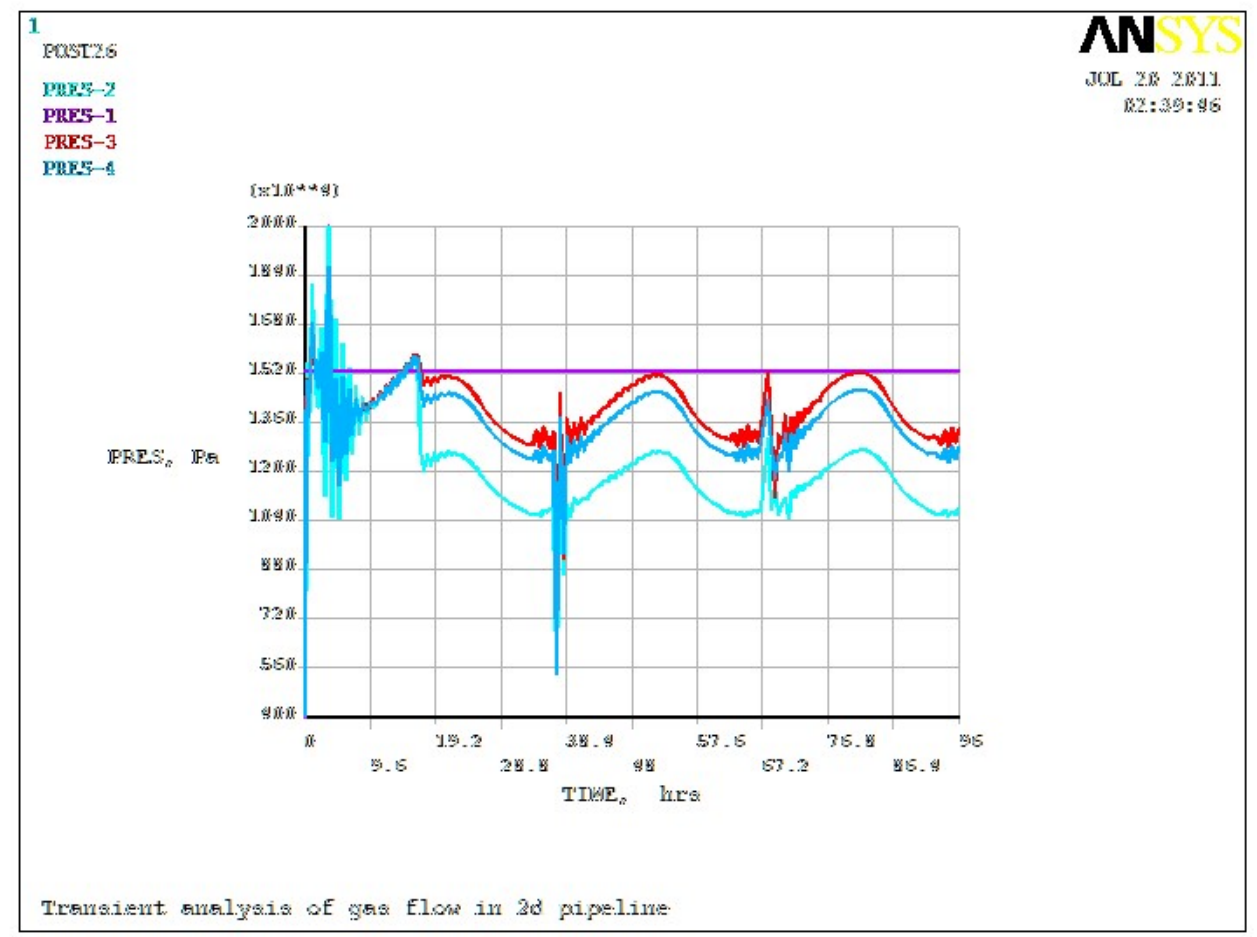

Fig 49: Comparison of Pressure changes at the four sections of flow (WAGP)

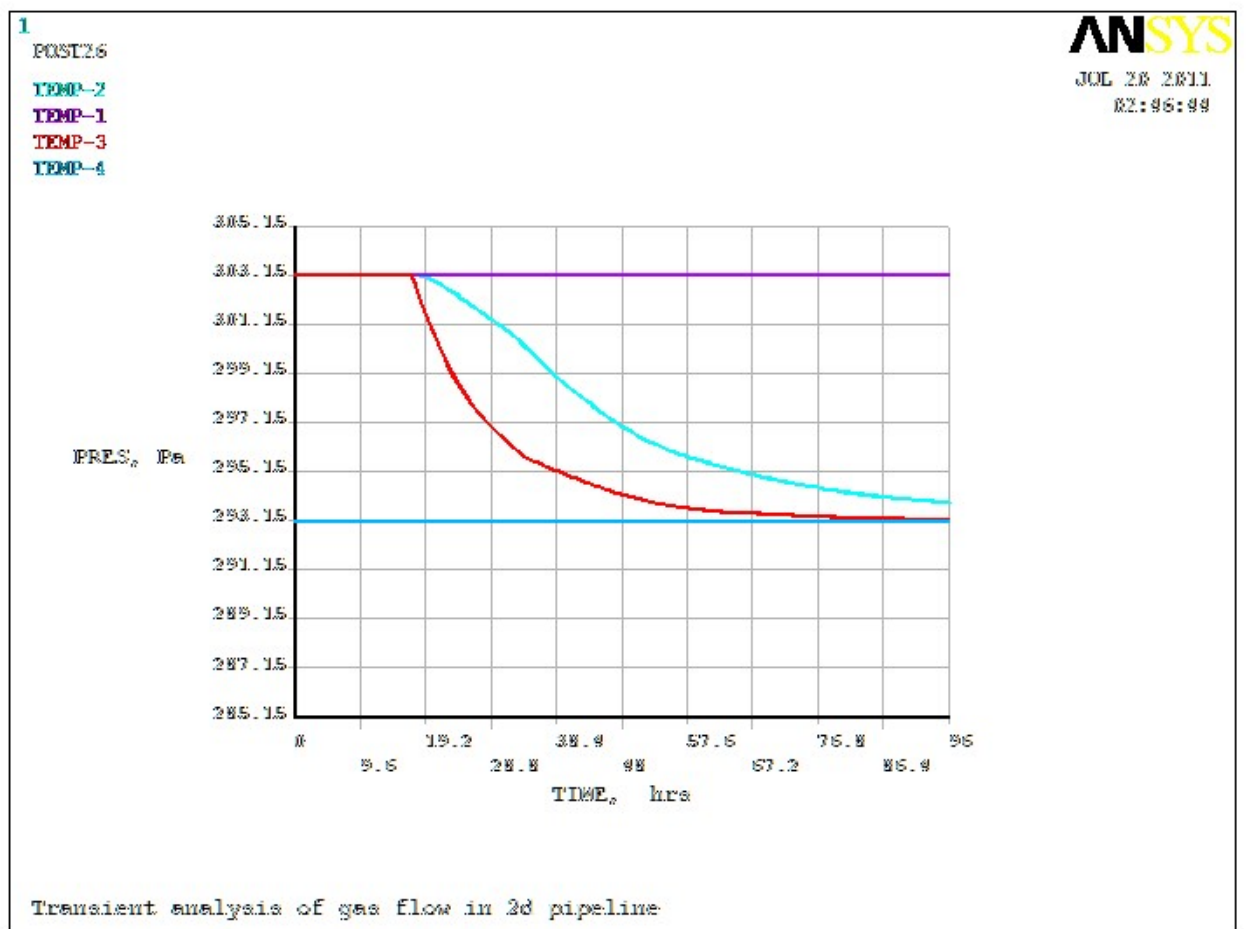

Fig 50: Comparison of Temperature changes at the four sections of flow (WAGP)

To ascertain the degree of turbulence in the simulation, the magnitude of turbulence in the flow from inlet to outlet was plotted as shown in fig $4.57-4.59$ for the various cases of simulation examined. 


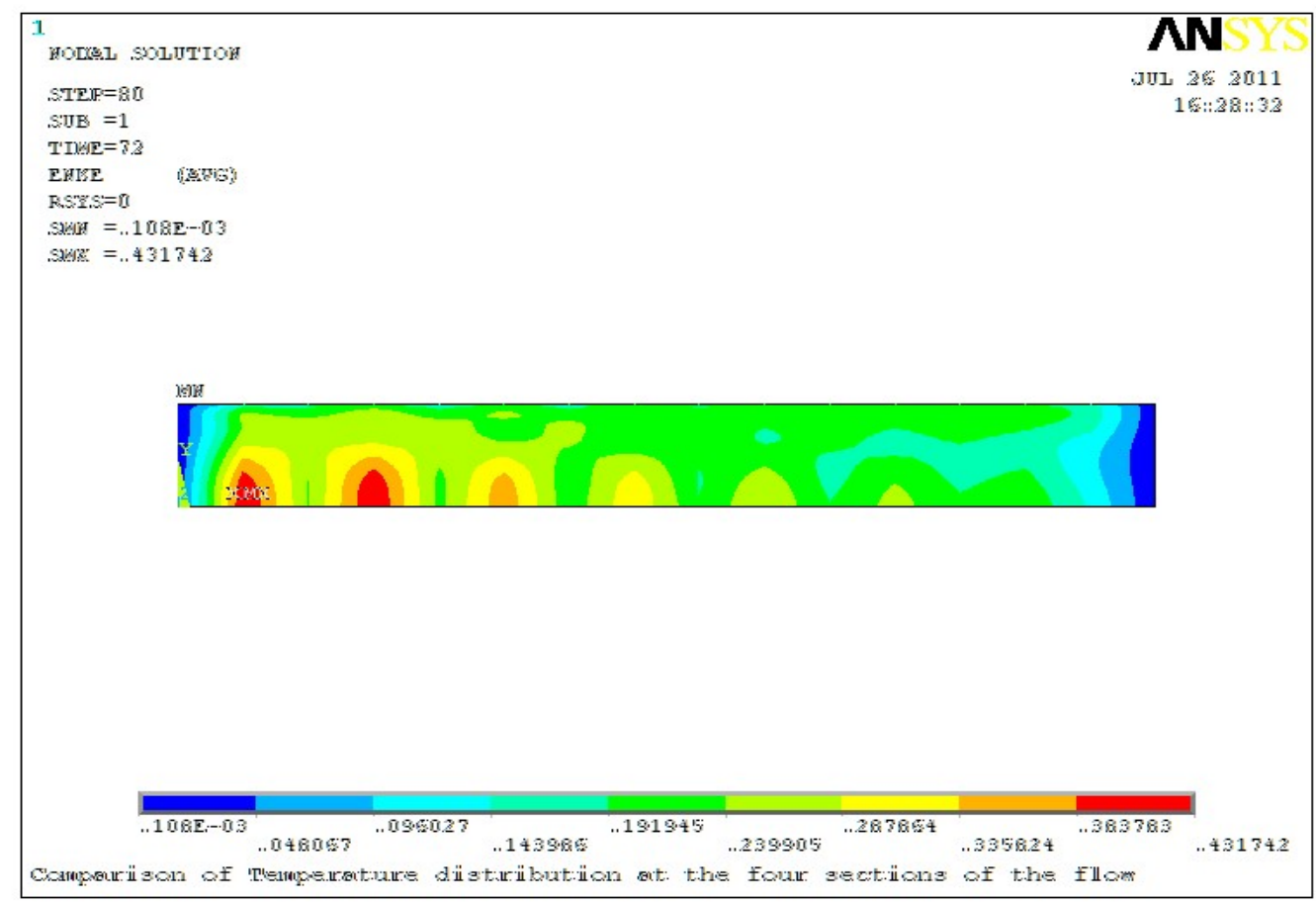

Fig 51: Contour plot of turbulent kinetic energy at time, $t=72 \mathrm{hrs}(\mathrm{T} 0=315.65 \mathrm{~K})$

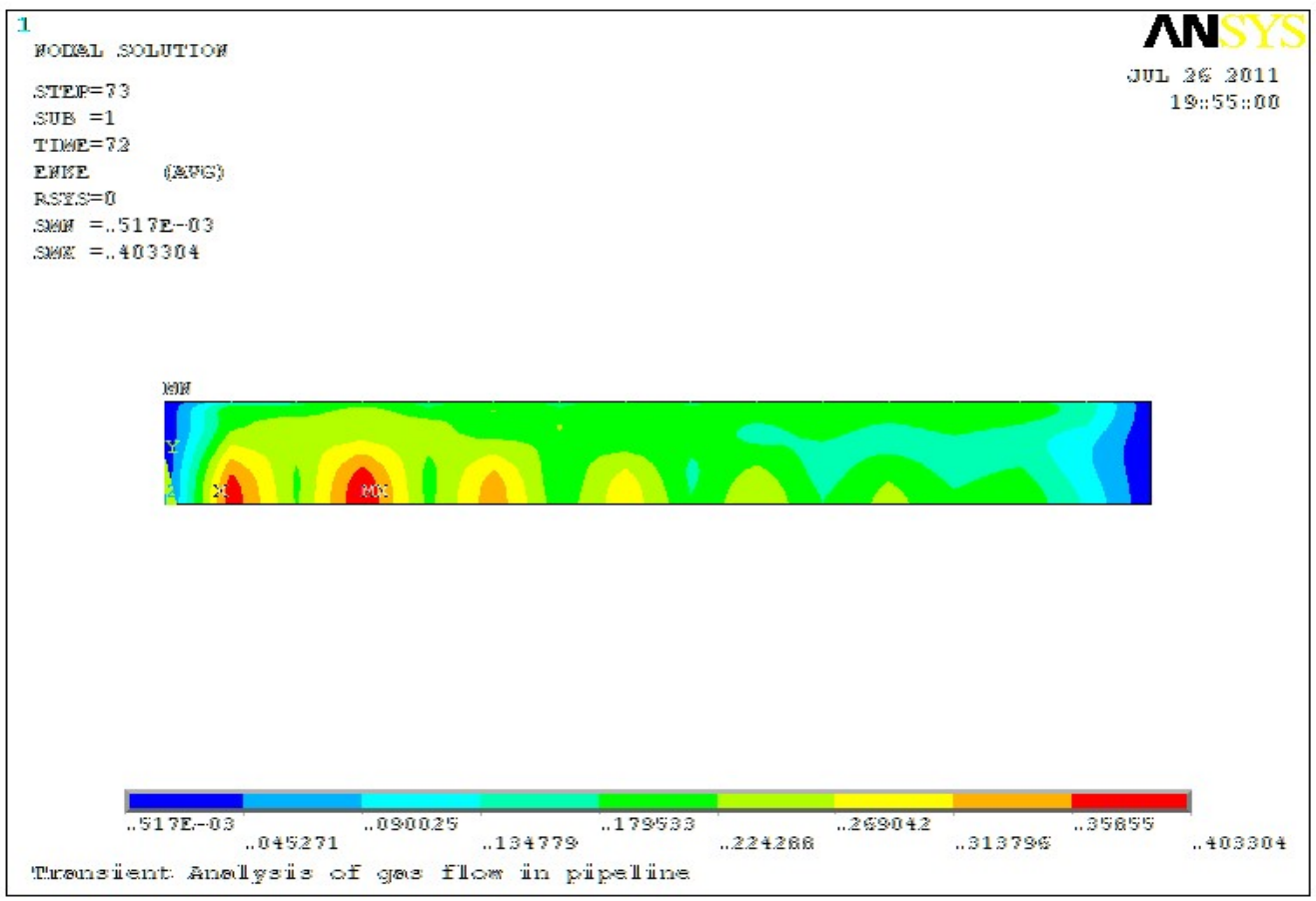

Fig 52: Contour plot of turbulent kinetic energy at time $t=72$ hrs T0 $=303.15 \mathrm{~K}$ 


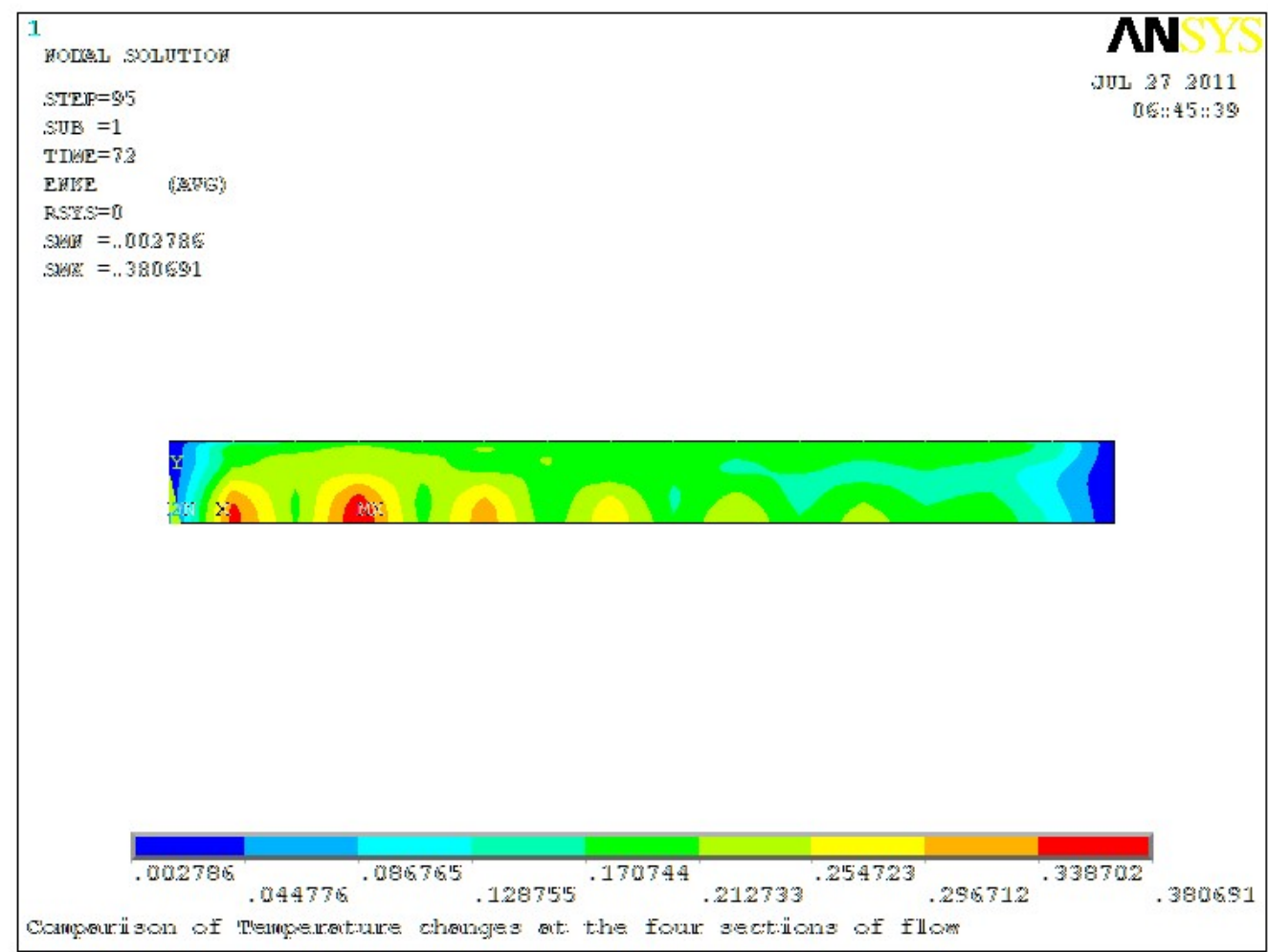

Fig 53: Contour plot of turbulent kinetic energy at time $t=72 \mathrm{hrs}$ for $\mathrm{T0}=\mathbf{2 8 5 . 1 5 \mathrm { K }}$

The turbulence plots indicate that turbulence was high at the initial stages of the simulation. This turbulence in the initial stages of the flow is possibly responsible for the initial high oscillations in pressures. 
Steady State Analytical Results:

In order to validate the numerical results, steady state analytical results are presented here below.

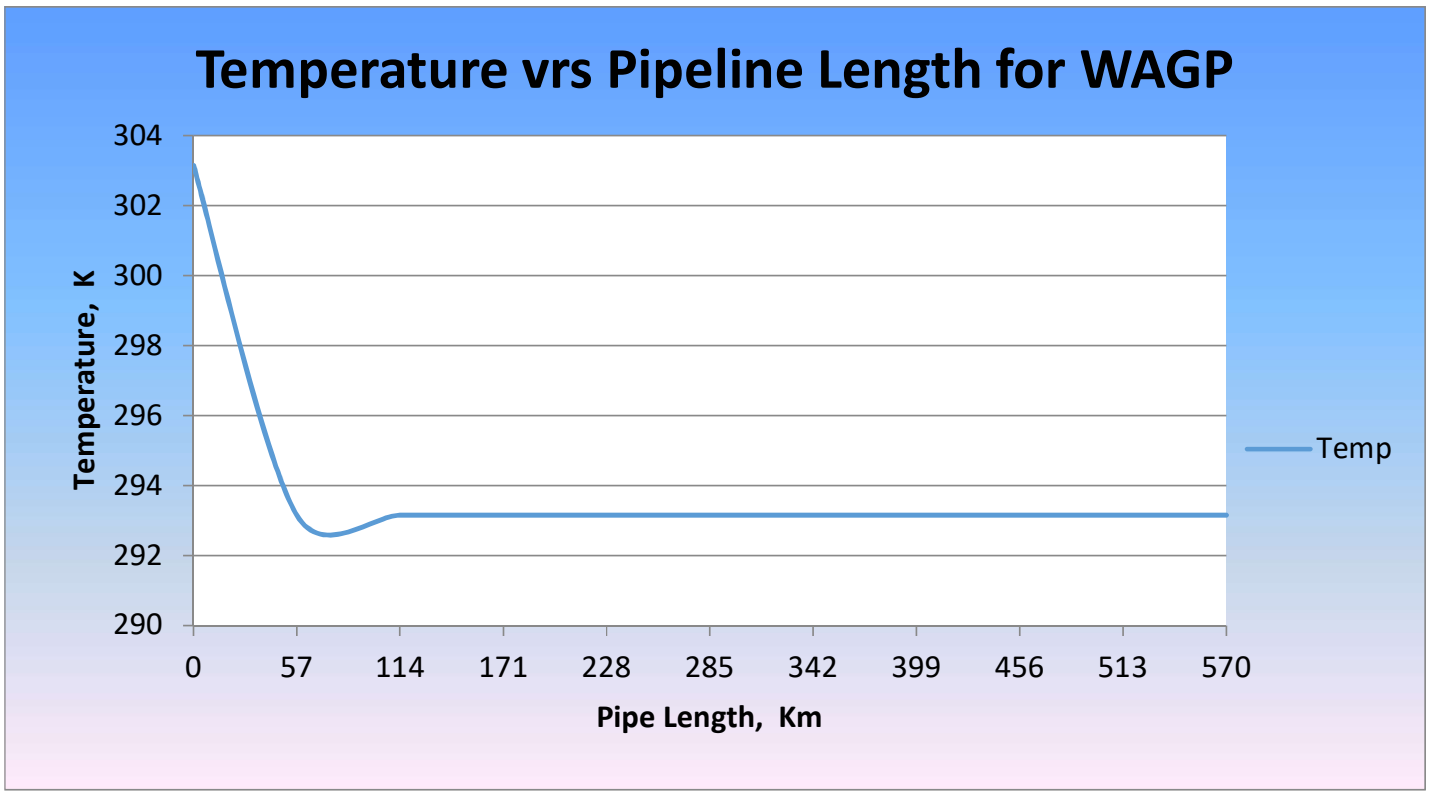

Fig 54: Temperature profile along pipeline for WAGP

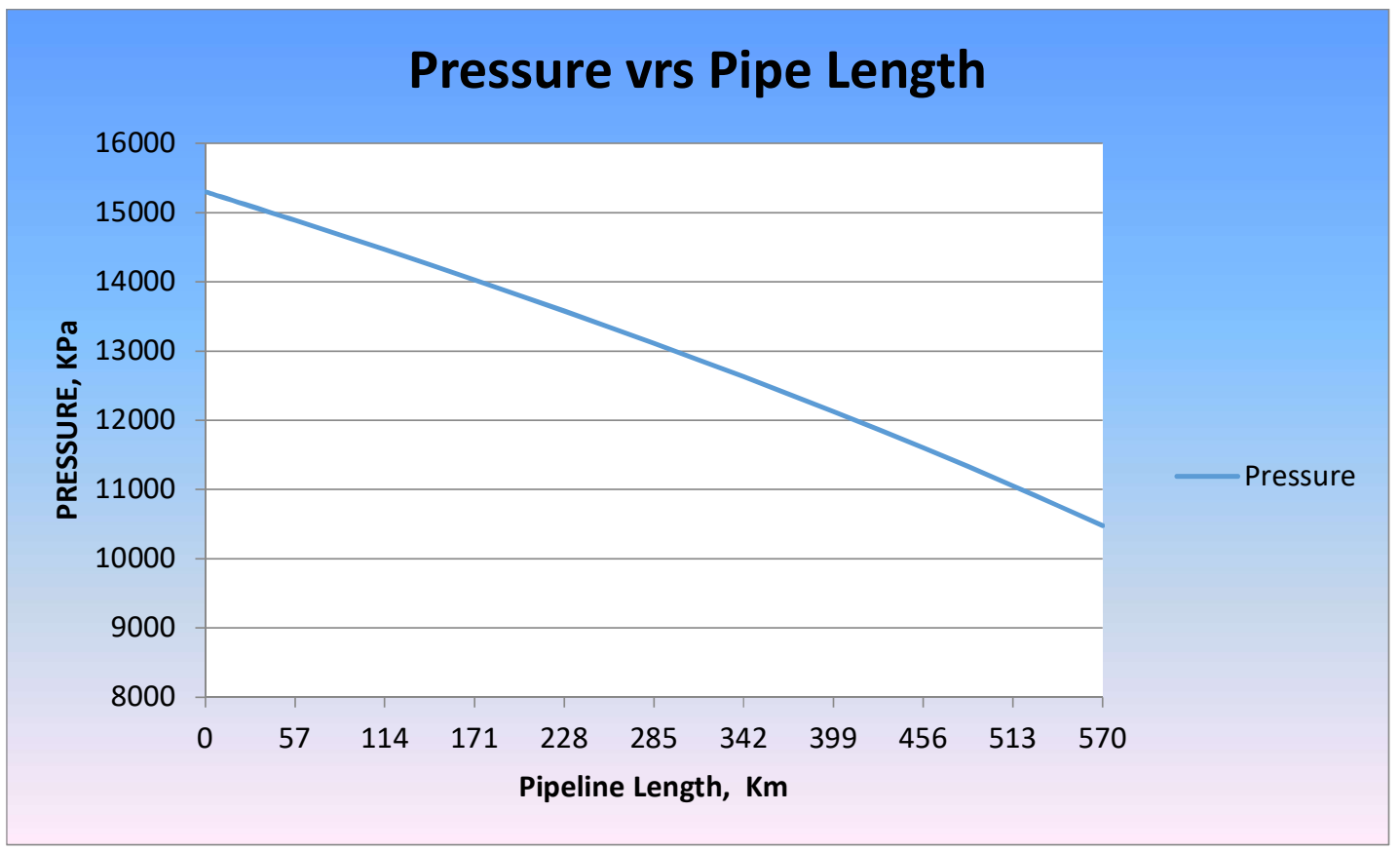

Fig 55: Pressure profile along pipeline for WAGP 


\section{Velocity vrs Pipe Length}

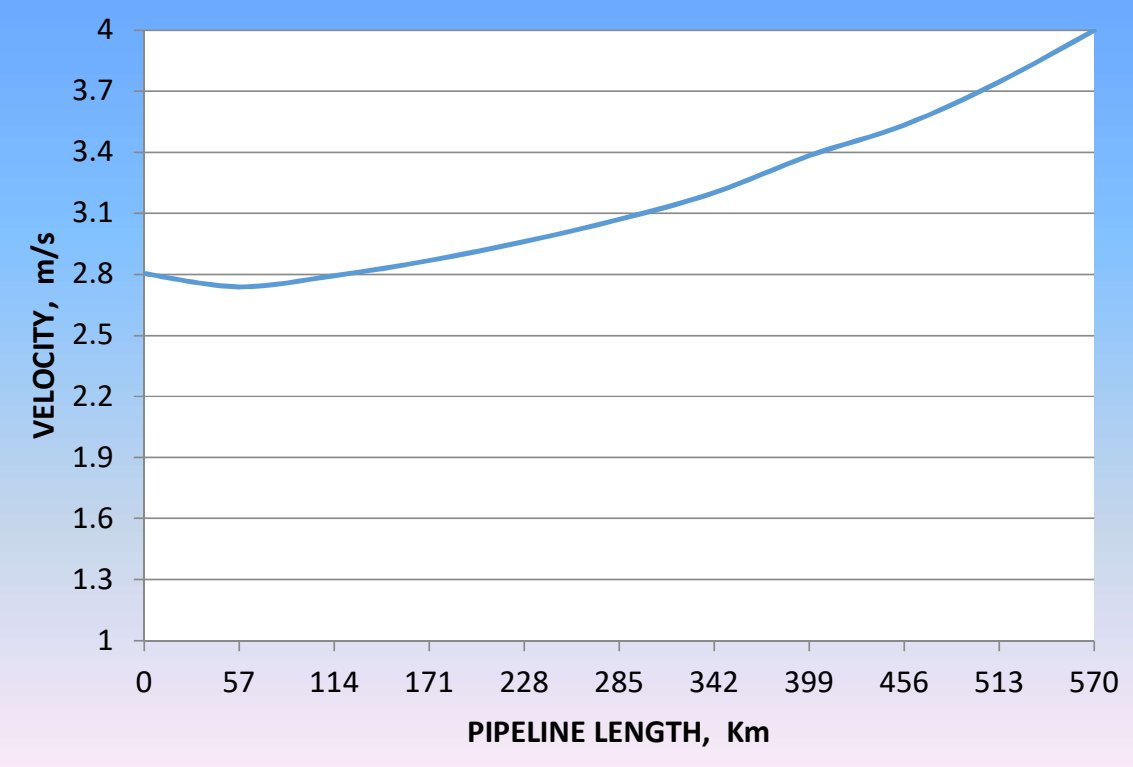

Fig 56: Velocity profile along the pipeline for WAGP

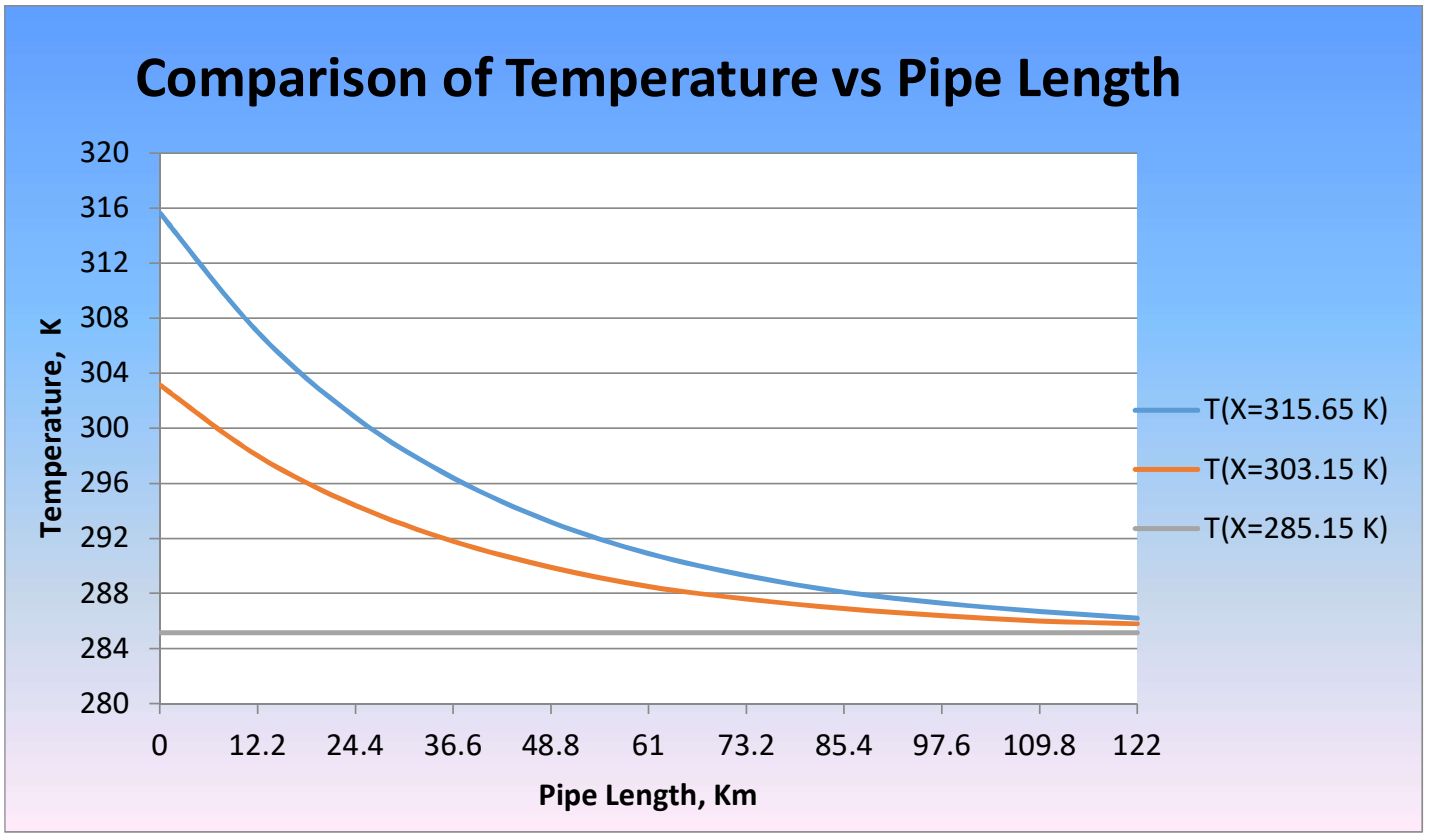

Fig 57: Comparison of Temperature profile versus pipe Length for Osiadacz system 


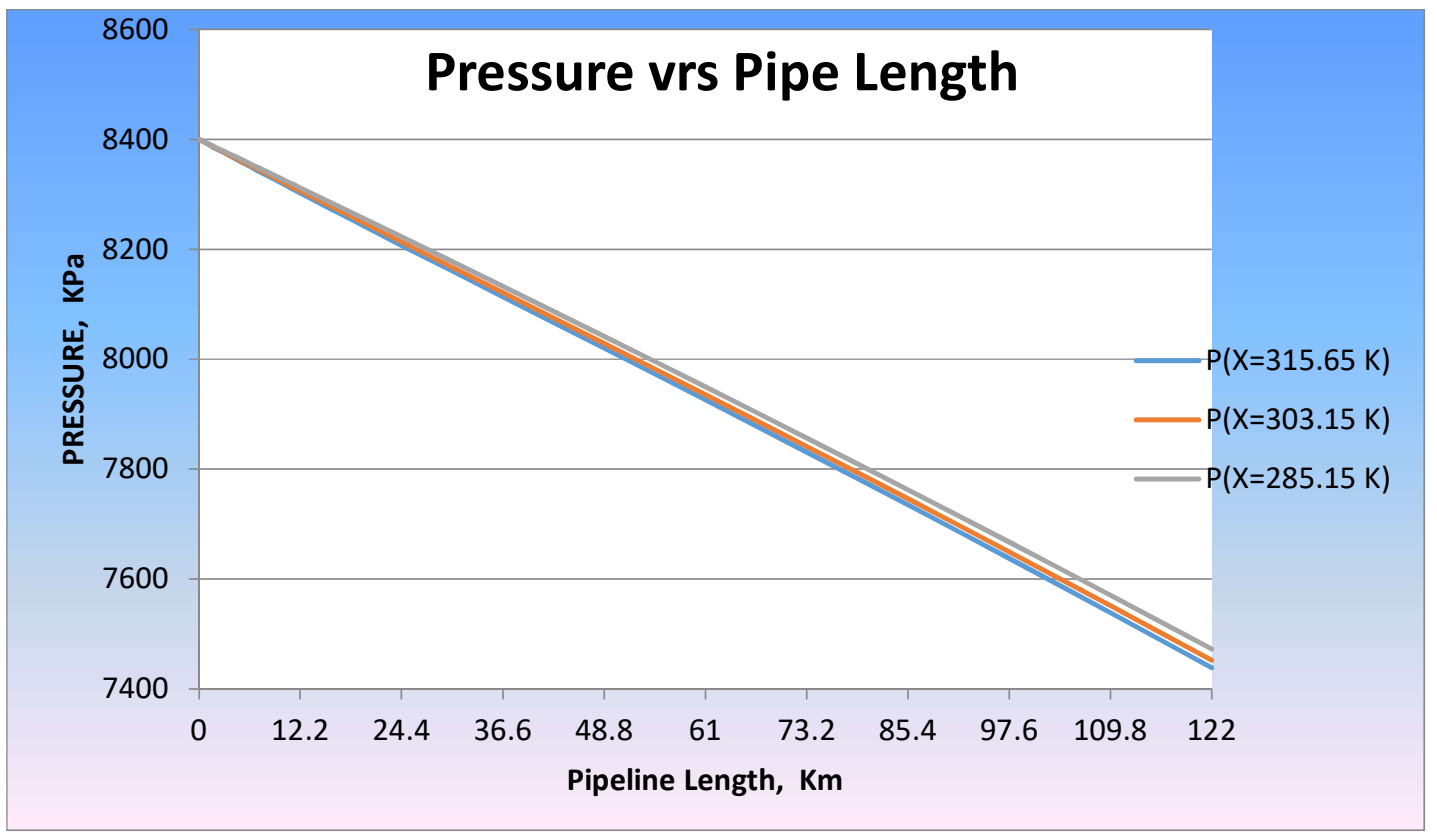

Fig 58: Comparison of steady state pressures with pipe length.

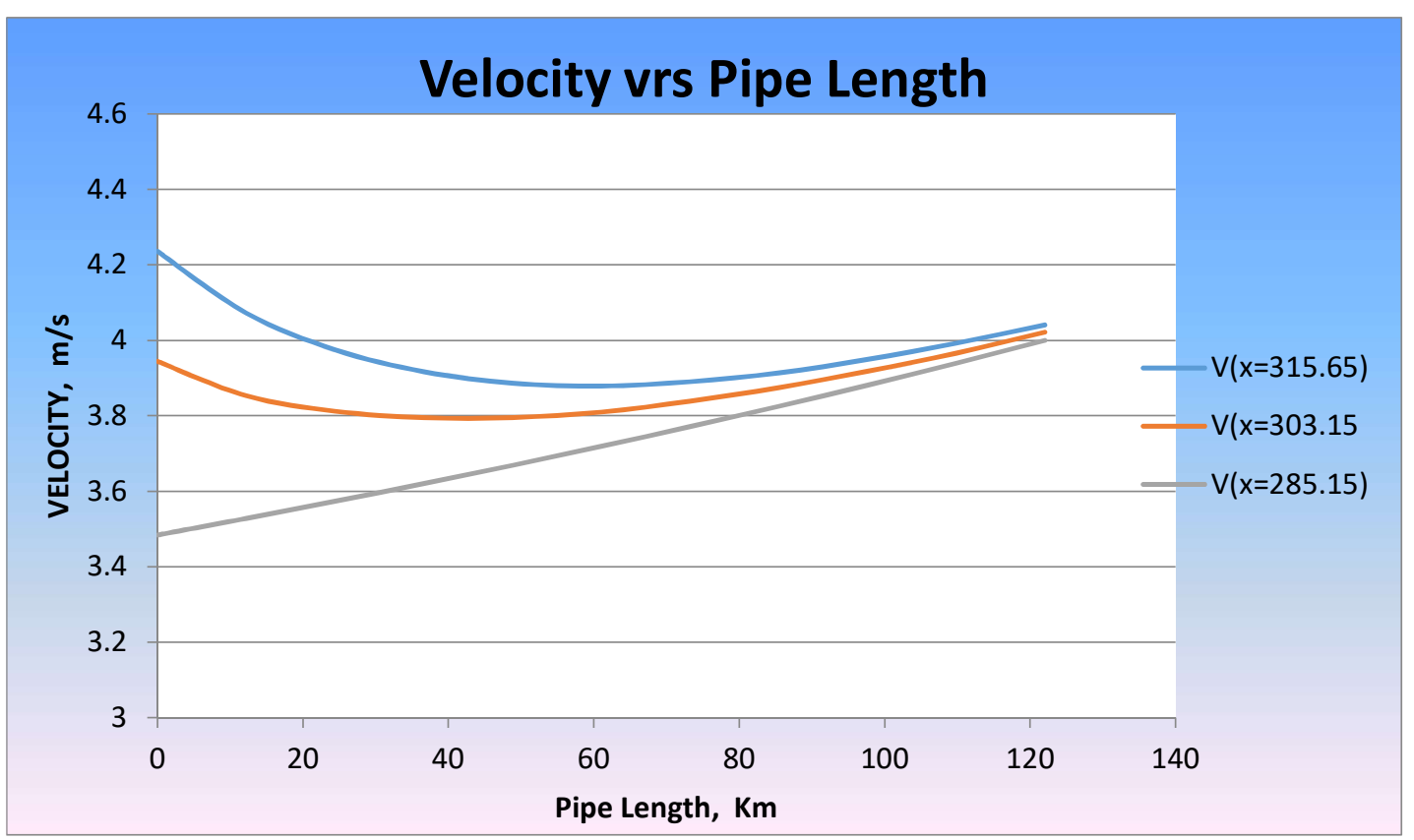

Fig 59: Comparison of Velocity profiles with Pipe Length

\section{Conclusions}

Transient studies with non-isothermal pipeline model that considers steady heat transfer and compressibility factor as function of pressure and temperature was studied. Three partial differential equation obtained from conservation of mass, conservation of momentum equation and conservation of energy gave predictions for gas flow pressure, temperature and flowrate when Ansys based Finite Element method was used to simulate. 
For non-isothermal steady state, it was found that there was steady drop in gas pressure as the natural gas travelled from upstream to downstream; the higher the initial gas temperature, the higher the average pressure drop and vice versa. It was also found that the magnitude of the average pressure drop was higher when pressure was predicted with constant compressibility factor, $\mathrm{z}$, but the same average pressure drop was reduced when the pressure was predicted with variable compressibility factor, $z$, for the non-isothermal results. Since compressibility factor is a function of temperature and pressure, the above findings signifies that in the case when gas temperature does not stabilize, the prediction of pressure with isothermal model and constant compressibility factor will lead to significant errors.

Results for density prediction along the pipeline from upstream to downstream were found to follow similar profile pattern as the pressure signifying that the gas density varies directly proportional to the pressure according to the equation of state. Therefore we form an opinion that, along the pipeline, the fluid density decreases as the pressure drops.

For temperature prediction, it was seen that the temperature of the gas cools as it travels from upstream to downstream until it becomes asymtotic or near to the ambient temperature signifying that the gas temperature in a flowing pipeline is not constant but varies along the pipeline. This shows that using isothermal models for predictions of pressure may give significant errors but nonisothermal predictions will give accurate results.

In viscosity results, it was found that increased temperature results in increased dynamic viscosity.

For non-isothermal transient results, the pressure and the flowrate (velocity) gave wave propagation as a result of slow transients created by demand condition at the outlet end of custody transfer. Results obtained were in agreement with the demand restrictions at the outlet end of custody transfer indicating that the predictions are accurate and reliable. All the results demonstrated that the Finite Element Method gives accurate prediction of pressure, temperature and flowrate in transient gas studies.

It is concluded that the transient non-isothermal model leads to accurate prediction of state variables and the inclusion of a variable compressibility factor in non-isothermal predictions results in accurate predictions and has significant effect on the pressure. Hence Finite Element Method is suitable for the prediction of pressure, temperature and flowrate in gas flow studies. 


\section{REFERENCE}

1. Wu, S., Rios Mercado, R. Z., Boyd, E. A., Scott, L. R., "Model Relaxations for the Fuel Cost Minimization of Steady State Pipeline Network", Math. Comput. Model 31(2000) p 197-220.

2. Herran-Gonzalez, A., De La Cruz, J. M., De Andres-Toro, B., Risco-Martin, J. L., "Modeling and Simulation of Gas Distribution Pipelines Network", Applied Mathematical Modeling. 33 (2009) p 1584-1600.

3. Kiuchi, T., "An Implicit Method for Transient Gas Flow in Pipe Networks", Int. J. Heat Fluid Flow 15 (5) (1994) p 378-383.

4. Ke, S. L., Ti, H. C., "Transient Analysis of Isothermal Gas Flow in Pipeline Network", Chem. Eng. J. 76 (2000) p 169-177.

5. Osiadacz, A. J., Chaczykowski, M., "Comparison of Isothermal and Nonisothermal Gas Flow Models", Chem. Eng. J. 81 (2001) p 41-51.

6. Tentis, E., Margaris, D., Papanikas, D., "Transient Gas Flow Simulation Using Adaptive Method of Lines", C. R. Mecanique 331 (2003) p 481-487.

7. Grayvenstein, G. P., "An Implicit Method for the Analysis of Transient Flow in Pipe Network", Int. J. Heat Fluid Flow 53 (2002) p 1127-1143.

8. Schroeder, Donald W., "A Tutorial on Pipe Flow Equations", Proceedings of PSIG Conference 1988.

9. Gato, L. M. C., Henriques, J. C. C., "Dynamic Behavior of High Pressure Natural Gas Flow in Pipelines", Int. J. Heat Fluid Flow 26 (2005) p 817-825.

10. Osiadacz, A. J., "Different Transient Models- Limitation, Advantages and Disadvantages", Proceedings of the PSIG - The $28^{\text {th }}$ Annual Meeting, San Francisco (1996).

11. Oke, A., Mahgerefteh, H., Economou, I., Rykov, Y., “ A Transient Outflow Model for Pipeline Puncture”, Chem. Eng. Sci. 58(20) (2003) p 4591-4604.

12. Abbaspour, M., Chapman, K. S., "Nonisothermal Transient Flow in Natural Gas Pipeline, J. Appl. Mech. Trans. ASME 75 (3) (2008) 0310181-0310188.

13. Chaczykowski, M., "Transient Flow in Natural Gas Pipeline - The effect of Thermal Model”, Applied Mathematical Modeling 34 (4) (2009) p 1051-1067.

14. Chang Man Fong, C. F., De Kee, D., Kaloni, P. N., "Advanced Mathematics for Engineering and Science", World Scientific Publishing Co. Pte. Ltd., Singapore (2003).

15. Tian, S and Adewumi, M.A., "Development of Analytical Design Equation for Gas Pipeline", SPE production and facilities, 15 (May 1994) p 100-106. 
16. Elsharkawy, A. M and Elkamel, Ali., " Compressibility factor of Sour gases" SPE, Asia Pacific Oil and Gas Conference, Australia, October, 2000, 16-18.

17. Osiadacz, J.A., Dynamic Optimization of High Pressure Gas Networks Using Hierarchical Systems Theory. Institute of Heating and Ventilation, Warsaw University of Technology, 00 - 653 Warsaw, Nowowiejska 20, Poland, (1994) $1-29$.

18. Jason Modisette and Jerry Modisette, "Physics of Pipeline flow", PSIG Presentation (2003).

19. Zaghloul, Jose, Adewumi, M. A and Ityokumbul, M.T, "Compositional Modeling of Two Phase (Gas/Water) Flow in Gathering and Transportation Pipeline Systems", SPE Journal (October, 2007) p 111136-MS.

20. Modisette, J, “Equation of State Tutorial”, PSIG 0008- 2000.

21. Chang, Seungyong, "A Program Development for Unsteady Gas Flow Analysis in Complex Pipe Networks", R\&D Centre, Korea Gas Corporation (year).

22. Modisette Jason, "Pipeline Thermal Models", in: Proceedings of the PSIG the $34^{\text {th }}$ Annual Meeting, Portland, 2002.

23. Boriyantoro, N. H and Adewumi, M. A., "An Integrated Single and Multiphase Flow Model for Predicting Fluid Flow behavior of Gas Condensate Pipelines", M.S. thesis, Pennsylvania State University, University Park, August 1994.

24. Behbahani-Nejad, M and Bagheri, A., "A MATLAB Simulink Library for Transient Flow Simulation of Gas Networks", World Academy of Science, Engineering \& Technology (43) p 2008 153-159.

25. Asante Ben, "Two Phase Flow: Accounting for the Presence of Liquids in Gas Pipeline Simulation", Enron Transport Services, Houston, Texas, USA.

26. Santos, S. P., "Transient Analysis A Must in Gas Pipeline Design, Engineering Services of Petrobras, Pipeline Simulation Interest Group (PSIG), October, 1997.

27. Thorley, A. R. D and Tiley, C. H., "Unsteady and Transient Flow of Compressible Fluids in Pipeline- A review of Theoretical and some Experimental Studies", International Journal of Heat and Fluid Flow, 8(1) March 1987, 3-15.

28. Yow Wushong, "Analysis and Control of Transient Flow in Natural Gas Piping Systems", $\mathrm{PhD}$ Dissertation, University of Michigan, 1971.

29. Jaeschke, M and Humphreys, A. E., "Simplification of Input Data Requirements for the GERG Virial Equation - An Alternative Means of Compressible Factor Calculation for Natural Gases and Similar Mixtures", GERG Technology Monograph 5 (1991).

30. Abdolahi Demneh, Mesbah Ali and Jaberi, A., "Comparative Evaluation of Natural Gas Pipeline Simulators", Technology Petromin Pipeliner, July - Sept 2008, 6-8.

31. Zhou, J and Adewumi, M. A., "Simulation of Transient Flow in Natural Gas Pipelines", the Pennsylvania State University, Petroleum and Natural Gas Engineering, GRI - PA $16802,1996$. 
32. Goldwater, M. H. and Fincham, A. E., "Modeling of Dynamical Systems", Peregrinus, Stevenage, 1981, p $150-177$.

33. Santos, S. P., Mokhatab Saeid, Petrobas Gas Energy and Tehran Raymand Consulting Engineers, "Transient Simulation During Gas Pipeline Design Saves on Later Costs", Pipeline and Gas Journal, Jan 2008, p 28 - 32.

34. Alvarez, Oscar G., Garranza, Hugo A., Cassanova, Jorge A., Cassares, Carlos A. M., "Natural Gas Power Generation Basic Pipeline Design Requirements", PSIG 0105 Natural Gas Power Generation, PSIG $-33^{\text {rd }}$ Annual Meeting, October $17-19$, Salt Lake City Utah, USA (2001) p $1-32$.

35. Barletta, A., Zanchini, E., Lazzari, S. and Terenzi, A., "Numerical Study of Heat Transfer from an Offshore Buried Pipeline under Steady-Periodic Boundary Conditions", Applied Thermal Engineering 29 (2008) p $1168-1176$.

36. Issa, R. I. and Spalding, D. B., "Unsteady One-dimensional Compressible Frictional Flow with Heat Transfer", J. Mech. Eng. Sci. 14(6) (1972) p 365 - 369.

37. Winterbone, D. E. and Pearlson, R. J., "A Solution of the Wave Equation using Real Gases”, Int. J. Mech. Sci. 34(12) (1992) p 927 - 932.

38. Langelandsvik, L. I., Postvoll Willy., Aarhus Britt., Kaste, K. K., and GASSCO AS, "Accurate Calculation of Pipeline Transport Capacity".

39. Doug Fauer, P. E., “The Making of a Useful Pipeline Simulation Model”, Southern Natural Gas.

40. Hall, K. R,, Iglesias - Silva, G. A., "Improved Equations for the Standing - Katz tables", Hydrocarbon Process 86 (4) (2007) p107 - 110.

41. Peiro', J and Sherwin, S., "Finite Methods for Partial Differential Equations", Handbook of Materials Modeling, Volume I, Methods and Models, 2005, Springer, Netherlands.

42. Yahya, S. M., "Fundamentals of Compressible Flow with Aircraft and Rocket Propulsion", Third Edition, New Age International Publishers, 2003.

43. Bathe Klaus-Jurgen, "Finite Element Procedures", Prentice Hall Inc., Upper Saddle River, New Jersey 07458, 1996.

44. Zienkiewicz, O. C and Taylor, R. L., "The Finite Element Method for Fluid Dynamics", 5 edition, Elsevier, Amsterdam, 2000.

45. Zienkiewicz, O. C and Taylor, R. L., "The Finite Element Method: Its Basis and Fundamentals", 5 edition, Elsevier, Amsterdam, 2000.

46. Nithiarasu, P., "A Unified Fractional Step Method for Compressible and Incompressible Flows, Heat Transfer and Incompressible Solid Mechanics", Int. Journal of Numerical Methods for Ideal and Fluid Flow, 18(2) p 2008, 111 - 130, 2007.

47. Nithiarasu, P., "On Boundary Conditions of the CBS Algorithm for Computational fluid dynamics", Int. Journal of Numerical Methods in Fluids, 31, 159-173, 2002.

48. Lewis, Roland W., Nithiarasu, P and Seetharamu, K. N., "Fundamentals of the Finite Element Method for Heat and Fluid flow" Wiley. 
49. Zienkiewicz, O. C., Sai, B. V. K. S., Morgan, K and Codina, R., "Split Characteristic based Semi-implicit Algorithm for Laminar and Turbulent Incompressible flows", Int. J. Num. Meth. Fluids, 23, 1996, p 1-23.

50. Zienkiewicz, O.C., "A new Algorithm for Fluid Mechanics: Compressible and Incompressible Flow. Proceedings of $9^{\text {th }}$ Int. Conf. Finite Element Fluids - New Trends and Application, Venezia, October, 1995, p 49-55.

51. Yiang, C.B and Kawahara, M., "A three Step Finite Element Method for Unsteady Incompressible Flows. Comput. Mech. 11, 1993,p 355-370.

52. Chorin, A. J, "Numerical Solution of Navier-Stokes Equations", Math. Comput. , 22, 1968, 745-762,

53. Chorin, A. J, "On the Convergence of Discrete Approximation to the Navier-Stokes Equations", Math Comput., 23, 1969, p 342-353.

54. Zienkiewicz, O.C and Codina, R., "Search for General Fluid Mechanics Algorithm: Frontiers of Computational Fluid Dynamics", Eds. D. A. Caughey and M. M. Hafez, J. Wiley, New York, 1995, p 101-113.

55. Zienkiewicz, O.C and Codina, R., "A General Algorithm for Compressible and Incompressible Flow: The Characteristic-Based Scheme”, Int. J. Num. Meth. Fluids, 20, 1995, p 869-885.

56. Simpson, M. J and Clement, T. P., "Comparison of Finite Difference and Finite Element Solutions to the variably Saturated Flow equations", Journal of Hydrology, 270, 2003, p 49 -64 .

57. Newmark, N. M., "Numerical Method of Analysis in Engineering", L. E Grinter (ed), Macmillan, New York, 1949.

58. Hirsch, C., "Numerical Computation of Internal and External Flows, Fundamentals of Numerical Discretization, Vol. 1, Wiley, New York, 1988.

59. Modisette, J. L and Modisette, J. P., "Transient and Succession-of-Steady-State Pipeline Flow Models", Pipeline Simulation Interest Group (PSIG).

60. Shashi Menon, E., “Gas Pipeline Hydraulics”, Online Course. 